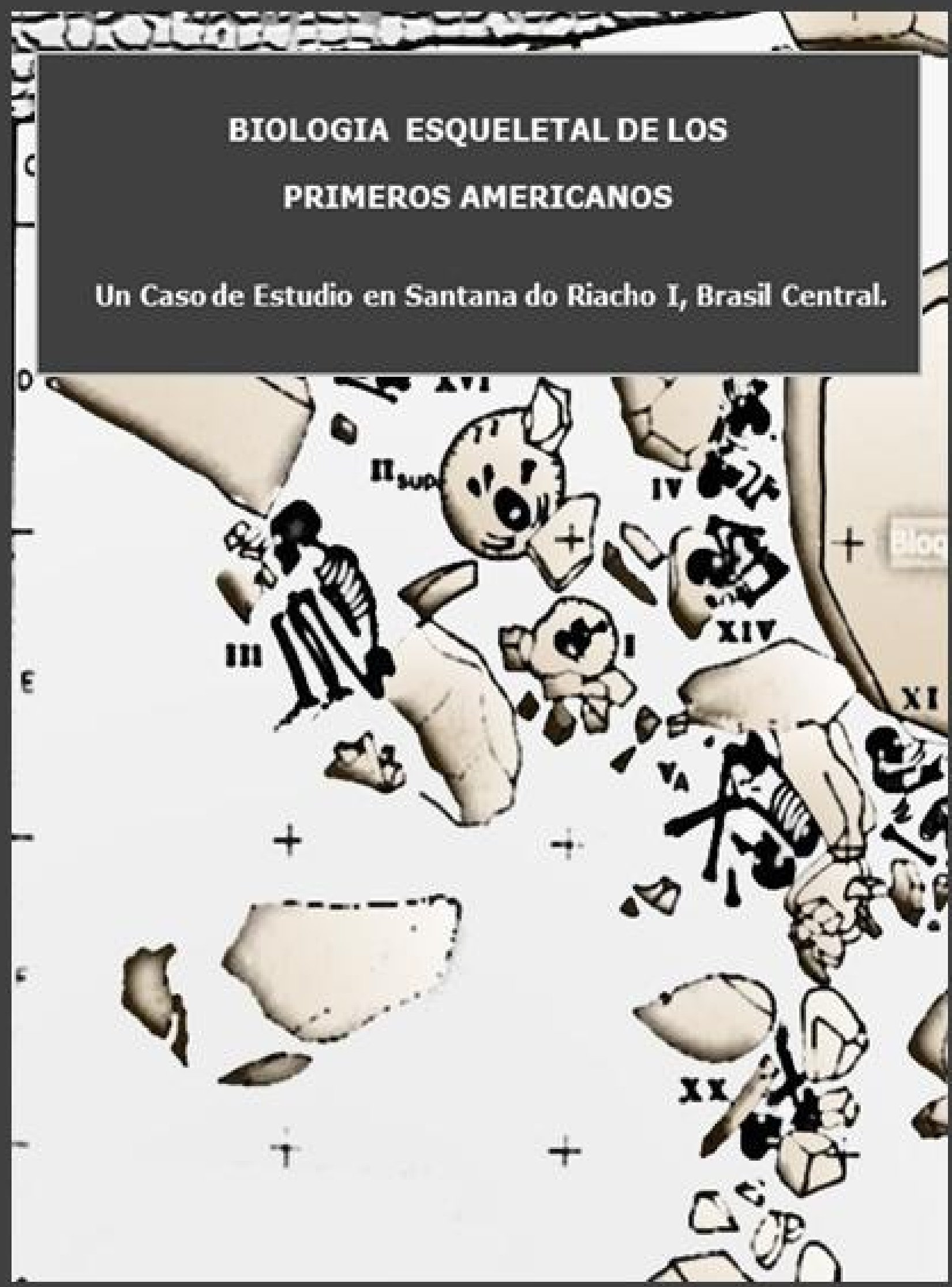

Silvia E. Cornero, U.N.Rostario

Dirección Dr. Walter Neves, UFSP, Sao Paulo Co-Dirección Dr. Hector Pucciarelli, U.N. de La Plata 


\title{
Biología Esqueletal de los Primeros Americanos
}

\section{Un Estudio de Caso en Santana do Riacho, Brasil Central}

\author{
Silvia Elena Cornero \\ Universidan Nacional de Rosario \\ Dirección: Dr. Walter A. Neves, \\ Laboratorio de Estudos Evolutivos Himanos Universidad de Sao Paulo \\ Co Dirección: Dr. Hector Pucciarelli \\ Laboratorio de Bioantropología, Universidad Nacional de La Plata
}

Evaluadores:

Dr. José A. Cocilovo, Universidad Nacional de Río Cuarto

Dr. Ricardo Guichón, Universidad Nacional de Mar del Plata

Dr. Gustavo Barientos, Universidad Nacional de La Plata

Tesis Doctoral para aspirar al título de Doctor en Ciencias Naturales orientación en Bioantropología.

Nota: Sobresaliente con recomendación de publicación. Acta Nro. 934. Fecha de Disertación: 5 de Agosto de 2007 
"Agradezco sobretodo, a los hombres prehistóricos de Santana, gracias a los cuales vivimos la felicidad de ser arqueólogos en el paisaje maravillosos del Abrigo Grande, que ellos también amaron."

André Pierre Prous, 1992. 


\section{RESUMEN}

El estudio de poblaciones prehistóricas posibilita inferir la magnitud de las fuerzas que ejercieron las presiones selectivas del ambiente. La salud constituye un efecto de la relación población-medio, útil al análisis de calidad de vida de las poblaciones extintas.

Esta investigación aborda, desde el análisis de indicadores óseos de salud y enfermedad, el impacto ambiental en una población paleoindia de los cerrados de Mina Gerais.

La muestra estudiada, proveniente del sitio Santana do Riacho y excavada por André Prous, se compone de 28 enterratorios $(\mathrm{MNI}=40)$ que se ubican en los 8.500 años AP.

El grupo presenta un notable dimorfismo sexual en favor de un normal proceso de crecimiento y desarrollo, consistente con talla y robustez, la población no estuvo sometida a episodios de desnutrición, o detención del crecimiento severo o prolongado.

De patologías óseas se consideraron: hiploplasia dental, hiperostosis porótica, cribra orbitalia, infecciones inespecíficas y específicas, caries, periodontitis, traumas, nódulos de Schmorl, osteoartritis y osteofitosis vertebral. Se observó baja incidencia de patologías metabólicas y mayor frecuencia de caries esperada para cazadores recolectores. Los resultados de los indicadores de tensión funcional, sugieren el uso de la columna vertebral, en ocupaciones asociadas al levantamiento, carga y transporte de materiales pesados, sin estrés biomecánico suficientes para provocar lesiones que afectaran la movilidad corporal de los individuos. Las afecciones traumáticas se observaron en adultos, indican un origen accidental, con adecuadas respuestas postraumáticas. La ausencia de infectocontagiosas implicaría una capacidad de respuesta inmunológica efectiva ante las enfermedades endémicas.

Los biomarcadores reflejan un leve y poco agresivo impacto del medio en los cuerpos de este grupo. En suma, los indicadores analizados sugieren un bajo 
impacto ambiental negativo y una calidad de vida adaptada, capaz de garantizar la reproducción y la supervivencia del grupo en Lagoa Santa constituyendo un modelo de éxito adaptativo biocultural.

\section{ABSTRACT}

The study of prehistoric populations makes it possible to infer the magnitude of the forces exerted by the selective pressures of the environment. Health is an effect of the population-medium relationship, useful to the analysis of the quality of life of extinct populations.

This research addresses, from the analysis of bone indicators of health and disease, the environmental impact on a Paleoindian population of the Mina Gerais closed.

The sample studied, from the site Santana do Riacho and excavated by André Prous, is composed of 28 burials $(\mathrm{MNI}=40)$ that are located in the 8,500 years BP.

The group presents a remarkable sexual dimorphism in favor of a normal process of growth and development, consistent with height and robustness, the population was not subjected to episodes of malnutrition, or severe or prolonged growth arrest.

Of bone pathologies were considered: dental hyploplasia, porotic hyperostosis, cribra orbitalia, nonspecific and specific infections, caries, periodontitis, traumas, Schmorl nodules, osteoarthritis and vertebral osteophytosis. There was a low incidence of metabolic pathologies and a higher caries frequency expected for hunter-gatherers. The results of functional strain indicators suggest the use of the spine in occupations associated with the lifting, loading and transport of heavy materials, without enough biomechanical stress to cause injuries that affect the physical mobility of individuals. Traumatic conditions were observed in adults, indicate an accidental origin, with adequate post-traumatic responses. 
The absence of infectious diseases would imply an effective immunological response capacity to endemic diseases.

The biomarkers reflect a mild and non-aggressive impact of the medium on the bodies of this group. In sum, the analyzed indicators suggest a low negative environmental impact and an adapted quality of life, capable of guaranteeing the reproduction and survival of the group in Lagoa Santa, constituting a model of adaptive biocultural success. 
Este estudio se desarrolló en el marco del Proyecto de Investigación sobre Poblaciones Paleoindias, dirigido por el Dr. Walter Neves del Laboratorio de Estudios Evolutivos Humanos de la Universidad de Sao Paulo. Las colecciones se alojan en el Museo de Historia Natural de la Universidad Federal de Minas Gerais, donde se realizó el relevamiento y estudio de los esqueletos procedentes del sitio Santa do Riacho, región de Lagoa Santa. Este trabajo comenzó en el año 1998 en el marco de un convenio interinstitucional entre la Universidad Nacional de La Plata y Universidad de Sao Paulo, se vió postergado por maternidad, siendo retomado en 2002 y finalizado en año 2006.

\section{AGRADECIMIENTOS}

Quiero expresar mi sentido agradecimiento a André Prous, a Hector Pucciarelli y a Paula del Río. A los evaluadores Dr. José Cocilovo y Dr. Ricardo Guichon, por sus valiosas contribuciones a este trabajo.

Muy especialmente a Walter Neves, por posibilitarme tan magnífica experiencia, por su generosidad y confianza.

A Victoria Marino, Hanna Basso, Joaquín Basso y Jóse Basso.

Por el Apoyo financiero prestado en esta invesitigacion a FAPESP - Fundación de Apoyo a la Investigación del Estado de São Paulo- . 


\section{INTRODUCCION}

Del proceso evolutivo humano resultan continuas modificaciones, que son producto de las relaciones del grupo con el medio particular que habita e interactúa produciendo, con el correr de los milenios, distintos desarrollos regionales, representados en la diversidad bio-cultural.

El estudio de la biología esqueletal de poblaciones prehistóricas posibilita inferir la magnitud de las fuerzas que ejercieron las presiones selectivas del ambiente y su impacto en el grupo.

Esta investigación aborda, desde el análisis del registro biológico en su contexto ambiental y cultural, el relevamiento de indicadores óseos de salud y enfermedad.

La salud constituye un efecto de la relación población-medio y, por lo tanto, un factor significativo para el análisis de calidad de vida biológica de las poblaciones humanas. Se contemplan, en primera instancia, las consideraciones teóricas básicas y el desarrollo de la conformación del pensamiento bioantropológico respecto de estilo y calidad de vida en la prehistoria. Basado en estos principios se presenta este trabajo, cuyo objetivo es caracterizar el impacto de distintos tipos de estrés biológico sobre un grupo de cazadores recolectores del paleoindio tardío que habitó los cerrados de la región de Lagoa Santa, en Minas Gerais, Brasil Central.

La muestra ósea estudiada proviene de una excavación efectuada en Santana do Riacho por Andre Prous, de la Universidad de Minas Gerais, en 1979. Posteriormente fue curada por Walter Neves, de la Universidad de Sao Paulo.

Santana do Riacho es un sitio del paleoindio tardío con intensa actividad funeraria. Fueron hallados 28 enterratorios y vestigios orgánicos y tecnológicos. Los esqueletos humanos, correspondientes a 40 individuos, se ubican mayoritariamente entre los 8.000 y 8.500 años de antigüedad.

Se seleccionaron como indicadores de salud, la estatura y el dimorfismo sexual, los cuales aportan información respecto del proceso de crecimiento y desarrollo que experimentó el grupo. Como indicadores de patologías óseas se 
consideraron: hiploplasia dental, hiperostosis porótica / cribra orbitalia, infecciones inespecíficas y específicas, caries, periodontitis, traumas, nódulos de Schmorl, osteoartritis y osteofitosis vertebral. Estos indicadores fueron tomados de acuerdo con las posibilidades que ofrecía la muestra.

Se efectuaron las consideraciones teóricas para cada indicador y se presentaron otros casos de poblaciones cazadoras recolectoras, horticultoras y agricultoras.

La finalidad de este estudio comparativo es obtener parámetros de referencia que permitan describir contextualmente la situación adaptativa del grupo en estudio.

Si bien los grupos control considerados no expusieron todos los indicadores seleccionados, pudo hacerse un estudio pormenorizado, en ajuste a las particularidades de las colecciones y a los objetivos de cada investigación.

La consulta bibliográfica se orientó hacia la búsqueda de casos que coincidieran, por un lado, en las metodologías empleadas, y por el otro, con los parámetros de estudio seleccionados para este trabajo.

Dadas las bases teóricas en que se apoya la investigación, fue expuesto el contexto ambiental de Santana do Riacho, su inserción geográfica que contempla la localización, la geología local y sus cuencas hidrológicas, así como el componente ecológico en el cuál interactúan vegetación, fauna y poblaciones humanas.

La curadoría y el análisis de los materiales comenzaron en la década de 1990, en el marco de las investigaciones de Walter Neves sobre las colecciones de la región. Este trabajo constituye una de las primeras experiencias de investigación en poblaciones paleoindias sudamericanas y nos posibilita un acercamiento a la calidad y estilo de vida en su contexto ambiental. Esto nos acerca al conocimiento de los procesos evolutivos y del costo adaptativo que soportaron estos pueblos cazadores-recolectores en pos de su supervivencia.

Se consideraron similares estudios con casos de muestras de poblaciones de diferentes momentos cronológicos, sistemas ambientales y respuestas adaptativas. Entre ellos se citan en este trabajo a las colecciones osteológicas humanas provenientes de sitios en Chile -Punta Teatinos I y II (Quevedo 
Kawasaki, 1998), Pisagua (Quevedo Kawasaki y Cocilovo, 1996), Baño Nuevo en Patagonia (Mena y Reyes, 2001), San Pedro de Atacama (Neves y Costa, 1999) -; Ecuador - La Tolita (Ubelaker, 1997)-; Brasil Litoral de Parana (Neves, 1984); Argentina -Delta del Paraná (Torres, 1911) y Paraná Medio (Cornero $Y$ Puche, 2000 y 2002), Arroyo Seco (Barrientos, 1994 Barrientos y L'Heureux 2000), Patagonia (Perez Perez, 1995), (Guichón, 1993), Egipto -Wadi Halfa (Carlson et al. 1974)-; Estados Unidos -Dickson Mounds en Illinois (Goodman et al. 1984), (Rose, et al., 1984), Dakota (Steinbock, 1976) y Missouri, (Williams, 1994).

El capítulo uno, contempla las consideraciones teóricas básicas y el desarrollo de la conformación del pensamiento bioantropológico en Estilo y Calidad de Vida en la prehistoria en los cuáles se funda este trabajo.

Los indicadores osteológicos empleados en el relevamiento se presentan en el capítulo dos. Se seleccionaron como indicadores de salud a la estatura y al dimorfismo sexual, los cuales aportan información respecto del proceso de crecimiento y de desarrollo que experimentó el grupo. Como indicadores de patologías óseas se consideraron, la hiploplasia dental, la hiperostosis porótica - la cribra orbitalia, las infecciosas inespecíficas, las infecciosas específicas, las caries, las periodontitis, el trauma, los nódulos de Schmorl, las artropatías, las osteoartritis y los osteofitosis vertebral.

Estos indicadores fueron seleccionados de acuerdo a la potencialidad del registro ósteológico. Además de las consideraciones teóricas para cada indicador, se presentaron casos de poblaciones cazadoras recolectoras, horticultoras y agricultoras. La finalidad de este estudio comparativo fue obtener parámetros de referencia, de acuerdo a las distribuciones de los indicadores en las muestras, que permitieran describir contextualmente la situación adaptativa del grupo de estudio respecto de otros, considerados como grupos de control para el análisis realizado.

El capítulo tres presenta el contexto ambiental donde se ubica el sitio Santana do Riacho I, su inserción geográfica que contempla la localización, la geología local y sus cuencas hidrológicas. 
En el componente ecológico se consideran los sistemas actuantes: vegetación, fauna y poblaciones humanas.

Los antecedentes de investigación en el sitio son presentados en el capítulo cuatro, a partir de la llegada de Peter W. Lund en 1825, naturalista dinamarqués, que llega a esta región para realizar estudios científicos. Un siglo y medio después, A. Prous realiza las primeras excavaciones y W. Neves realiza en los últimos años la curadoría y análisis de los materiales.

La presentación del contexto arqueológico se expone en el capítulo cinco. Se describe el registro faunístico, estudiado por Kipnis en el año 2002, el etnobotánico, el instrumental lítico y óseo, el material textil, los pigmentos y enterratorios, a partir de los trabajos de Neves y de su equipo. Se contextualizaron los 28 enterratorios, los momentos de inhumación, posición y orientación de los esqueletos. Se presentan además las dataciones obtenidas para este sitio.

En el capítulo seis se expone la importancia de esta colección y se presentan los antecedentes de investigación de la misma. En este apartado se realizan también las consideraciones teóricas y metodológicas acerca de la muestra. Se presenta su caracterización, estructura y composición, que contempla el número de individuos, la estructura etaria y sexual y se evalúa el estado actual de su conservación.

La metodología y los resultados se presentan en el capítulo siete. El trabajo de relevamiento de datos se realizó bajo la supervisión de Walter Neves. Los items considerados son antropometría; odontológica básica consistente en: presencia, pérdida ante y postmortem, agénesis congénita, no erupcionado, caries, retención alveolar, periodontitis y desgaste dental; indicadores nutricionales o metabólicos: hiperostosis, hipoplasia; indicadores ocupacionales: trauma, artropatías, osteófitos, y nódulos de Schmorl y de enfermedades infecciosas inespecíficas. De modo que para la realización de este trabajo fueron relevados y procesados un conjunto de 669 atributos óseos por individuo, incluidos los datos de ausencia de evidencia.

La información individual obtenida se volcó en planillas de MS Excel para la confección de un banco de datos. Aunque la muestra total para cada marcador 
analizado sea pequeña teniendo en cuenta la gran recurrencia de datos ausentes, adoptamos como estrategia presentar los resultados de manera cuantificada, dado que este es el primer estudio sistemático de una colección de esqueletos paleoindios en términos de población. Aun en virtud de la pequeña muestra, restringimos nuestra cuantificación a la presentación de estadísticas descriptivas muy sencillas, como frecuencias y medidas de tendencia central. Sólo en los casos en que fue factible se aplicaron pruebas de hipótesis para evaluar el grado de significancia de los resultados obtenidos.

En el capítulo ocho se presenta la discusión y en el nueve las consideraciones finales. Los resultados obtenidos hasta el momento exhiben una coherencia interna entre las variables, en dónde se evidencia que las condiciones de salud resultaron buenas y las condiciones patológicas se han demostrado entre bajas y moderadas.

La colección presenta un notable dimorfismo sexual que habla en favor de un normal proceso de crecimiento y desarrollo, que, junto a los datos de talla y robustez, concuerdan en que la población no estuvo sometida a ningún episodio de desnutrición, malnutrición, o detención del crecimiento severa o prolongada. Asimismo, las patologías de origen metabólico, que pueden dar cuenta de alteraciones nutricionales, se representan con una baja incidencia.

La frecuencia de caries de la población de Santana do Riacho I resultó ser mayor a las expectativas planteadas por los modelos propuestos para economías cazadoras recolectoras.

Los resultados obtenidos de los indicadores de stress funcional u ocupacional sugieren que el uso de la columna vertebral, en ocupaciones asociadas al levantamiento, carga y transporte de materiales pesados, no habría demandado exigencias biomecánicas suficientes como para provocar lesiones que afectaran la movilidad corporal de los individuos. Aunque las afecciones traumáticas se manifestaron en los adultos, por sus características indican un origen accidental.

La escasa presencia de enfermedades infecciosas, como en el caso de la periostitis, las inflamaciones óseas inespecíficas, y las moderadas lesiones traumáticas reflejan un mesurado y no agresivo impacto del medio en los 
cuerpos. Como así suma una adecuada respuesta inmunológica postraumática, evidenciada por la sobrevivencia de los individuos al impacto traumático.

La ausencia de marcadores diagnósticos de enfermedades infectocontagiosas refleja una fuerte respuesta inmunológica ante las enfermedades infecciosas endémica.

La muestra no presentó signos óseos que pudieran asociarse directamente con causas específicas de muerte.

Teniendo en cuenta el concepto de la "paradoja osteológica" planteada por Wood et al. (1992), en el cual los individuos más afectados por patologías son los más resistentes a la enfermedad, porque lograron sobrevivirla a pesar de que las infecciones hubieran afectado al sistema esqueletal y dejar su registro. En tanto, aquellos otros individuos que no presentan evidencias de patologías óseas pueden ser los que, por su baja resistencia inmunológica a los microorganismos patogénicos, murieron antes que las patologías pudieran dejar su evidencia en los huesos. La paradoja presentada no puede ser resuelta en este caso y con los datos disponibles, pero el conjunto de los resultados obtenidos con otros marcadores no infecciosos.

De acuerdo a todo lo expuesto y a modo de una evaluación general pensamos que, según los resultados obtenidos a través de los indicadores de stress funcional y nutricional, éstos son sugerentes de un bajo impacto ambiental negativo y de una calidad de vida apropiada, capaz de garantizar la reproducción y la supervivencia del grupo en Lagoa Santa constituyendo un modelo de éxito adaptativo. 


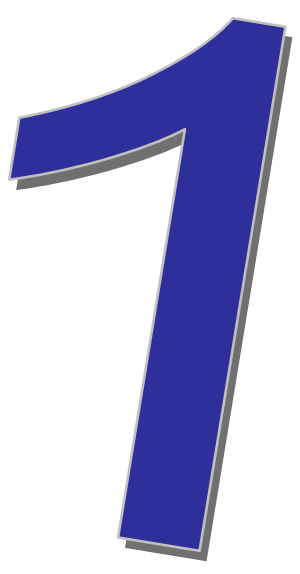

BASES

TEÓRICAS 
Las poblaciones humanas durante su proceso evolutivo, han ocupado en el planeta regiones con una amplia variedad climática, resistiendo a las presiones selectivas continuas del ambiente, y han respondido a éstas no solo con procesos de adaptación biológica, sino también con procesos de naturaleza cultural.

De estos procesos resultan continuas modificaciones que son producto de las relaciones del grupo con el medio particular que habita e interactúa produciendo, con el correr de los milenios, distintos desarrollos regionales, representados en la diversidad bio-cultural.

El estudio de poblaciones prehistóricas, desde la biología del esqueleto posibilita inferir, a través del registro óseo, la magnitud de las fuerzas que ejercieron las presiones selectivas y de qué modo impactó el ambiente en el grupo. En este sentido, el esqueleto constituye un sistema sensible al medio ambiente, debido a las propiedades orgánicas de su constitución, que le otorgan una plasticidad capaz de registrar las fuerzas y los factores de acción y reacción que operaron a lo largo de la vida (Huss-Ashmore et al. 1982; Neves 1984b; Martin, Goodman y Armelagos 1985; Iscan Yasar y Kennedy 1989; Saul 1976; Larsen 1987, Buikstra y Ubelaker, 1994, entre otros).

Debido a las posibles fluctuaciones ambientales, los grupos pueden variar su grado de eficiencia adaptativa, que puede medirse en parámetros de salud, pues son efecto de la relación población-medio y por lo tanto un factor significativo para el análisis de calidad de vida.

Basado en estos principios, se presenta en este trabajo un análisis de la calidad de vida de un grupo paleoindio tardío, que habitó los cerrados de la región de Lagoa Santa, con una muestra osteológica excavada en 1979 en el sitio Santana do Riacho.

Los estudios de poblaciones humanas prehistóricas pueden abordarse desde el análisis del registro biológico, mediante el relevamiento de indicadores óseos que contienen información acerca de las paleodietas, de las condiciones de salud (nutrición, crecimiento y desarrollo) y enfermedad (paleopatologías).

Si a través del análisis de los indicadores relevados detectamos la presencia de patologías de origen metabólico, infeccioso, traumático o genético, podemos 
considerar que la calidad de las estrategias de ajuste ambiental podría no haber sido suficientemente eficaz. Esta situación es conocida como estrés.

El estrés ha sido definido por varios autores, entre ellos, y quien mostró desde temprano una preocupación por los estudios de adaptabilidad humana en la década del 1960, fue Paul Baker, para él, los organismos están expuestos a constantes presiones selectivas del ambiente físico y biológico. Los humanos hemos respondido a estas tensiones con procesos adaptativos especiales, que se basan en la constante interacción biológico-cultural que caracteriza el accionar de nuestra especie.

La capacidad de crear cultura debe considerarse como un producto del comportamiento humano, cuya mejor representación la constituye la capacidad de aprendizaje en respuesta a la información que provee el ambiente en el cual los miembros de esta especie se desarrollan. Otros ejemplos de plasticidad fenotípica funcional y morfológica, son las adaptaciones a diferentes temperaturas y altitudes (Baker, 1965). Este autor propone que uno de los métodos más directos para determinar el grado de estrés en poblaciones humanas, es el estudio de las causas de esterilidad y muerte. Pero reconociendo la dificultad de acceso a esta información, en la mayoría de los casos, propone un segundo método basado en determinar el grado de estrés ambiental mediante una evaluación de los procesos homeostáticos humanos. Determinando estos factores podemos ver, de acuerdo con Baker (1965), qué tan exitosa puede ser una población humana en el ambiente que ocupa.

La década del 1960 se caracterizó, en Estados Unidos, por promover los estudios de los mecanismos adaptativos de las poblaciones vivientes sometidas a diferentes formas de estrés ambiental. Se lograron importantes avances en temas como crecimiento y desarrollo, composición corporal, tolerancia climática, estatus nutricional, aislamiento grupal y migraciones, entre otras temáticas afines. Estos fueron estimulados por programas como el IBP International Biological Program-, apoyado por la Wenner-Gren Foundation, del que participaron 40 países y 230 proyectos en Adaptabilidad Humana (Little, 1982).

Esta corriente de investigaciones en poblaciones actuales pasó, gradualmente, a poblaciones extintas. Goodman (1980) hace interactuar los factores 
ambientales, biológicos y culturales, en un modelo que destaca las consecuencias del impacto del estrés (o disrupciones fisiológicas) en las poblaciones prehistóricas, considerando entre ellas la alteración en el crecimiento corporal, la disminución de los índices de fecundidad y fertilidad, enfermedades y muerte.

Huss-Ashmore, Goodman y Armelagos (1982), propusieron al estrés como un trastorno fisiológico de un organismo, resultante de una perturbación ambiental. Aunque no pueda ser directamente observado, puede dejar su impacto sobre el esqueleto. Para estos autores, el grado en que se manifiesta este trastorno es una función de la severidad del medio y de la capacidad de respuesta del organismo/población.

Este modelo consolidó los principios de un cambio de paradigma, que se venia gestando desde Paul Baker y que se afianzó a partir de la publicación de dos trabajos, cuyas líneas de investigación convergían desde la paleopatología, la nueva arqueología y la biología evolutiva.

Uno de ellos (Cohen, 1984) contiene los trabajos de investigación, subvencionados por la Wenner-Gren Foundation, que evalúan la medida del impacto que significó el cambio de estrategias de subsistencias cazadoras recolectoras a agricultoras, desde el registro óseo.

El otro, (Gilbert y Mielke, 1985) compila trabajos de veinte investigadores orientados en una perspectiva biocultural, que alcanzaba su desarrollo con el refinamiento de técnicas, confiabilidad en los resultados, comprensión de diagnósticos y, especialmente, con un cambio de objetivos, desde una antropología física clásica más preocupada por la descripción de los episodios adaptativos que por su comprensión.

Angel (1987) y Kelley y Angel (1987) presentaron el concepto "life stresses" en su estudio de poblaciones negras esclavas de Filadelfia, donde el estrés sería el resultado de todas las fuerzas externas usuales que afectan al individuo, tales como dieta inadecuada, enfermedad, ocupación, accidente y violencia, entre otros. Para los esclavos, todo el ambiente es considerado estresante y el estrés psicológico es conocido por causar efectos directos sobre el sistema inmune (Angel, 1987; Kelley y Angel, 1987). Las fuerzas internas operan por 
determinantes biológicos inherentes a la composición genética. El estrés puede ser patológico, pero generalmente deriva de la dieta, de la ocupación y de las relaciones con el medio.

Los estudios bioarqueológicos enfocados desde una perspectiva de investigación de estilo y calidad de vida, desde la evidencia osteológica, se distribuyeron por diferentes cronologías, economías, ambientes y culturas.

En los últimos años se han realizado estudios en sociedades de diferentes economías agricultoras, horticultoras, pastoriles, cazadoras-recolectoras y de transición, cambio y contacto entre distintos sistemas. Estos grupos han sido caracterizados, comparados y evaluados, en términos de status de salud, como una capacidad de respuesta bio-cultural a los procesos adaptativos de las poblaciones humanas en momentos prehistóricos e históricos, como el de contacto.

En América del Sur, esta línea de investigación fue introducida por Walter Neves, de la Universidad de San Pablo, a mediados de la década del 1980. En 1987, Neves dictó un curso internacional:

Biología y Cultura: Anatomía funcional y Estilo de Vida, de cuya repercusión resultó la aplicación de este modelo a colecciones de varios países latinos, como Brasil, Argentina, Chile y Uruguay.

En 1992, un grupo de investigadores norteamericanos, de las universidades de Ohio y Arkansas, emprendieron un proyecto general sobre estudios de las condiciones de salud, desde el registro osteológico, aplicado a colecciones osteológicas procedentes de poblaciones nativas americanas, euroamericanas y afroamericanas.

Se formó una base de datos, sobre los resultados del relevamiento de siete indicadores observados en 12.520 esqueletos provenientes de 218 sitios de América del Norte, Central y Sur, en un rango cronológico de 7000 años, cuya información fue codificada.

Este proyecto estaba destinado a estandarizar variables ecológicas y biológicas y a sistematizar los resultados obtenidos para calificar, evaluar y comparar las condiciones de la calidad de vida, introduciendo algunas innovaciones en la propuesta metodológica, mediante el empleo de ecuaciones propuestas para el 
standard de vida del desarrollo humano, de acuerdo con el documento de las Naciones Unidas (Steckel,1995).

Diez años de trabajo convergieron en la suma de esfuerzos de 50 investigadores, que se plasmó en un valioso trabajo (Steckel y Rosen, 2002) otorgando de este modo actualización y vigencia a los estudios bioantropológicos de estilo y calidad de vida. 


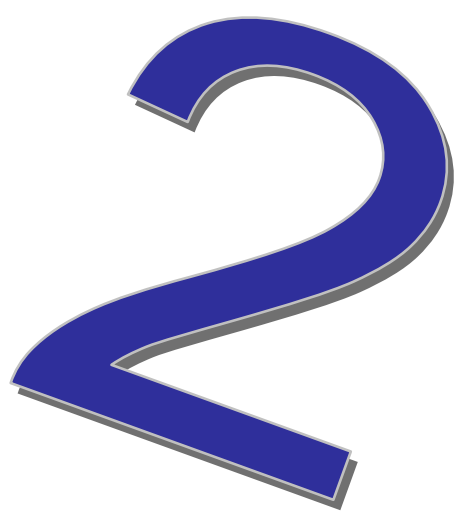

INDICADORES OSEOS 
INDICADORES DE SALUD

\subsection{TALLA}

El crecimiento es resultado de una compleja relación de factores, tanto genéticos como ambientales, sobre todo nutricionales. El estatus socioeconómico produce un impacto igualmente importante sobre el crecimiento (Bogin, 1988). De modo que la estatura individual refleja la influencia de la interacción genética y ambiental durante el período de crecimiento.

Aunque los genes constituyan un importante determinante en la talla individual, Steckel (1995) dice que los estudios de poblaciones genéticamente afines, bajo variadas condiciones ambientales, sugieren que las diferencias entre promedios de talla son atribuibles, en su mayor parte, a factores ambientales.

La alteración, insuficiencia o inadecuación nutricional severa afecta el normal proceso de crecimiento y desarrollo, como lo demuestran Guimarey, Carnese y Pucciarelli en estudios realizados con poblaciones actuales (Pucciarelli et al., 1995).

Bajo condiciones de estrés, el crecimiento de un organismo tiende a retardarse o detenerse hasta tanto mejore la disponibilidad de nutrientes, de manera que el crecimiento es un útil instrumento de análisis del grado de estrés ambiental (Goodman, et al., 1984).

Los datos de cientos de poblaciones humanas fueron estadísticamente procesados y correlacionados con variables de tipo climático, térmico, altitudinal, ecotonal, de estatus social, etc., procurando obtener patrones que dieran cuenta de regularidades para la elaboración de modelos de crecimiento humano. Desafortunadamente no se obtuvieron muchos resultados válidos (Bogin, 1988).

No obstante, los datos de crecimiento derivados de muestreos poblacionales estadísticamente representativos son utilizados en la construcción de estándares de peso y estatura. Estos referentes son empleados en trabajos de salud pública para control de crecimiento, desarrollo y status nutricional de grupos considerados en riesgo y para el monitoreo de programas de salud. 
También estos estándares se utilizan como dato para la obtención de índices de calidad de vida, aplicados tanto en exámenes médicos relacionados con eventos de asistencia y seguro social.

La estatura constituye un reconocido indicador de standard y calidad de vida, tanto en poblaciones actuales como extintas (Stekel, 1995), dado que los disturbios nutricionales manifestados por los desórdenes metabólicos, suelen dejar indicios de su acción en la estructura ósea.

Angel (1984) propuso para el estudio de la salud como factor de cambio de estrategias de subsistencia, una serie de indicadores osteológicos, entre los cuales incluye la estatura total, con lo que el tamaño corporal en adultos es un claro recurso informativo de los cambios de estado nutricional.

Las comparaciones intrapoblacionales demuestran, según Clark Larsen (quien compiló diversos casos de estudio), que el rango social parece estar directamente vinculado con la variación estatural. Dicho autor piensa que las altas jerarquías sociales contarían con ventajas nutricionales, lo que se manifiesta en mayores tallas (Larsen, 1997).

Numerosos ejemplos ilustran esta relación proporcional de elites y estaturas en contextos mesoamericanos, atacameños, etruscos y del oeste medio norteamericano (Larsen, 1997). También Neves y Costa (1998) han planteado la relación entre estatura, nutrición y calidad de vida en un estudio realizado en una colección osteológica de San Pedro de Atacama (Chile). En ese mismo trabajo fue demostrado que la influencia Tiawanacota en la región aumentó, en parte, la calidad de vida, según indicaran, entre otros biomarcadores de origen metabólico, el aumento de la longitud de los fémures analizados.

\subsection{DIMORFISMO SEXUAL}

Como dimorfismo sexual se conoce al conjunto de las diferencias morfológicas, fisiológicas, bioquímicas y comportamentales entre machos y hembras de una misma especie. Cuando estos rasgos están directamente vinculados con la reproducción, se conocen como caracteres sexuales primarios y como secundarios cuando no se relacionan de manera directa a ésta actividad (Pucciarelli et al., 1996). 
Las diferencias sexuales humanas constituyen un complejo fenómeno, que se expresa en la anatomía, fisiología y comportamiento. Son muchos los factores intervinientes en su grado de expresión, pero hay un determinante genético de los grados sexuales, que se plasma en los rasgos fenotípicos del adulto (Stini, 1985). Es la expresión de la diferenciación entre los patrones de crecimiento masculinos y femeninos y puede considerarse como el producto de la interacción genético-ambiental a nivel de una población (Pucciarelli, 1991).

El dimorfismo sexual se manifiesta en diferencias de tamaño y forma de órganos y tejidos. La anatomía ósea refleja, también, las diferencias en los rasgos morfológicos.

La diferencia entre sexos se reduce cuando la población se halla sometida a condiciones de estrés nutricional prolongado y severo. El crecimiento puberal de los varones al ser más prolongado, es también más sensible que el de las mujeres (Baffi y Cocilovo, 1989), debido a que el proceso tiene un mayor tiempo de exposición. El mantenimiento fisiológico y la capacidad de almacenamiento de reservas de nutrientes de las mujeres difieren de la de los varones, en tanto que éstos tienen un requerimiento mayor de energía y de proteínas, que las mujeres, a excepción de las embarazadas, debido a una mayor actividad metabólica.

La expresión del dimorfismo sexual es, por lo tanto, funcionalmente dependiente de la disponibilidad de recursos y del equilibrio energético. La estrategia reproductiva de nuestra especie parece garantizar una mayor estabilidad genético-ambiental en las mujeres, a diferencia de los varones, los cuales acusan mayor sensibilidad ante circunstancias de estrés. La respuesta inmunológica y la capacidad de recuperación ante la enfermedad del grupo femenino es, en promedio, más efectiva que la del grupo masculino (Stini, 1985; Bogin, 1988, Pucciarelli, 1991, Ortner, 1998).

Pero una de las preocupaciones mayores con respecto al uso de este indicador fue planteada por Armelagos (1998), quien plantea la dificultad existente para diferenciar entre las diferencias sexuales fisiológicas y de comportamiento sociocultural. 
Si bien el dimorfismo sexual es un biomarcador complejo, sus resultados conducen a una información válida, pasible de ser contrastada con el empleo de otros marcadores. Tal es nuestro caso, en el cual optamos por incluir estos datos y acercarlos a resultados comparativos.

\subsection{INDICADORES DE PATOLOGÍAS OSEAS}

\subsubsection{HIPLOPLASIA DENTAL}

El desarrollo de defectos en la formación de esmalte dentario es reconocido como un importante indicador de salud, tanto para poblaciones contemporáneas como extintas (Hillson 1990).

El desarrollo esmaltario es el resultado de la integración de dos procesos: formación de matriz y mineralización. La formación de matriz comienza alrededor de los cuatro meses uterinos y consta de un crecimiento por superposición de los depósitos minerales (Duray, 1992). La presencia de este marcador nos informa acerca de episodios de detención del crecimiento. Las razones que producen este efecto pueden ser múltiples, como por ejemplo eventos febriles prolongados, cambios repentinos o alteración de dietas, ingestión de antibióticos o síndromes heredados (Hillson, 1990, 1996).

Rose, Condon y Goodman (1985) sostienen que el estrés nutricional es el principal factor de ocurrencia, especialmente en poblaciones prehistóricas. Los trabajos de Powell (1991) y Storey (1992) evidencian estos postulados, e indican que se debe a una deficiencia en el grosor del esmalte, debido a una alteración en la formación, desde el nacimiento hasta los 13 años de edad (Lukacs, 1989). Estos eventos se manifiestan en forma de líneas o bandas paralelas horizontales sobre la cara labial, pudiendo presentar también pequeños hoyos y estrías.

La Hipoplasia de esmalte dental es considerada un importante indicador, capaz para medir la intensidad del estrés nutricional que experimentaban las poblaciones prehistóricas. Muchos autores (Ubelaker, 1992; Cook y Buikstra 1979; Larsen 1987; Storey 1992, entre otros) encontraron que la frecuencia y grado de severidad de hipoplasias de esmalte se incrementaba con la adopción 
del sedentarismo y la incorporación de productos agrícolas, en la medida que aumentaba la densidad de población y se restringían los recursos alimenticios.

Barrientos y L"Heurex (2000) no encuentran diferencias significativas de hipoplasia de esmalte de las muestras observadas en el sudeste de la región Pampeana, entre los períodos del Holoceno tardío (ca. 1.000 a 400 años AP) del Holoceno tempreano-medio (ca. 8.000 a 6.000 años AP) y Holoceno medio-tardío (ca. 3.500 a 2.000 años AP). No obstante, comunican que la prevalencia de hipoplasia es relativamente alta $(40,4 \%)$ comparada con otras poblaciones de cazadores.

Nema y Reyes (2001) no registran casos en la Cueva de Baño Nuevo, en esqueletos datados entre 9000 y el 8500 A.P en Patagonia Central.

\subsubsection{HIPEROSTOSIS PORÓTICA - CRIBRA ORBITALIA}

La presencia de hiperostosis porótica y cribra orbitalia en esqueletos humanos constituye un indicador útil en la reconstrucción de los sistemas de salud en la prehistoria, ya que informa acerca de la afección de anemias por dietas deficientes en hierro, por resistencia inmunológica anti-malaria o por la presencia de parásitos intestinales (Steinbock, 1976; Goodman et al., 1984; Larsen, 1987, 1997; Huss-Ashmore et al., 1982).

La respuesta más obvia del esqueleto a la anemia consiste en la hiperostosis porótica ( $\mathrm{Hp}$ ) y la cribra orbitalia (Co), las cuales son lesiones producidas por la expansión del espacio medular. El aumento de producción medular produce el reemplazo de la tabla externa de hueso compacto, con exposición de hueso intertabular, tomando la apariencia de hiperostosis hipervascularizada y provocando su adelgazamiento (Steinbock, 1976).

Otras lesiones relacionadas son a) la hiperostosis esponjosa (spongy hyperostosis), caracterizada por la aparición de osteofitos que forman una red de hueso trabecular sobre la superficie externa del cráneo y b) el picado osteoporótico ("osteoporotic pitting") de la tabla externa de la calota (Larsen, 1997).

Si bien estas manifestaciones pueden ocurrir independientemente, todas comparten una etiología en común: la anemia ferropriva. 
Los factores que pueden producir anemia son múltiples. Holland y O’Brien (1997) proponen tres modelos etiológicos que explicarían la ocurrencia anémica desde lo genético, lo nutricional y lo parasitario. Desde la perspectiva genética, se asocia a las anemias hereditarias (talasemia y de células falciformes) con procesos adaptativos.

Muchos autores sostienen que la hipoferremia constituye una respuesta adaptativa ante una persistente invasión de Plasmodium. Cuatro especies de este género parasitan al género humano, que se transmiten a través de la hembra del mosquito Anopheles, del cual existen más de cien especies (Merbs 1992; Stuart-Macadam 1992; Smith, 1993; Polednak 1987).

Carlson, Armelagos y Van Gerven (1974) propusieron a los casos de hiperostosis porótica y cribra orbitalia, encontrados en una población prehistórica de Nubia, como efectos de anemias (talasemia y falciforme) producidos como un posible carácter inmunológico adaptativo contra la presencia de malaria. Este significado adaptativo de la talasemia, como protección contra la malaria, es sugerido no sólo por la coincidencia de sus distribuciónes a escala mundial, sino también por estudios locales que han determinado correlaciones espaciales y altitudinales.

En los registros arqueológicos, la hiperostosis porótica y la cribra orbitalia ocurren con mayor frecuencia en tierras bajas, tropicales y de mayor densidad de población (Stuart-Macadam 1992). Las evidencias indican que la malaria falciforme no estuvo presente en América, al menos hasta 1542 (Merbs, 1992). Las hemoglobinas polimórficas como talasemia, $\mathrm{HbS}, \mathrm{HbC}, \mathrm{HbD}, \mathrm{Hbo}$ y $\mathrm{G} 6 \mathrm{PD}$, se encuentran en África, Asia y Europa, donde falciparum m. está o estuvo presente, pero este tipo de hemoglobinas no existen en los amerindios (Merbs, 1992).

El modelo dietético, por su parte, sostiene que algunas dietas son bajas en hierro o contienen determinados elementos que interfieren en la absorción del mismo. La eficiencia de absorción del hierro dietario depende de su estado en los alimentos. Los vegetales contienen sustancias que inhiben (fitatos) y/o estimulan (ácidos ascórbido y cítrico) la absorción de hierro (Baynes y Bothwell,1990). 
Los cereales, especialmente el maíz, poseen, además de un bajo contenido en hierro, fibras y sustancias que interfieren en la absorción del mismo. El tanino, por ejemplo, es un polifenol inhibidor de hierro, que se encuentra en el té, el café y el sorgo. Esta hipótesis se conoce en la bioantropología americana como “maize-dependency” (El-Najjar et al 1982 citado en Holland y O’Brien, 1997).

En contraste, el modelo parasitario propone la deficiencia de hierro como consecuencia de una infección parasitaria. La parasitosis intestinal es de amplia distribución, especialmente en áreas subtropicales (Layrisse y Roche, 1964). Su efecto es devastador, debido a la pérdida de sangre y a la menor resistencia a otras infecciones. Las parasitosis por Ancylostoma duodenale, Giardia lambia ó Necator americanus producen anemia, aun cuando la ingesta de hierro sea adecuada (Hotez y Pritchard, 1995) llegando a provocar una pérdida sanguínea de entre 0,2 y 0,5 ml. por cada anquilostoma (Holland y O’Brien, 1997).

La esquistosomiasis desencadena una respuesta inmunitaria, después que los parásitos se instalan en los órganos del cuerpo. La enfermedad está distribuida mundialmente (Farley, 1993). Los neonatos y los niños son más sensibles que los adultos a este tipo de infecciones parasitarias. Generalmente se asocian estas manifestaciones con poblaciones de economías agricultoras y horticultoras, pero también se presenta en grupos cazadores, aunque con bajas incidencias.

En Sud-América, por ejemplo, la revisión que hizo Larsen (1997) refiere a la observación de cribra orbitalia sólo en Perú (Hrdlicka, 1914) y Ecuador (Ubelaker, 1981 citado en Larsen, 1997). Asimismo, se registraron casos en el litoral brasileño, de acuerdo a la información suministrada por Neves (com. pers.).

En el norte de Chile, los pescadores arcaicos del Morro de Arica presentaron una incidencia de Hiperostosis porótica del $10 \%$ (8/80 casos) con igual distribución por cada sexo, en tanto que la cribra orbitalia se manifestó con una incidencia mayor del 21,7\% (Costa et al. 2000).

En Argentina, se reportaron casos de alta frecuencia en la población antigua de Las Pirguas (1.500 AP). Los restos de alimentos asociados indican, en este 
caso, una dieta basada en hortalizas y cereales. El análisis de coprolitos humanos obtenidos en las excavaciones, indicó la presencia de parásitos intestinales hematófagos causantes de anemias severas (Baffi y Cocilovo, 1989). Los estudios en colecciones osteológicas de cazadores sudpatagónicos, presentan una baja prevalencia (Pérez Pérez 1995; Guichón 1993) y los cazadores del área pampeana y cuyo (río Atuel) no exponen casos de esta patología (Barrientos 1994; Novellino, Guichón y Lagiglia, 1996).

De los grupos cazadores y pescadores del litoral fluvial argentino, se relevó sólo una mención de caso para el Delta del Paraná. Torres (1913) y Cornero y Puche (2002) encontraron una notable incidencia para el grupo de La Lechuza, en el valle aluvial del río Paraná, (datado en 1.760 años AP), representado por el $54,5 \%$ de $\mathrm{Hp}(7 / 11$ adultos) y $63 \%$ de Co incipiente y moderada (7/11 infantiles).

En las excavaciones en Wadi Halfa (Nubia, Egipto) se descubrieron tres horizontes con restos esqueletales: meroítico (350 AC a $350 \mathrm{DC}$ ), grupo $\mathrm{X}$ (350-550 DC) y cristiano (550-1400 DC), de marcada homogeneidad cultural en las tecnologías de subsistencia y economía. Estos pueblos eran agricultores, con limitada ingesta de proteínas de primera calidad. Las colecciones que fueron analizadas por Carlson et al. (1974) presentaron frecuencias bajas de hiperostosis $(5 \%)$ y altas de cribra orbitalia (21.4\%). Sólo uno de los 123 cráneos estudiados exhibió las dos lesiones (CO y HP) simultáneamente. La cribra orbitalia fue significativamente más frecuente en niños.

Quevedo (1998) reportó para Punta Teatinos II (período agrícola de la costa chilena) ausencia de estos indicadores y para Punta Teatinos I (arcaico), una baja incidencia (4\%) de cribra orbitaria. Neves y Costa (1999) realizaron un estudio en la población de San Pedro de Atacama durante tres diferentes períodos -pre-Tiawanaku (Solcor-3 12\%), Tiawanaku (Solcor-3 22,86\%) y Posttiawanaku (Coyo-3 9,30\% y Quitor-3 10 \%)-, para determinar si se alteraba la distribución de frecuencia de hiperostosis porótica en el grupo, no hallando resultados estadísticamente significativos para este indicador. 


\subsubsection{INFECCIOSAS INESPECÍFICAS}

Existe un amplio consenso en afirmar que las enfermedades infecciosas se vinculan estrechamente con los sistemas ecológicos, genéticos y nutricionales, así como con los múltiples efectos surgentes de la relación de los grupos con su ambiente, en particular con la dieta, la estructura social, la demografía, los patrones de asentamiento, la domesticación de plantas y animales, las guerras, la calidad de vida, la resistencia inmunológica y el grado de estrés (Kelley, 1989; Ortner et al. 1992, Powell, 1988; Morán, 1990, Larsen, 1997; Polednak, 1987, entre otros).

Las enfermedades infecciosas han influído sobre la historia humana, movilizando transformaciones culturales como sociales, económicas y políticas, procurando controlar las devastadoras epidemias (como sarampión o gripe) o debilitar las infecciones crónicas (como malaria o schistosomiasis) y transformaciones biológicas, forzando respuestas adaptativas a nivel de inmunidad genética (Inhorn y Brown, 1990).

De acuerdo con la Professional Guide of Diseases (Merbs, 1992), infección es la invasión y multiplicación de microorganismos en los tejidos del cuerpo, los cuales causan daño celular por su producción de toxinas, multiplicación intracelular o por competencia con el metabolismo del organismo afectado. En la mayoría de los casos, la etiología es desconocida y por eso se denominan infecciones inespecíficas. Este tipo de lesiones en hueso se organizan como conjunto de reacciones periostíticas, cuando afectan al periostio del hueso y osteítis, cuando la lesión involucra al tejido cortical y a la médula (Goodman, Martin, Armelagos, y Clark, 1984).

La osteomielitis puede ocasionar serios trastornos, llegando en estados críticos a causar la muerte por afección de órganos vitales. En tanto que la periostitis casi nunca resulta fatal y en muchos casos suele volverse crónica (Larsen, 1997). Las rutas de acceso de la infección al sistema óseo pueden ser múltiples. Ortner y Putschar (1985) proponen tres vías: 1- por lesiones traumáticas o quirúrgicas, 2 - por extensión de tejidos blandos infectados y 3 por vía sanguínea, transportando los focos sépticos. El $90 \%$ de los casos infecciosos es producido por Staphylococcus aureus o por Streptococcus sp. Y, 
en menores proporciones, por Escherichia coli, Salmonella typhi y Neisseria gonorrohea (Resnick y Niwayama, 1988; Steinbock, 1976; Biddle, 1995).

Ciertos organismos producen rápidas y destructivas enfermedades óseas y articulares, mientras que otros se asocian con procesos más benignos. Algunos agentes muestran predilección por ciertas regiones anatómicas, en tanto que otros producen cambios simultáneos en diferentes lugares. De allí, por ejemplo, la diferencia entre infecciones producidas por Staphylococcus, comúnmente en niños, o por Streptococcus mas frecuente en procesos localizados (Resnick y Niwayama, 1988).

Las infecciones pueden ser sistémicas o localizadas, las primeras se manifiestan simétricamente en diferentes regiones del esqueleto, como diáfisis o articulaciones y las segundas son producto de eventos que se centran en un área ósea determinada y que generalmente son producidas por el impacto de alguna lesión traumática (Ortner y Putschar, 1985).

La tibia humana constituye uno de los indicadores de infecciones más sensibles, ya que los porcentajes de afección son mucho mayores respecto de otras partes del esqueleto. Para Larsen (1997), esto puede relacionarse con que la tibia es en general un área muy vascularizada, de poca actividad fisiológica, lo cual permitiría crear un ambiente favorable para la colonización bacteriana y su localización anatómica implica una corriente circulatoria más lenta (Martin et al 1991, Steinbock, 1976)

Las evidencias de infecciones no específicas han sido bien documentadas en muchas muestras de colecciones osteológicas provenientes de diferentes sistemas ambientales. Los registros fueron analizados y comparados desde perspectivas diferentes, dadas por cuestiones de condición económica y de rango social. En este sentido, Larsen (1997) compiló algunos resultados de estudios de caso, concluyendo que existió un fuerte incremento en la frecuencia y severidad de lesiones infecciosas (periostitis y osteomielitis), coincidente con cambios de asentamiento en las poblaciones de Dickson Mounds.

El sitio Dickson Mounds del valle del río Illinois presenta una interesante relación entre sistemas de subsistencia, asentamientos y salud. Goodman et al. 
(1984) compararon las prevalencias de infecciones en los períodos temprano y tardío, coincidiendo en este último con un incremento en el consumo de maíz, reducción de proteínas de origen animal y consolidación de unidades habitacionales, con consiguiente incremento de la densidad poblacional (Larsen, 1997).

La prevalencia de individuos afectados se duplicó en el período tardío de 30,8 a $67,4 \%$. Considerando solo la tibia, la prevalencia pasó del 26 al $84 \%$, afectando a todos los grupos etáreos y a ambos sexos.

Un caso similar fue presentado por Ubelaker (1997) en el sitio ecuatoriano de La Tolita. En el período temprano hubo una prevalencia del $20 \%$ de lesiones infecciosas en adultos y del $38 \%$ en el período clásico, representado este último por incrementos en la densidad de población, especialización urbana, intensificación de la agricultura y expansión cultural.

En el sudeste de la región pampeana argentina, Barrientos y L’Heureux (2000) demostraron comparativamente que las lesiones óseas, atribuíbles a procesos infecciosos, resultaron en significativo aumento de prevalencias $(p<0,05)$ en las muestras del Holoceno tardío (ca. 1.000 a 400 años AP) respecto de las muestras del Holoceno tempreano-medio (ca. 8.000 a 6.000 años AP) y Holoceno medio-tardío (ca. 3.500 a 2.000 años AP).

En poblaciones prehistóricas cazadoras-recolectoras de Australia se encontró, de acuerdo con los estudios de Webb (1995), que la prevalencia de infecciones inespecíficas resultó para tibias derechas del $6,1 \%$ y del 1,8\% para fémures derechos, en un grupo de la costa del Este. La mas alta frecuencia ocurrió en un grupo del desierto, que reportó un $11,1 \%$ de lesiones infecciosas en tibias derechas y un $16,7 \%$ en fémures de igual lateralidad. Webb nota que las infecciones en huesos largos, entre las seis poblaciones aborígenes australianas observadas, son mas frecuentes en el lado derecho que en el izquierdo.

La muestra ósea de una aldea del sitio Moundville estudiado por Powell (1988), presentó lesiones infecciosas distribuidas en las siguientes prevalencias: de los 75 casos de lesiones observadas, el 5,3\% resultó ser en subadultos y el $94,7 \%$ en adultos. El esqueleto apendicular presentó afecciones con mayor 
prevalencia en los miembros inferiores: tibia $(57,6 \%)$, peroné $(29,4 \%)$, fémur $(17,1 \%)$, húmero $(4,4 \%)$. En el esqueleto axial las costillas presentaron el máximo de afección con un $(6,2 \%)$.

Kelley (1989) expone dos grupos provenientes de Mobridge, South Dakota del período protohistorico del siglo XVII pre-contacto y Avervuch, Tennessee, del siglo XIII y XIV A.D. Estos grupos desarrollaron similares estrategias de subsistencia a base de horticultura, pesca, caza domesticación de animales y recolección.

Los perfiles de mortalidad resultaron muy similares y las lesiones inflamatorias reportaron, para ambas muestras, un 4,7\% (59/1260). La mayoría de las lesiones afectó a individuos entre 30 y 50 años y la relación observada entre masculinos y femeninos resultó de 2:1 respectivamente.

Resultados diferentes obtuvo Quevedo (1997) en su estudio del grupo agroalfarero de Punta Teatinos en la costa Chilena, donde se observó un $23,4 \%$ de periostitis, mayormente distribuida en los miembros inferiores, especialmente en tibia, y un $4,5 \%$ de osteomielitis en antebrazos y piernas. Resultados que indican una presencia del $28 \%$ de lesiones inflamatorias, en una relación mayor en masculinos (2,6:1).

\subsubsection{INFECCIOSAS ESPECÍFICAS}

Muchas de las enfermedades infecciosas específicas se encontraron en América precolombina (Merbs, 1992; Ortner, 1992). Generalmente presentan una distribución sistémica y simétrica, como en la tuberculosis, la treponematosis o la neumonía, las que pueden ser diferencialmente diagnosticables (Douglas Ubelaker, com pers.).

Steinbock (1976) cita estudios de casos que posibilitan inferir un mayor incremento de enfermedades infecciosas a partir de la dieta y de un cambio en el sistema de producción agrícola y pastoril. 


\subsubsection{CARIES}

El estudio epidemiológico de las patologías dentales ha permitido establecer una estrecha relación entre dieta, cultura y economías de subsistencia prehistórica. Las caries constituyen una patología infecciosa, producida por la actividad bacteriana que prolifera bajo determinadas condiciones del ambiente bucal (Lukacs, 1989; Goodman et al., 1984).

Entre los principales factores que inciden en los procesos cariogénicos, se encuentran la composición y textura de los alimentos. El pH de la saliva actúa como agente defensivo, en tanto inhibe el desarrollo de algunas colonias microbióticas. Los azúcares y los aminoácidos son fermentados por las placas bacterianas, produciendo energía, este proceso se dá en espacios vacíos de oxígeno por microorganismos anaeróbicos.

La fermentación de carbohidratos y sacáridos produce ácidos que desmineralizan paulatinamente el esmalte dental, hasta provocar la exposición pulpar. Se produce así una apertura del sistema orgánico de contacto con el exterior y sobrevienen infecciones por colonización bacteriana. (Hillson 1990; Lukacs 1989; Powell 1985).

Entre los azúcares naturales, la sacarosa es la sustancia más cariogénica, seguida por la glucosa, la fructosa y la lactosa. Se encuentran en la caña de azúcar, miel, frutas, raíces y hortalizas. Una dieta rica en carnes reduce la capacidad de acción acidogénica de la placa bacteriana y la grasa reduce tanto la adherencia de los residuos alimenticios como la formación de la placa sobre la superficie del esmalte dental.

La incidencia de caries en una población está condicionada por el tipo de ingesta, y tiende a aumentar con el consumo de una dieta basada en la ingesta de carbohidratos y sacáridos, respecto de dietas basadas en carnes (Hillson, 1990; Lukacs, 1989; Powell, 1985; Goodman et al., 1984).

Algunos autores norteamericanos han considerado una relación entre el rango de frecuencias porcentuales y de frecuencias per cápita de caries en la muestra ósea y el tipo de economía de subsistencia practicada por el grupo (Rose et al., 1984). 
De los estudios realizados en series asociadas a diferentes sistemas dietéticos, se observó que los grupos cazadores-recolectores presentaban una frecuencia entre baja y moderada de caries, y respecto de los grupos practicantes de economías mixtas, horticultoras y/o agricultoras se observó que exhibían una frecuencia mayor y mas severa de lesiones cariogénicas (Larsen 1987 y 1997; Turner 1979).

De las diferentes frecuencias de caries resultantes de los sistemas dietéticos propios de economías cazadoras-recolectoras, mixtas, horticultoras y agricultoras, Turner (1979) y Larsen (1987) proponen rangos asignados a los diferentes sistemas. El primer autor propone un rango de frecuencia entre 0,0\% y $5,3 \%$ para cazadores-recolectores, de $0,44 \%$ a $10,3 \%$ para economías mixtas y de $2,2 \%$ a $26,9 \%$ para horticultores y agricultores. Larsen, por su parte, propone un rango entre $0,4 \%$ y $7,8 \%$ para economías cazadoras-recolectoras e incidencias mayores para sociedades mixtas y agricultoras.

Rose et al. (1984) sugieren, en otra escala, que a partir de un promedio de 2,5 $\%$ de caries por persona indicaría una subsistencia de tipo agrícola y que poblaciones con un promedio individual menor al $2 \%$ de lesiones, indicaría economías no agricultoras.

Cornero y Puche (2000) presentan una muestra dental que representa a grupos provenientes de 9 sitios de la región costera del río Paraná, con un total de 41 individuos de subsistencia cazadora -especializada en ciervos y nutrias-, recolectora y pesquera de aguas dulces. Observaron 659 elementos dentales correspondientes a adultos de ambos sexos, de los cuales 32 elementos exhibieron presencia de caries. Lo cual significa una incidencia de caries del $4,8 \%$ total.

Pérez Pérez (1995), en su estudio de cazadores recolectores patagónicos provenientes de 4 grupos de Tierra del Fuego, observó una incidencia total del $0,5 \%$. Los pescadores del arcaico del norte chileno presentaron una incidencia del 1,6 \% de caries sobre el total de piezas observadas (Costa et al. 2000). En tanto que las muestras esqueletales estudiadas por Quevedo (1998), Powell (1988) y Baffi (1996) provenientes todas de grupos agricultores develan una incidencia del 5,6 \%, 17,3\% y del $43 \%$ respectivamente. Neves y Costa (1999) por su lado, hallaron para San Pedro de Atacama una alta incidencia de caries 
dentales, que varía desde $32 \%$ para el período Tiawanaku hasta un 52\% para los momentos posteriores tardíos a Tiawanaku. No se hallaron diferencias sexuales significativas en este indicador.

Barrientos y L'Heurex (2000) y L'Heureux (2000) presentan un estudio donde compara muestras dentales correspondientes a tres periodos, Holoceno temprano/medio (ca. 8,000 a 6,000 años AP), Holoceno tardío inicial (ca. 3,000 a 2,000 años AP) y Holoceno tardío final (ca. 1,000 a 400 años AP); y a ocho sitios en el sudeste de la región pampeana. De la comparación de distribución de caries encuentra un muy significativo incremento $(18,81 \%)$ en la prevalencia de caries en la muestra más reciente que, según concluyen, resulta compatible con un aumento en el consumo de alimentos de origen vegetal por parte de estas poblaciones.

\subsubsection{PERIODONTITIS}

El tejido periodontal rodea y contiene a los dientes, incluido el hueso alveolar del maxilar y de la mandíbula, los ligamentos, las encías y las mucosas.

Entre las defensas del cuerpo contra los microorganismos, se reconocen la inmunidad innata y la adquirida. La primera envuelve factores que están siempre presentes, como la mucosa oral con bactericidas naturales, en contraste la inmunidad adquirida es una respuesta de las células llamadas linfocitos a un antígeno específico (Hillson, 1996).

Las bacterias producen muchos diferentes antígenos, los cuales sensibilizan a los linfocitos en su primer contacto, pero ante contactos reiterados con el mismo antígeno ellos reaccionan con mejor velocidad de dos maneras. Los linfocitos-B se transforman en plasma celular con un antígeno específico que los neutraliza y los linfocitos-T actúan transformándose en células destructivas (Hillson, 1990).

Los micro organismos que generalmente se ven asociados con enfermedades periodontales pueden corresponder a más de 40 taxones (Hillson, 1990), destacándose el grupo de los Streptococcus, los cuales ingresan en el sistema a través de las encías, provocando irritación, inflamación y reabsorción del 
tejido alveolar durante el avance del proceso, llegando a ocasionar la pérdida de los elementos dentales.

En las series osteológicas la periodontitis se manifiesta generalmente como una retracción del tejido alveolar, y la formación de una cresta horizontal que acompaña la línea de contorno alveolar (Larsen, 1996). Se la reconoce también por la presencia de una periostitis y una porosidad macroscópica (Lukacs, 1989)

Muchas de las lesiones causadas por infecciones periodontales son el resultado de una inadecuada respuesta del sistema inmunológico.

Una gran cantidad de estudios clínicos han señalado una relación proporcional entre las afecciones periostíticas y la edad. Se demostró un gradual incremento en la proporción de la población afectada a partir de los 30 años y el avance de la severidad de las afecciones periapicales.

La epidemiología de enfermedades periodontales es de alguna manera problemática, dada su etiología multicausal, ya que involucra factores hereditarios, ambientales, de estrés mecánico -como mala oclusión-, dietéticos o higiénicos.

No obstante, Hillson (1996) y Larsen (1997) registraron variados estudios que revelan que el cambio de estrategias cazadoras recolectoras fue acompañado por un incremento en la incidencia de enfermedades periodontales y pérdida de piezas dentales. Así también demostraron los estudios que realizó Lukacs (1989) entre poblaciones de diferentes economías, en el sur asiático.

\subsubsection{TRAUMA}

Los traumas pueden tener múltiples definiciones, aunque convencionalmente refiere a daños producidos directa o indirectamente sobre tejido óseo vivo causado por fuerzas o mecanismos internos, tales como las fracturas de tipo patológicas, y, externos al mismo cuerpo, como las respuestas físicas frente al medio natural o conflictos de tensión social.

El estudio de las patologías de origen traumático ha permitido una aproximación al estilo de vida, comportamiento, estrategias de subsistencia, 
ocupación, tensión social o violencia interpersonal, diferenciación sexual del trabajo, condiciones de salud, y tratamiento terapéutico de las poblaciones humanas prehistóricas, vinculados con el grado de hostilidad ambiental y con su relación con el medio (Roberts y Manchester 1995; Merbs 1989; Steinbock, 1976; Larsen, 1987 y 1997; Judd and Roberts, 1998; Miles 1975; Knowles 1983; Márquez Morfín 1984 y White 1991, entre otros).

De acuerdo con los autores arriba mencionados, la naturaleza, la localización, el tipo y la distribución de traumas posibilitan la interpretación de las causas de daño y patrones en el grupo nos aproxima a etiologías de origen ambiental o sociocultural.

Los daños producidos por el rigor del medio pueden asociarse, por ejemplo, en ambientes montañosos o rocosos, con fracturas de tobillo, o la fractura de radio distal con desplazamiento de fragmentos (fractura de Colles, Ortner y Putschar, 1985; Merbs, 1989) producidas generalmente por caídas; o bien fracturas espontáneas provocadas por deficiencias nutricionales y dietas inadecuadas (Lovell, 1997).

En tanto que los traumas vinculados a causas sociales presentan un patrón diferencial de daño, muchos son los autores que han estudiado los impactos de origen antrópico sobre huesos humanos, ya que constituyen una intensa fuente de información del comportamiento prehistórico, como por ejemplo sacrificios humanos y canibalismo. Tim White (1992) ofrece una propuesta metodológica para el análisis de indicadores de agresión, definiendo atributos para un funcional diseño de patrones de daño. White aplica su análisis a la colección prehistórica de Mancos (sitio Mancos 5MTUMR-2346, CO, E.E.U.U.), caracterizada por su estado de alta fragmentación y traumas perimortem, a la cual realiza 98 observaciones por fragmento y elemento, organizadas en 8 grupos de atributos: identificación, preservación, fractura, marcas de corte, estrías de percusión, fauna-turbación, alteración térmica y dimensiones. A partir de allí, pudo establecer la etiología de los indicadores resultantes de descarne, desarticulación y golpes, cuya incidencia en el grupo se vincula a comportamientos de predación intraespecífica.

Existen patrones de trauma mayormente asociados a grupos sexuales 0 etarios. En este sentido, Lovell (1997) dice que los altos riesgos de fracturas 
están también asociados a prácticas laborales o deportistas, algunas más vinculadas a los grupos masculinos de actividades agrícolas, forestales o de construcción, o a los grupos femeninos, como las fracturas secundarias o patológicas de cuello femoral en individuos mayores.

Varios autores plantearon la relación entre sistemas de subsistencia y frecuencia de traumatismos accidentales, presentando, en base a estudios de casos, un patrón general de incidencia decreciente en fracturas poscraneanas de grupos de cazadores recolectores a agricultores sedentarios, sugiriendo estos datos un estilo de vida de riesgo mayor para cazadores, que para grupos agricultores sedentarios (Larsen, 1997; Roberts y Manchester, 1995; Steinbock, 1976; Meiklejohn et al., 1984; Ortner y Putschar 1985) como puede observarse en la Tabla 1.1.

Tabla 2.1. Traumas Procedentes de Diferentes Sistemas de Subsistencia

\begin{tabular}{|c|c|c|c|c|c|c|c|}
\hline Sitio & Subsistencia & $\begin{array}{l}\text { Trauma por } \\
\text { Individuo } \%\end{array}$ & $\begin{array}{l}\text { Trauma por } \\
\text { total de Huesos \% }\end{array}$ & $\begin{array}{c}\text { Trauma por } \\
\text { Huesos Largos \% }\end{array}$ & \multicolumn{2}{|c|}{$\begin{array}{l}\text { Trauma / sexo } \\
\text { Masc } \quad \text { Fem }\end{array}$} & Fuente \\
\hline Libben & $\begin{array}{l}\text { Cazadores- } \\
\text { Recolectores }\end{array}$ & 45 & 3 & 3 & \multicolumn{2}{|c|}{$\begin{array}{l}\text { Diferencia no } \\
\text { significativa }\end{array}$} & $\begin{array}{l}\text { Lovejoy \& Heiple, } 1981 \\
\text { Charlotte \& Manchester } 1995\end{array}$ \\
\hline L.W & $\begin{array}{l}\text { Cazadores } \\
\text { estacionales }\end{array}$ & 20.5 & - & - & $>$ & $<$ & $\begin{array}{l}\text { Lallo, } 1973 \\
\text { (En Goodman et al 1984) }\end{array}$ \\
\hline Knoll & Cazadores-Rec. & 10.7 & - & - & - & - & \multirow{2}{*}{$\begin{array}{l}\text { Show, } 1948 \text { USNM } \\
\text { (En Steinbock 1976) }\end{array}$} \\
\hline $\begin{array}{l}\text { Knoll - } \\
\text { Middle - } \\
\text { Archaic }\end{array}$ & $\begin{array}{l}\text { Cazadores- } \\
\text { Recolectores }\end{array}$ & 11.4 & - & - & - & - & \\
\hline MALW & Mixto caz-rec./Agric. & 16.4 & - & - & $>$ & $<$ & \multirow{2}{*}{$\begin{array}{l}\text { Lallo, } 1973 \\
\text { (En Goodman et al 1984) }\end{array}$} \\
\hline Kulubnarti & Agricultores & 32 & & 3.7 & 43.8 & 56.2 & \\
\hline P. Teatinos I & Agricultores & - & - & - & $>$ & $<$ & Quevedo, 1998 \\
\hline Atacama & Agricultores & 25 & 4 & 1.86 & \multicolumn{2}{|c|}{$\begin{array}{l}\text { Diferencia no } \\
\text { siqnificativa }\end{array}$} & Neves y Costa, 1998 \\
\hline Moundville & Agricultores & 8.8 & 8.7 & 0.5 & 1 & 0.4 & Powell, 1988 \\
\hline Ala -329 & & & & 1.8 & 52 & 47.8 & Jurmain \& Kilgore, 1998 \\
\hline CA-SCI-038 & & 14.1 & 2.3 & 10.5 & $>$ & $<$ & Jurmain, 2001 \\
\hline
\end{tabular}

\subsubsection{NÓDULOS DE SCHMORL}

Una de las frecuentes manifestaciones de lesión en la columna vertebral, atribuidas a efectos traumáticos, son los denominados nódulos de Schmorl. Los 
discos intervertebrales poseen, durante la niñez y parte de la adolescencia, una estructura de

fibras gelatinosas, que con el paso del tiempo van solidificando su estructura. Cuando estos discos están sujetos a severos esfuerzos, como por ejemplo fuerzas de comprensión por transporte de objetos pesados, se producen las hernias de disco, los cuales ejercen una presión sobre la superficie interna del cuerpo vertebral, que forma una pequeña cavidad en el área central (Knowles, 1983).

Estos eventos se consideran hernias de disco y resultantes de un severo y constante estrés biomecánico, que afecta gradualmente a los adultos cuyos discos han perdido resistencia, o han sido superados por el esfuerzo (Kennedy, 1989; Lovell, 1997).

Raramente se encuentran por sobre la cuarta vértebra toráxica, su mayor frecuencia se localiza entre las ultimas vértebras toráxicas y las primeras lumbares.

Los nódulos de Schmorl han sido considerados, por algunos investigadores, como indicadores de calidad de vida (Quevedo, 1998; Kelley y Angel, 1987).

Algunos estudios realizados con colecciones de afroamericanos procedentes de asentamientos urbanos de Filadelfia del siglo XVIII han revelado una prevalencia de Nódulos de Schmorl del $31 \%$ en el grupo masculino respecto del $13 \%$ en el grupo femenino, siendo esta prevalencia más alta que la encontrada entre sus contemporáneos afroamericanos de asentamientos rurales en Arkansas (Larsen, 1997)

\subsubsection{ARTROPATÍAS}

Las artropatías engloban un gran grupo de enfermedades articulares, las cuales se organizan de acuerdo a su complejidad y localización: osteoartritis, osteofitos vertebrales, artritis traumática, reumatoidea o infecciosa, gota y espondilitis anquilosante, constituyendo la osteoartritis el grupo más común de las artritis que afecta a humanos y a animales desde tiempos muy antiguos (Steinbock, 1976). 


\subsubsection{OSTEOARTRITIS}

La osteoartritis es un proceso inflamatorio y destructivo del tejido cartilaginoso que rodea las superficies articulares, lo cual ocasiona un engrosamiento óseo como consecuencia de la compresión o neoformación reactiva de hueso. Ocurre cuando el cartílago, que normalmente cubre y acolcha las terminaciones de los huesos, se rompe (Robbins y Angell, 1989).

En la medida, en que hueso contra hueso se friccionan, la articulación pierde su forma y alineación y los extremos de los huesos se ensanchan. Es característico que aparezcan "espolones" o pequeñas protuberancias óseas en los bordes del espacio articular (Steinbock, 1976; Robbins y Angell, 1989).

Su etiología puede resultar por una causa o por el cruce de varios factores como genéticos, metabólicos, hormonales, infecciosos, de densidad ósea, deficiencia vascular o sobrepeso. Pero el factor principal que contribuye a la formación de osteoartritis es el producto del estrés biomecánico por actividad física (Ortner y Putschar, 1985; Larsen, 1997).

La osteoartritis afecta sólo a pocas articulaciones y con una distribución poco simétrica y refleja un uso de reincidentes, forzados y exigentes movimientos, afectando las zonas articulares más involucradas en la demanda mecánica, ejerciendo una acción progresiva en los puntos de mayor tensión.

Esta patología presenta variaciones relacionadas con la edad y el sexo, dado que generalmente prevalece en adultos y raramente se encuentra en individuos jóvenes, así como se ha demostrado que se manifiesta mayormente en grupos femeninos (Larsen, 1997).

Para muchos investigadores, los estudios paleopatológicos sobre articulaciones demostraron la relación entre ciertos patrones de actividad ocupacional y esta patología, tales como por ejemplo el levantamiento, carga y transporte de materiales pesados. Larsen, et al. (1992) sostienen que el análisis de osteoartritis expuso un descenso de la incidencia en el período agricultor de La Florida. 
En cuanto a la distribución sexual de dicho marcador óseo los autores informan que los masculinos presentan una incidencia mayor que los femeninos, de acuerdo a los siguientes datos porcentuales presentados en la Tabla 2.2.

TABLA 2.2. Distribución de Osteoartritis en Poblaciones Agrícolas Previas 1150 AD

\begin{tabular}{l|c|l|c}
\hline Masculinos & $\%$ & Femeninos & $\%$ \\
\hline Cervical & 40 & Cervical & 17 \\
\hline Toráxica & 12,5 & Toráxica & 6,7 \\
\hline Lumbar & 34,6 & Lumbar & 19,5 \\
\hline Hombro & 10,5 & Hombro & 2,4 \\
\hline Codo & 13,7 & Codo & 9,6 \\
\hline Muñeca & 2,6 & Muñeca & 2,6 \\
\hline Mano & 0 & Mano & 0 \\
\hline Rodilla & 18,6 & Rodilla & 15 \\
\hline Cadera & 0 & Cadera & 4,3 \\
\hline Tobillo & 4,1 & Tobillo & 4,5 \\
\hline Pie & 0 & Pie & 0 \\
\hline
\end{tabular}

Neves (1984a) analizó seis articulaciones de una muestra de 40 individuos sambaquíes procedentes del Litoral del Estado de Paraná Brasilero, hallando una prevalencia del 19,4\% de osteoartritis moderada, siendo más frecuente en los hombres $(26 \%)$ que en las mujeres $(10 \%)$. La articulación del codo constituyó la mas afectada ( $50 \%$ en hombres y $27 \%$ en mujeres) y, en términos de lateralidad, el hombro derecho expuso una prevalencia del $40 \%$ en el grupo masculino respecto del $28 \%$ del izquierdo y del $17 \%$ de los hombros derechos del grupo femenino.

Quevedo (1998), presenta como resultado de su estudio en el Arcaico de la costa chilena sobre las articulaciones de Punta Teatinos I, que un $62 \%$ de los individuos sufrieron lesiones en el esqueleto apendicular, donde los masculinos se ven levemente más afectados que los femeninos. El codo presenta un 24,7 $\%$ en los varones y un $16 \%$ en las mujeres. Las muñecas presentan un $14,5 \%$ $y$ un $1,5 \%$ y los hombros un $8,7 \%$ y un $14,7 \%$, en hombres y mujeres respectivamente. La rodilla expone una diferencia de $24,6 \%$ en los individuos 
masculinos respecto de un 6\% en los femeninos, como así los tobillos de un $16,1 \%$ a un $1,5 \%$ y los pies de $4,3 \%$ correspondiente al grupo masculino y 0 $\%$ al femenino.

Williams (1994), consideró la incidencia de osteoartritis en el estudio de una población pre-horticultora del período arcaico, procedente de la región nordeste de Missouri, cuyos resultados muestran que, de los 402 adultos observados, el $36 \%$ expuso evidencias de osteoartritis en diferentes niveles de afección, de los cuales el $38 \%$ se presenta como incipiente, el $45 \%$ como mediana y el 17 $\%$ como severa.

Williams (1994), organizó las localizaciones en tres categorías: apendicular superior (hombro, codo y muñeca), apendicular inferior (cadera, rodilla y tobillo) y otros (temporo-madibular y columna), obteniendo los siguientes casos de afecciones presentadas en la Tabla 2.3.

Tabla 2.3. Distribución de osteoartritis en prehorticultores en NE de Missouri (Williams, 1994).

\begin{tabular}{c|c|c|c}
\hline No. afectados & Apendicular sup. & Apendicular inf. & otros \\
\hline 80 & 59 & 51 & 17 \\
\hline
\end{tabular}

Mena y Reyes (2001) hallaron un esqueleto femenino adulto en el sitio de Baño Nuevo, en Patagonia central estimado en una antigueda entre el 9000 y el 8500 A.P., que presenta diferentes modificaciones a nivel de la columna vertebral y la cintura pélvica, con claras evidencias de osteoartritis que, unida a otros indicadores, los autores interpretan como evidencia de sobrecarga reiterada y no sólo como efecto de envejecimiento o anemia "naturales" en la mujer adulta (cuadro osteoporótico).

Observaron además en dicho esqueleto desarrollos osteofíticos en el calcáneo y el primer metatarso izquierdos, que atribuyen a desgarros que comprometieron los ligamentos del pie. 


\subsubsection{OSTEOFITOSIS VERTEBRAL}

También conocida como espondilosis deformante o espondilitis hipertrófica, es una patología que afecta a la columna vertebral en sus articulaciones intervertebrales. Los osteofitos constituyen formaciones exostósicas, que se localizan en los bordes externos del cuerpo vertebral, su crecimiento puede ser horizontal o vertical, en cuyo caso puede fusionar vértebras adyacentes formando un hueso continuo, provocando una reducción en la movilidad del área afectada. Este cambio se conoce como anquilosis y se caracteriza por una reducción y aumento de presión en el espacio de los discos intervertebrales. Cualquier segmento espinar puede ser afectado y las lesiones se manifiestan generalmente en más de una vértebra (Steinbock, 1976).

Muchos son los factores que pueden contribuir al desarrollo de osteofitos, pero para Ortner y Putschar (1985) es indudable que el factor más significativo es el estrés mecánico.

De acuerdo con Larsen (1997), la columna vertebral ha sido ampliamente estudiada en la prehistoria americana, revelando algunas tendencias.

En particular, se ha demostrado que: a) la mayor prevalencia estaría dada en la región articular, entre la quinta y sexta cervical, b) que existe una tendencia de afección de las toráxicos inferiores respecto de las superiores, c) que el sector comprendido entre la segunda y la cuarta lumbar es el más críticamente afectado y d) que el segmento entre la última cervical y las primeras lumbares es el menos afectado. No es sencillo proponer una directa asignación de la prevalencia de osteofitosis espinal a los patrones de actividad y ocupación prehistórica (Bridges 1992 citado en Larsen, 1997). 


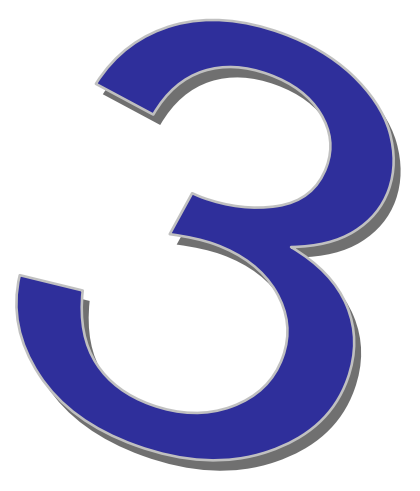

$$
\text { EL MEDIO }
$$

AMBIENTE 


\section{LOCALIZACION GEOGRAFICA Y ECOLOGICA}

El sitio arqueológico Santana do Riacho I (SR1) se localiza en el borde de la "Gran Región Arqueológica de Lagoa Santa" (Lamine Emperaire et al., 1974), situándose en la Sierra do Cipó, Estado de Minas Gerais, en la zona central de Brasil (Figura 3.1.).

El Abrigo de Santana do Riacho se encuentra a $4 \mathrm{Km}$ al este de la ciudad que lleva su nombre, dentro de los terrenos propiedad de la Companía Industrial de Belo Horizonte. Se abre en la escarpa occidental de la Sierra do Cipó, a $50 \mathrm{Km}$ al norte de la ciudad de Lagoa Santa, ubicado a los $19^{\circ} 10^{\prime}$ de latitud Sur y $43^{\circ}$ 35 ' de longitud Oeste (Figura 3.2.).

La Sierra do Cipó constituye el límite oriental del planalto, que se desenvuelve sobre las rocas graníticas precámbricas del Grupo Bambuí, presentando un relieve accidentado entre las cotas de $750 \mathrm{~m}$ y $1400 \mathrm{~m}$. De sus escarpas descienden los dos principales afluentes del Rio das Velhas (Malta y Kohler, 1991).

La Sierra do Cipó divide las aguas de las cuencas de los ríos San Francisco y Doce, formando paisajes de gran belleza como la Cascada de la Farofa, con más de 70 metros de altura y el Canyon de las Bandeirinhas por donde corre un riachuelo.

En cuanto a los aspectos geológicos, el sitio se encuentra en el límite litológico estructural de las unidades Espinhaço y Macaúbas (Karfunkel et al., 1991).

Las sabanas amazónicas de tierra firme se caracterizan por la ocurrencia de dos estaciones diferenciadas, que duran alrededor de seis meses cada una. Son áreas llamadas "cerrados" en Brasil y "llanos" en Venezuela.

El clima es tropical semi-húmedo, con cuatro a cinco meses secos al año. La temperatura media anual oscila entre $20^{\circ}$ y $22^{\circ} \mathrm{C}$, con una máxima de $34^{\circ}-36^{\circ}$ $\mathrm{C}$ y una mínima que varia entre $0^{\circ}$ y $4^{\circ} \mathrm{C}$.

Las precipitaciones oscilan entre 800 y $2000 \mathrm{~mm}$ anuales, y casi no se presentan entre mayo y septiembre. La insolación es bastante elevada en la región, debido a largos períodos de cielos claros y varía entre 350 y 450 calorías/cm2/día (Goedert, 1985 en Morán, 1993). 
Esta zona climática puede ser referida al tipo de vegetación de el cerrado, que constituye el $23 \%$ del territorio de Brasil, aproximadamente 1,8 millones de km2 (Ledru, 1993).

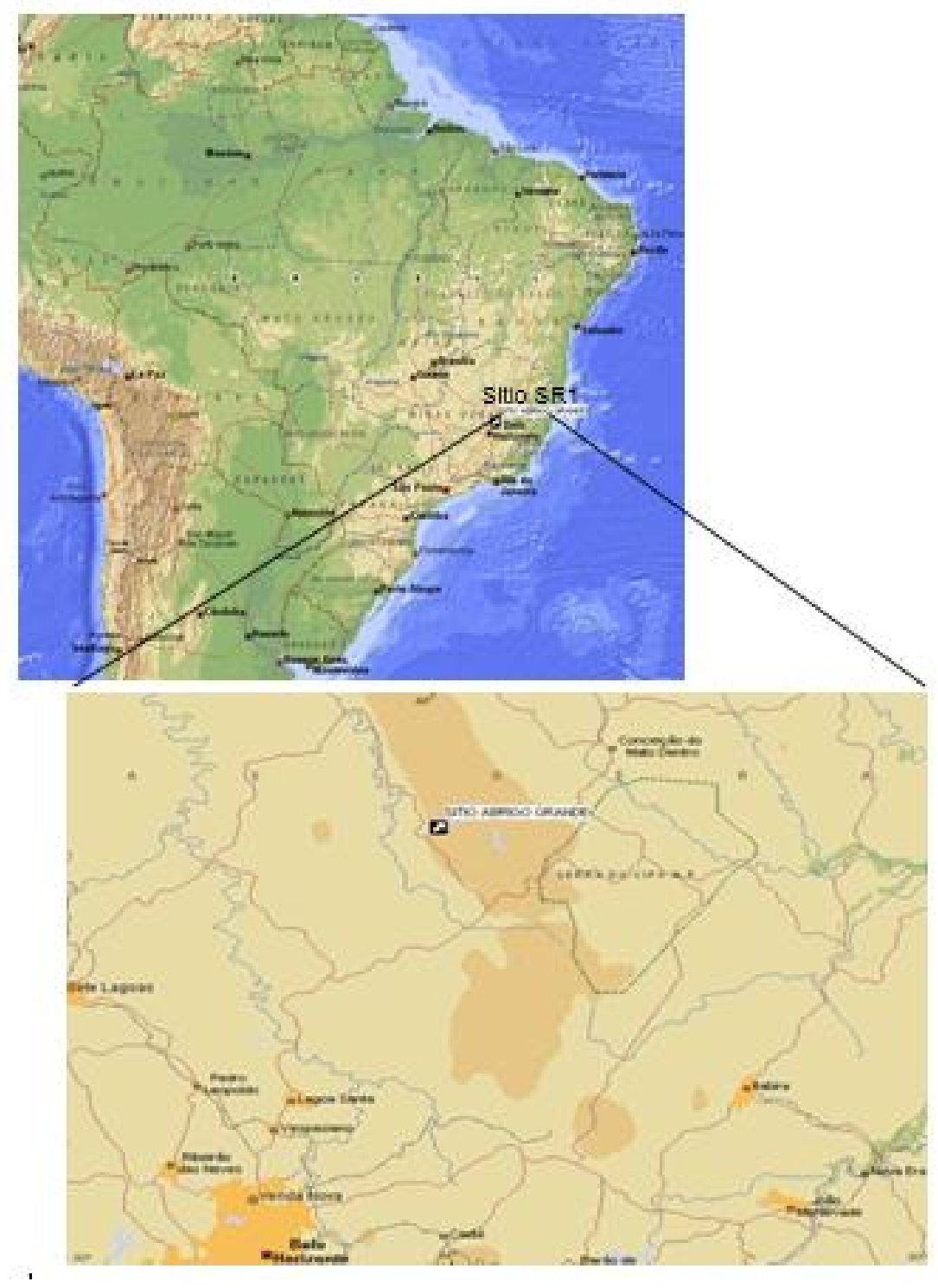

Figura 3.1. Localización del sitio, según el atlas mundial Encarta (2000).

En el cerrado, el clima es subtropical húmedo con un invierno seco que vá de mayo a octubre. La caatinga (llanura con vegetación de gramíneas, arbustos y árboles de bajo porte) tiene un clima tropical seco y semiárido. En algunas áreas se presentan períodos de seis o más años sin lluvias. 
En Santana do Riacho el clima se caracteriza por una estación cálida y seca en invierno y cálida y húmeda en verano. El promedio anual de lluvias es de 1564 $\mathrm{mm}$ distribuido de forma heterogénea a lo largo del año. En primavera y verano las lluvias representan el $70 \%$, mientras que la temperatura media es de $20,6^{\circ} \mathrm{C}$.

El área es generalmente plana con declive de un $3 \%$, los suelos son profundos y bien drenados, son ácidos, el pH medio es de 5 , variando entre 4,3 y 6,2. El $98 \%$ de los suelos estaba por debajo de 6 en la escala pH, El $92 \%$ tiene menos de 2 ppm de fósforo, nivel crítico para el cultivo de muchos cereales. Los niveles de materia orgánica y arcilla son medios, la mayor cantidad de estas últimas se asocia a mejores suelos y a una mejor retención de humedad (Ledru, 1993).

Los suelos se presentan altamente lixiviados y deficientes en los principales nutrientes y con alto contenido de aluminio (Ledru, 1993). Hay mayormente oxisoles latosoles rojos, con baja capacidad de intercambio de cationes y alta saturación de aluminio. El $15 \%$ del área corresponde a tierras arenosas.

La vegetación se presenta bajo tres tipos diferentes: bosque de galería, campos cerrados y campos rupestres o de altitud (Moran, 1993). A lo largo de los cursos de los ríos predomina el bosque en galería, con gran cantidad de árboles frondosos.

La región del cerrado puede ser reconocida por sus árboles bajos y por las especies arbóreas como Byrsonimia verbascifolia (murici), Qualea grandiflora (palo-tierra), Sclerolobium paniculatum, Caryocar brasiliense, Kielmeyera rubriflora.

Por encima de los 900 metros, los campos de altitud son en general más abiertos y cortados por ríos y riachuelos permanentes. Para la protección de una especie autóctona de la Sierra, la canela-de-ema (Vellozia piriseana), sobre la cual crece un raro y exótico tipo de orquídea (Constantia cipoensis), se creó en 1984 el Parque Nacional de la Sierra do Cipó.

La vegetación de los cerrados es variable, predominando las gramíneas, en el área denominada campo sucio, áreas con arbustos y árboles de bajo porte conocidas como campo cerrado y áreas de vegetación densa o cerradões (Eiten, 1972; en Morán, 1993). 
La mayoría de las especies de la región del cerrado constituyen una vegetación de áreas con escasez de agua, que caracterizan árboles y arbustos con ramas retorcidas, baja altura (menos de tres metros), corteza gruesa y hojas coriáceas (Ferri, 1977; en Morán, 1993). Estas plantas, de presencia discontinua, poseen raíces profundas que llegan hasta el manto freático.

El cerradão en términos estructurales, es un área vegetal intermedia entre el cerrado y la selva, con árboles de hasta nueve metros de altura, y presencia de tres estratos de vegetación: arbórea, arbustiva y herbácea (Moran, 1993).

La cantidad de árboles en la sabana es resultado de la fertilidad diferencial de los suelos y de su capacidad de retención de humedad. Como la densidad y el diámetro de los árboles siguen la misma dirección vemos que en el cerradão los árboles son más densos y mayores, mientras que en campo herbáceo son menores por la carencia de nutrientes edáficos (Moran, 1993).

El cerradão, que contextualiza al sitio, presenta árboles de alturas diversas, representados por alrededor de veinte especies. El estrato arbustivo se muestra poco compacto y representado por un menor número de especies, mientras que el estrato graminoso herbáceo es casi inexistente alrededor del abrigo (Brandão, 1993).

El cerradão y el cerrado ofrecen una serie de plantas que dan frutos como el Pequí (Caryocar brasiliense), la Cagaita (Eugenia dysenterica), el Jatobá (Hymenaea courbaril), y otras especies, conocidas como Araçás y Gavirobas. También hay pequeñas palmeras que ofrecen frutos comestibles.

La fauna de la región incluye, entre las especies más representativas, a venados (Mazama sp.), roedores (Agouti paca, Dasyprocta sp., Kerodon rupestris, Cavia aperea, Sylvilagus brasiliensis), armadillos (Dasypus novemcinctus, Euphractus sexcinctus), pecaríes (Tayassu tajacu, Tayassu pecari), comadrejas (Marmosa sp., Didelphis sp.) monos (Cebus apella, Allouatta sp, Lagothrix lagotrichia, Callicebus personatus), coatí, (Nasua nasua), oso hormiguero (Tamandua tetradactyla), tapir (Tapirus terrestris), reptiles (Polychrus acutirostris, Tupynambis teguisin, Chelonia chelidae), entre otros pequeños reptiles, aves y peces. 


\subsection{ADAPTACIONES INDIGENAS EN EL BRASIL CENTRAL}

Los cerrados fueron considerados "marginales" en la clasificación de Steward en el Handbook of South American Indians (1939-1946) debido a las limitaciones que presentan estas áreas para la actividad agrícola y hortícola. Los antiguos habitantes del cerrado eran nómades estacionales y dependían de la caza y la recolección. El potencial agrícola de las áreas del cerrado difiere significativamente del de las áreas de florestas o matas (Guimarães, 1991). Las poblaciones indígenas del cerrado, que se encuentran ubicadas en áreas próximas a las selvas de galería donde tienen sus cultivos, no cultivan en el cerrado, debido a sus limitaciones (Guimarães, 1991). Las aldeas indígenas actuales están relativamente pobladas, oscilando entre 500 y 1500 habitantes (Guimarães, 1991).

Los pueblos de habla Gê (principal grupo lingüístico en las áreas del cerrado) incluyen a los grupos Timbira (Canela, Apinajé, Craó, Gavião, Paracheje y Cricatí); Acuém (Xerentes, Xavantes) y Caiapó (Gorotiré Txucarramae, Cubencranquegn, Cubencragnotire, Diore y xicrin). Los Bororo, los Nambiquara Paracanás y Tapirapés,

también habitan en estas áreas, pero difieren lingüísticamente de los Gê (Zarur, 1979; en Morán, 1993).

Desde el registro arqueológico se evidencia que, al menos en el siglo IX de nuestra era, existían poblaciones horticultoras instaladas en grandes aldeas capaces de albergar hasta 2000 personas (Wüst, 1989; en Morán, 1993). Si bien se demostró que el abastecimiento de estos grupos a base de maíz y de tubérculos es anterior al uso de la mandioca, es posible que ese reemplazo esté relacionado con las migraciones provocadas al cerrado como consecuencia del contacto con el europeo (Guimarães, 1991).

La Sierra do Cipó era antiguamente llamada Sierra da Vacaria y fue el primer camino natural de los Bandeirantes que se dirigían al noreste de Minas Gerais en busca de piedras preciosas (Guimarães, 1991).

En el siglo XVIII, la región de Lagoa Santa ya era conocida y ocupada por poblaciones pastoriles. La ciudad de Santana do Riacho tiene su origen en 1744, en la fazenda Riacho Fundo, propiedad del Sargento Ferreira de Aguiar 
de Sá. Para ese tiempo la región ya comenzaba su desarrollo en base a la explotación agrícola, especializada en la caña de azúcar y minera, rica en la producción de hierro, basada en la explotación de trabajo esclavo. Posteriormente, comenzó una etapa abocada a la industrialización metalúrgica (Moran, 1993).

La ocupación y explotación de la agricultura intensiva altamente capitalizada y del latifundio ganadero del cerrado es relativamente reciente. Actualmente, se emplea la deforestación para el establecimiento de monocultivos forrajeros, técnica usada para grandes extensiones en Brasil.

Esta práctica provoca impactos negativos sobre el medio ambiente (biodiversidad, CO2, agua) y la producción animal (degradación de pastos). Los sistemas silvopastoriles vienen tornándose una alternativa sustentable para la producción animal, integrando leñosas arbóreas, pasturas y animales (Moran, 1993). 


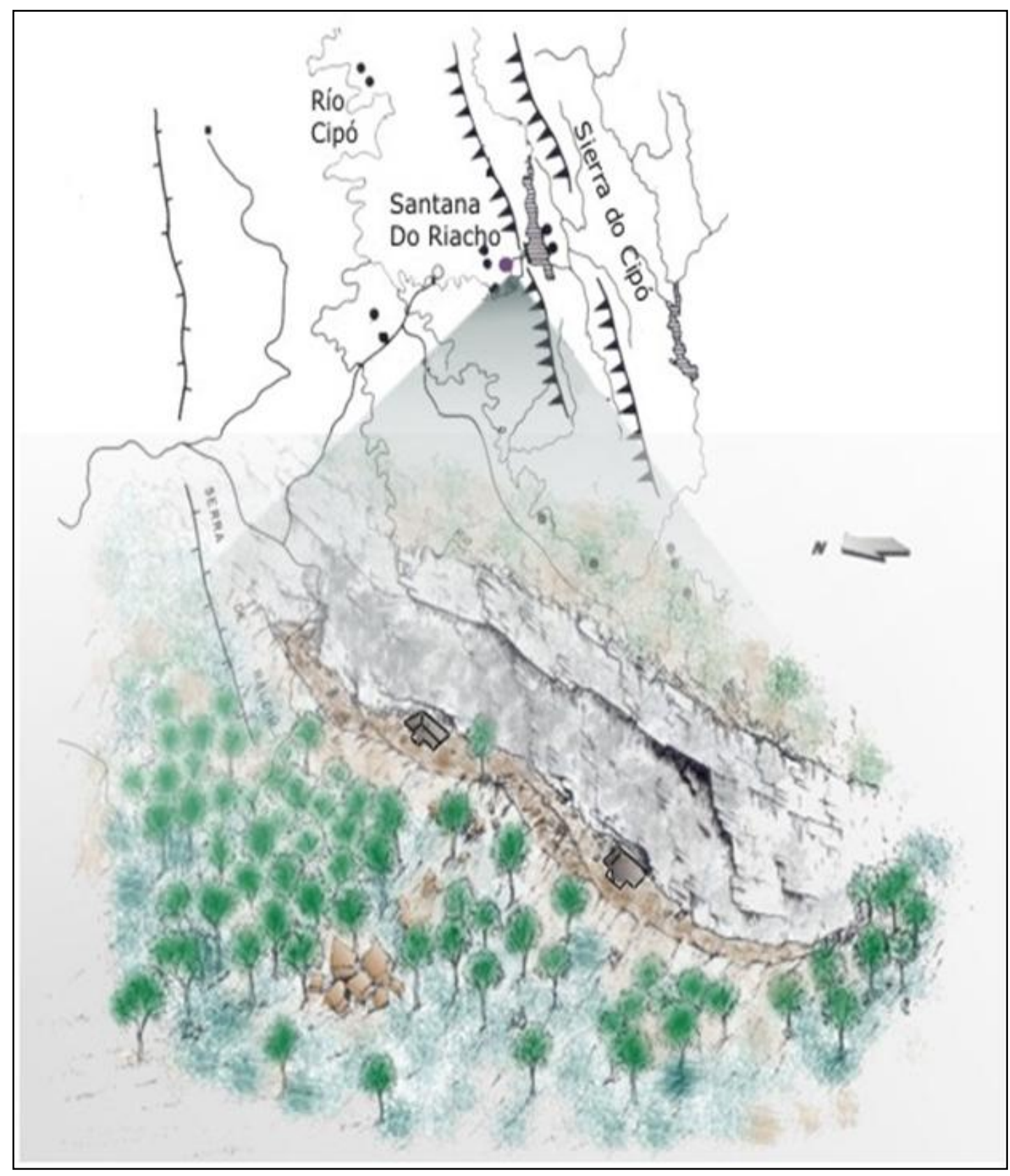

Figura 3.2. ABRIGO GRANDE. (Adaptada de Prous y Malta 1991) 


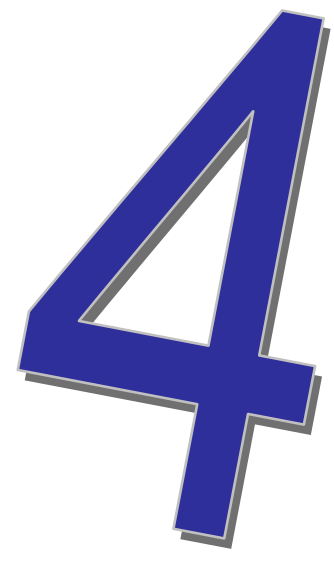

HISTORIA DE LA INVESTIGACION EN LAGOA SANTA 


\subsection{Historia de las Excavaciones}

Lagoa Santa es una región arqueológicamente conocida desde mediados del siglo XIX, cuando en 1825 un naturalista dinamarqués, Peter W. Lund (Figura 4.1.) llegó a Brasil para realizar estudios en la región comprendida entre los ríos Das Velhas y Ribeirão da Mata (Neves, 1997).

En 1833, prospectando el valle aluvial del río San Francisco, Lund se encontró con Peter Claussen, quien lo invitó a observar materiales fósiles provenientes de las grutas calcáreas del valle del Rio das Velhas, los cuales habían sido hallados en terrenos de la propiedad de Claussen (Mello e Alvim, 1977).

Lund se había formado en la escuela francesa como discípulo de Cuvier y comprendió inmediatamente el valor científico de aquellos fósiles.

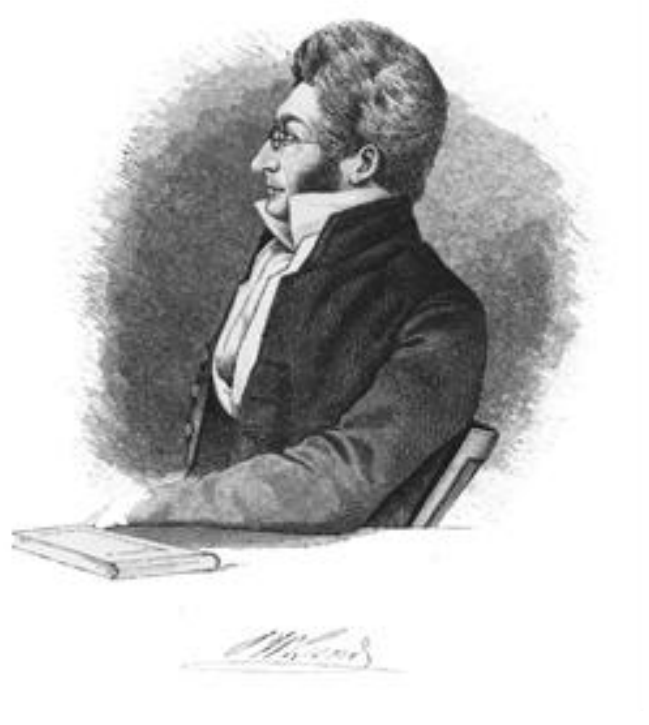

Figura 4.1. Peter W. Lund

Entre 1836 y 1844 colectó materiales provenientes de 60 grutas, de las 800 prospectadas (Figura 4.2.).

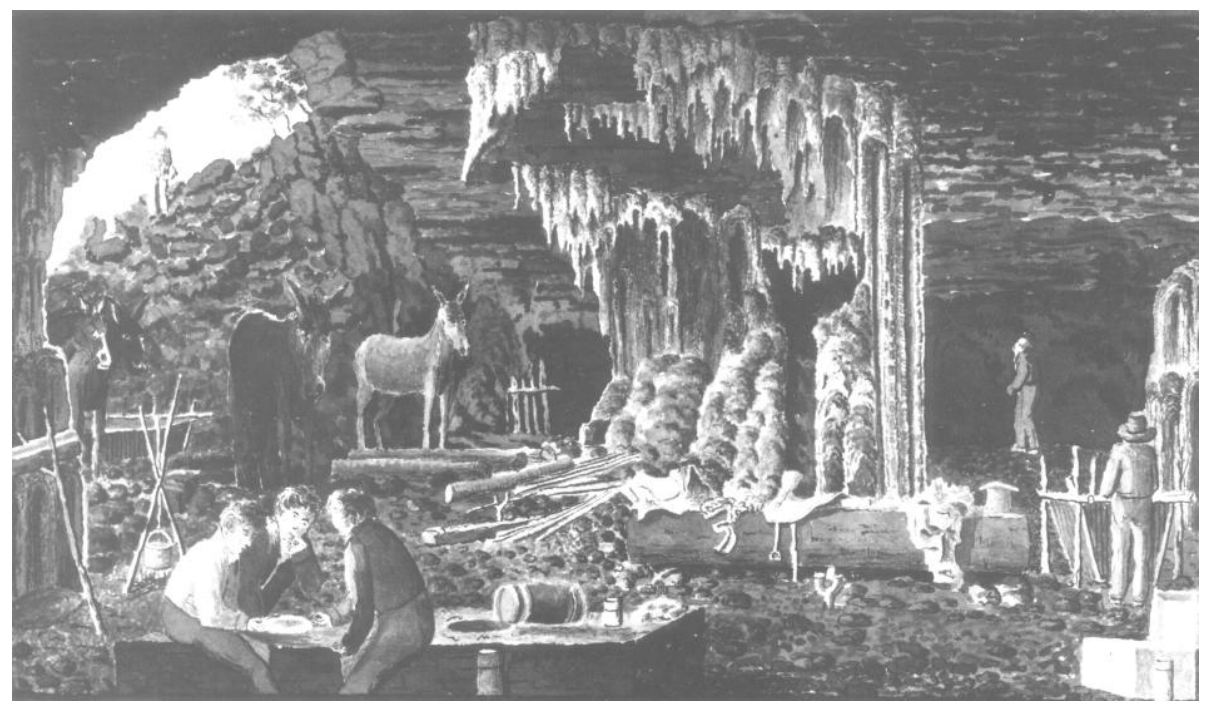

Figura 4.2. Lappa do Mosquito, Lagoa Santa, 1837. 
Clasificó las colecciones de fauna fósil en 56 géneros y 114 especies. En 1845 todos los materiales fueron remitidos para Copenhagen, donde actualmente se encuentran en el Museo de Zoología de la Universidad de Copenhagen (Mello e Alvim 1977; Emperaire et al., 1975).

Sus hallazgos despertaron en aquel momento intensas controversias, dado que no le fue fácil presentar sus descubrimientos de humanos asociados a fauna extinguida, en una época donde el catastrofismo constituía el único paradigma dominante en el campo del conocimiento.

Desde entonces, el lugar ha sido sistemáticamente recorrido y trabajado. Poco después de Lund, Cássio Lanari exploró varias grutas en su fazenda de Mocambo, Municipio de Matozinhos. Halló 3 esqueletos humanos, que describió en una publicación de los Anais da Escola de Minas Gerais (Mello e Alvim, 1977).

Entre los años 1935 y 1960 Harold Walter exploró la región de Lagoa Santa y estudió los depósitos de lapas y abrigos con presencia de restos óseos humanos y animales extintos. En 1956, en el marco de un proyecto arqueológico llevado a cabo por norteamericanos y brasileños (Hurt y Blasi, 1960-1969), se verificó la posibilidad real de la contemporaneidad de la ocupación humana en Lagoa Santa y la fauna pleistocénica, una vez que las primeras dataciones dieron como resultado $9029+-120$ y $9720+-128$ BP (Hurt y Blasi, 1969).
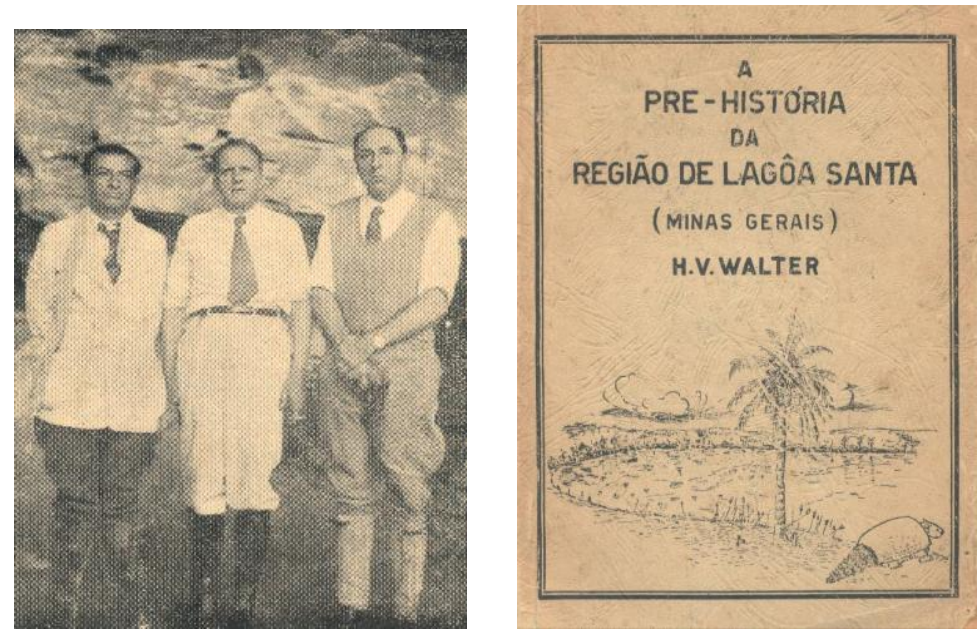

Figura 4.3. Harold Walter (1935 - 1960) y su libro. 
La misión arqueológica francesa de Lagoa Santa comenzó su investigación en 1971. El objetivo de estas investigaciones era descubrir sitios intactos que permitiesen nuevos estudios. En ese año realizaron prospecciones en el macizo de Cerca Grande, perturbado por la explotación de la calcita.

Las excavaciones principales fueron realizadas en el abrigo de Lapa Vermelha (Municipio de Pedro Leopoldo), cuyos sedimentos se excavaron hasta 13 metros de profundidad sin lograr llegar a la base (Prous y Schlobach, 1997). El sitio Santana do Riacho (figura 4.3.) fue casualmente descubierto en 1951 por un amateur de la zona, el odontólogo J. Penna. Este sitio era conocido por la población local como "Lapa dos Gentios" y rebautizado por el Dr. Penna como "Abrigo do Riachinho".

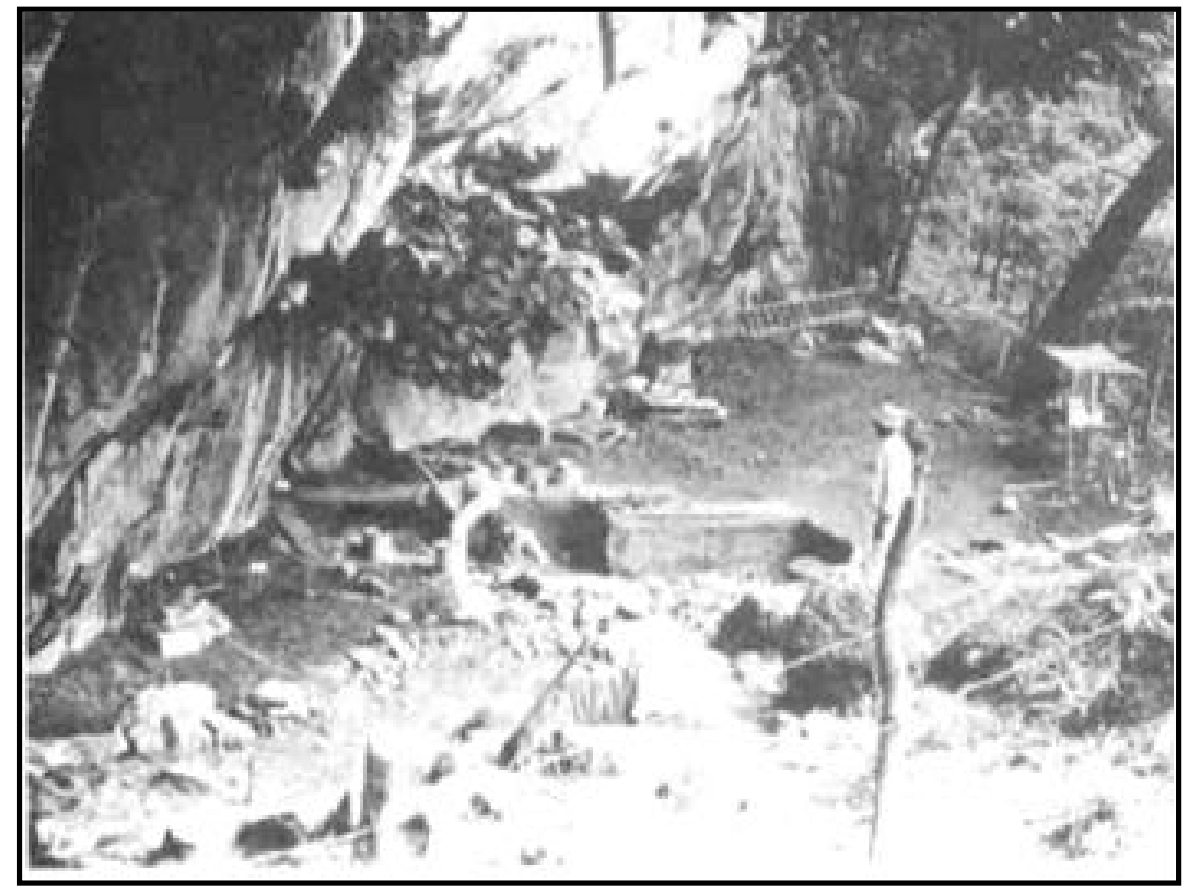

Figura 4.4. Excavación en el Abrigo Grande de Santana do Riacho. (Foto 58 Prous y Malta, 1991: 411)

En 1974, A. Laming-Emperaire decidió extender sus investigaciones en Sierra do Cipó, una vez que los sitios en el área central de Lagoa Santa estaban muy impactados por las excavaciones anteriores y por la explotación comercial de calcáreo y salitre. En 1976 se redescubre el abrigo Santana do Riacho. 
A partir del año siguiente y hasta 1979, fueron realizadas excavaciones en el Abrigo Grande por el equipo de la Universidad Federal de Mina Gerais (UFMG), bajo la dirección de Andrés Prous (Walter Neves, com. pers.).

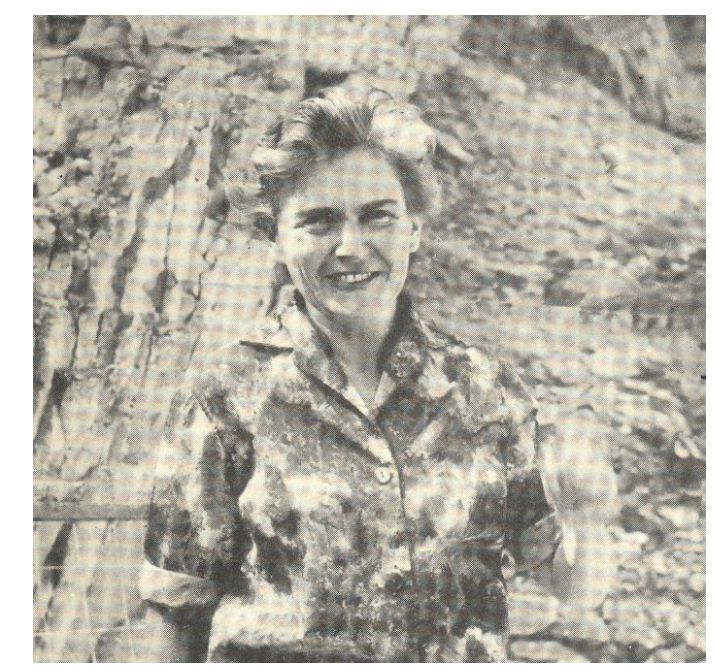

Figura 4.5. Anette Laming -Emperaire en Lagoa Santa

De acuerdo con Neves y Atui (2004), desde el original descubrimiento de los esqueletos realizado por Peter Lund en 1842 y 1843, los restos humanos exhumados de los abrigos y las grutas de la región de Lagoa Santa, aún hoy continúan despertando interés en la comunidad bioantropológica y arqueológica nacional e internacional, tal como lo demuestran las investigaciones sobre poblamiento y afinidad biológica (Neves y Atui, 2004). 


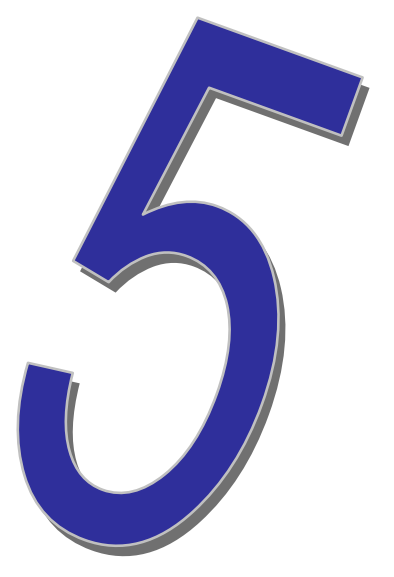

EL CONTEXTO

ARQUEOLOGICO 


\subsection{EL SITIO}

En las excavaciones llevadas a cabo por A. Prous, Santana do Riacho demostró ser un sitio paleoindio de actividad funeraria. Asociados a los enterratorios se encontraron vestigios frutales, pigmentos rojos, raspadores, instrumentos de huesos como puntas, espátulas y anzuelos, y cuentas de collar confeccionadas con semillas (Prous, 1991). Entre enero de 1978 y julio de 1979 se llevaron a cabo 3 campañas arqueológicas (Figura 5.1.) dirigidas por André Prous.

Las excavaciones se realizaron con técnicas de decapado, bajando en cada unidad estratigráfica estratos artificiales de 5 y $10 \mathrm{cms}$ de espesor.

Prous logró reunir una colección osteológica representada por 40 individuos humanos, procedentes de 28 enterratorios primarios y secundarios. La serie está integrada por individuos de ambos sexos y representada por todos los intervalos etarios.

El sitio se estratificó en 7 unidades o camadas, que se visualizan en pocos sectores libres de bioperturbación. Presenta sectores separados por accidentes topográficos, como grandes bloques caídos, que quiebran la continuidad de los estratos sedimentarios, impidiendo la mayor parte de las veces establecer una correlación entre los niveles. De acuerdo con Prous, se atribuye a estas irregularidades las incoherencias que presentan algunas dataciones efectuadas (Prous, 1991).

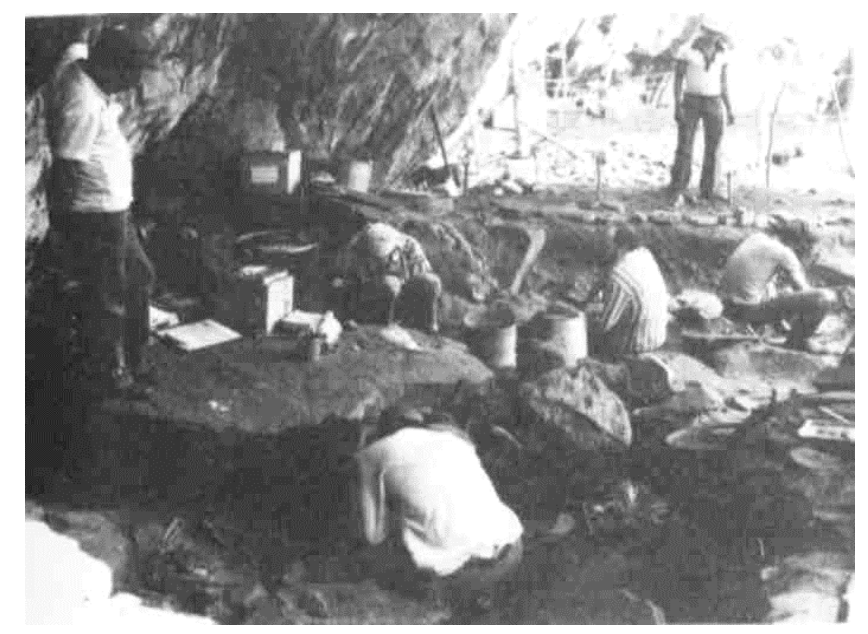

Figura 5.1. Excavación en Santana do Riacho (PROUS Y MALTA, 1991: 411) 
Los esqueletos humanos representados por 40 individuos estaban distribuidos en unos $46 \mathrm{~m} 2$ excavados, concentrándose casi todos en sólo $12 \mathrm{~m} 2$ (Prous, 1992-1993).

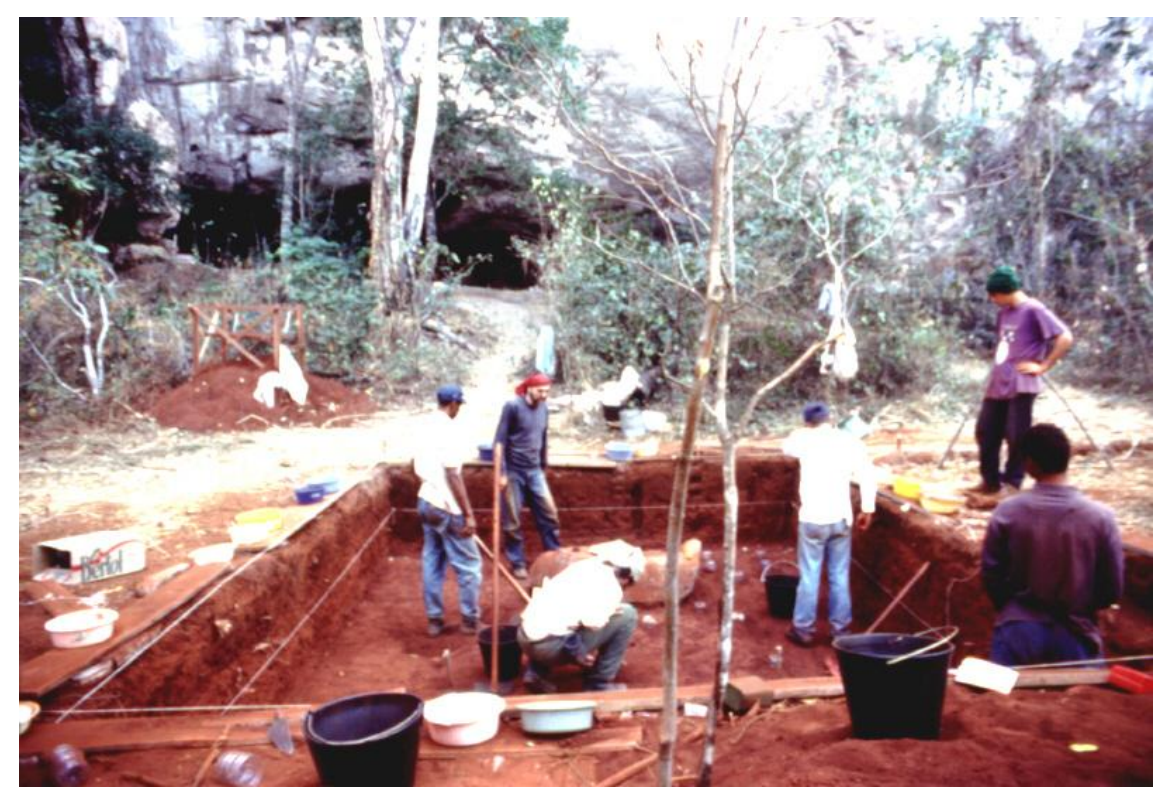

Figura 5.2 Excavaciones en el sitio Peruacu. Andre Prous, Walter Neves y equipo, Foto S. Cornero, 1999.

\subsection{DATACIONES}

Para el conjunto del sitio fue analizado un total de 39 muestras, siete por G. Delibrias en el laboratorio de Gif Sur Yvette, Francia; y 32 por Y. Chausson en el laboratorio del centro de desarrollo de tecnología nuclear en Belo Horizonte. Los fechados mas antiguos obtenidos en el abrigo, datan de 18.000 años AP (EF/71-72). Las muestras analizadas proceden de un carbón vegetal, de dudoso origen antrópico.

En las capas III y IV se hallaron enterratorios humanos, no necesariamente contemporáneos entre sí. Las capas $\mathrm{V}$ y $\mathrm{VI}$ carecen de registro arqueológico, aunque en algunas áreas se encontraron elementos procedentes de ocupaciones más tardías (Neves et al. 2003). La capa VII fue dividida en dos niveles, en el primero se hallaron restos de ceniza y carbón asociados a 
pigmentos y a unas pocas lascas de cuarzo. El fechado para este nivel arrojó una antigüedad de $11.960+250$ AP (Gip 5089), aunque sin claras evidencias de origen antrópico (Prous 1992-1993).

Hasta la fecha se realizaron trece dataciones, once sobre carbones vegetales y dos en huesos humanos (Tabla 5.1), la mayoría de estos datos son consistentes entre sí. Las muestras de la capa 0 fueron contaminadas por ácido húmico de raíces de vegetales modernos.

Se realizaron otros intentos de datación sobre restos humanos, pero no tuvieron éxito debido a la ausencia de colágeno. Las dataciones correspondientes a la capa 7 arrojaron las fechas más antiguas del Brasil Central, alrededor de 12.000 AP (Neves et al. 2003). Los esqueletos humanos se ubican entre los 8.000 y 9.000 años, mas específicamente entre 8.000 y 8.500 años de antigüedad. 
TABLA 5.1. FECHADOS RADIOCARBÓNICOS DEL SITIO SR1

(Adaptada de Neves et al. 2003)

\begin{tabular}{|c|c|c|c|}
\hline Capa / Nivel & Datación AP & Laboratorio No & Muestra \\
\hline 1 superior & $2875 \pm 50$ & CDTN 1038 & Corbón vegetal \\
\hline 1 superior & $3360 \pm 70$ & CDTN 1040 & Carbón vegetal \\
\hline 1 medio superior & $3990 \pm 70$ & GIF 4510 & Carbón vegetal \\
\hline 1 inferior & $4340 \pm 70$ & GIF 4509 & Carbón vegetal \\
\hline Entierro IV & $8150 \pm 150$ & GIF 5087 & Carbón vegetal \\
\hline 2 base & $8185 \pm 110$ & CDTN 1039 & Carbón vegetal \\
\hline Entierro $\mathrm{XX}$ & $8280 \pm 40$ & BETA 162014 & Hueso \\
\hline Entierro XXIII & $8230 \pm 150$ & GIF 5088 & Carbón vegetal \\
\hline 2 base & $8381 \pm 280$ & CDTN 1044 & Carbón vegetal \\
\hline Entierro XIII & $9460 \pm 110$ & GIF 4508 & Carbón vegetal \\
\hline 7 & $11960 \pm 250$ & GIF 5089 & Corbón vegetal \\
\hline Entierro Va & $12760 \pm 70$ & BETS 96759 & Hueso \\
\hline 8 & $18000 \pm 1000$ & CDTN 1045 & Carbón vegetal \\
\hline
\end{tabular}

\subsection{EL CONTEXTO ARQUEOLOGICO}

\subsubsection{Arqueofauna}

El estudio zooarqueológico del material proveniente de Santana do Riacho fue realizado por primera vez por Veloso y Prous (1991). El registro arqueofaunístico de los vertebrados provenientes del sitio es abundante y diverso en general. A pesar de ello, no se ha podido llevar a cabo un estudio 
tafonómico para establecer un patrón que posibilite su vinculación directa con el consumo, dado que:

"Siendo la casi totalidad de los huesos mayores encontrados en fogones, quemados y fragmentados, la superficie ósea estaba demasiado alterada para permitir la observación." (Veloso y Prous, 1991:140).

Es difícil estimar con precisión, en los niveles inferiores, el número de restos faunísticos hallados en los enterratorios, ya que, debido a su alto grado de fragmentación y alteración térmica, se dificulta la asignación elemental específica y la estimación del MNI, así como también la observación de marcas de corte.

Los grupos identificados corresponden a mamíferos, entre los que encontramos venados, roedores, dasípodos y marsupiales. También hubo peces, aves, reptiles y anfibios.

El estudio de invertebrados fue realizado en equipo (Moreira, et al, 1991). El material malacológico presenta muy mal estado de preservación. Los fragmentos carbonizados no presentan evidencias de relación con las ocupaciones humanas tempranas.

A partir del año 2000, un nuevo estudio del material faunístico fue realizado por Renato Kipnis en el marco de su tesis doctoral. Entre los objetivos de su investigación plantea estudiar las estrategias de caza de las poblaciones del Brasil central durante el Pleistoceno tardío y el Holoceno temprano (Kipnis, 2002). 
TABLA 5.2. Distribución De Los Restos Faunísticos Hallados En Sr1 Según Su Nivel Estratigráfico. Adaptada de Kipnis, 2002.

\begin{tabular}{|c|c|c|c|c|c|c|}
\hline \multirow{2}{*}{ Taxón } & \multirow{2}{*}{$\begin{array}{l}\text { Nombre } \\
\text { comín }\end{array}$} & \multicolumn{4}{|c|}{ Niveles estratigráficos } & \multirow{2}{*}{ Tots } \\
\hline & & 0 & 1 & 2 & 3 & \\
\hline \multicolumn{7}{|l|}{ Mammalia } \\
\hline Agouti pocs & Paca & 1 & 2 & 0 & 0 & 3 \\
\hline Cong sp. & Covy & 4 & 3 & 1 & 7 & 15 \\
\hline Dosyprocts sp. & Agouti & 1 & 2 & 1 & 1 & 5 \\
\hline $\begin{array}{l}\text { Dosypus } \\
\text { novemeinctus }\end{array}$ & armadillo & 4 & 2 & 2 & 2 & 10 \\
\hline Didelphis sp. & comsdreja & 1 & 0 & 0 & 0 & 1 \\
\hline $\begin{array}{l}\text { Euphrsctus } \\
\text { sexeinetus }\end{array}$ & armedillo & 2 & 2 & 2 & 2 & 8 \\
\hline Kerodan nupeetris & Rock cavy & 2 & 3 & 1 & 5 & 11 \\
\hline Marmoss sp. & Mouse & 1 & 1 & 1 & 1 & 4 \\
\hline Meraing sp. & Gussuneho & 2 & 4 & 1 & 1 & 8 \\
\hline Nosug NGSUE & costi & 1 & 1 & 0 & 0 & 2 \\
\hline $\begin{array}{l}\text { Sytvilagus } \\
\text { brosiliensis }\end{array}$ & liebre & 1 & 1 & 0 & 1 & 3 \\
\hline $\begin{array}{l}\text { Tamandus } \\
\text { tetradsctyils }\end{array}$ & peresozo & 1 & 0 & 0 & 0 & 1 \\
\hline Topirus terrestris & Topir & 1 & 0 & 0 & 0 & 1 \\
\hline Toyossu pecari & pecari & 0 & 0 & 0 & 1 & 1 \\
\hline Toyassu tojocu & pecari & 0 & 1 & 0 & 1 & 2 \\
\hline $\begin{array}{l}\text { Primates } \\
\text { humanos }\end{array}$ & primates & 1 & 4 & 0 & 1 & 6 \\
\hline Rodentis & Micro fauns & 1 & 1 & 0 & 5 & 7 \\
\hline \multicolumn{7}{|l|}{ Reptilis } \\
\hline Chalonis chelidse & tertugs & 1 & 1 & 1 & 1 & 4 \\
\hline Ameiva smeivs & legartija & 2 & 0 & 0 & 0 & 2 \\
\hline $\begin{array}{l}\text { Palychrus } \\
\text { acutibrostris }\end{array}$ & Iguane & 1 & 0 & 0 & 1 & 2 \\
\hline $\begin{array}{l}\text { Tupinsmbis } \\
\text { beguixin }\end{array}$ & lagartifa & 2 & 1 & 0 & 1 & 4 \\
\hline & serpientes & 1 & 1 & 0 & 1 & 3 \\
\hline \multicolumn{7}{|l|}{ Amphibis } \\
\hline & sapos & 2 & 2 & 1 & 1 & 6 \\
\hline Peces & & 1 & 1 & 0 & 1 & 3 \\
\hline Aves & & 1 & 1 & 0 & 1 & 3 \\
\hline Total & & 32 & 32 & 9 & 33 & 105 \\
\hline
\end{tabular}

Respecto del sitio SR1, del total de elementos hallados (1197) correspondientes al registro faunístico del sitio, sólo el 9,7\% no fue considerado para el análisis, dado que se presentó en un contexto arqueológico alterado, de manera que el conjunto faunístico se conformó por 1081 especimenes.

Se identificaron 19 taxones de mamíferos y 4 de reptiles. Se hallaron, además, huesos de mamíferos y reptiles que no pudieron asignarse a ningún taxón, lo 
mismo que huesos de aves, peces y anfibios (Tabla 5.2) (Kipnis, 2002). Tampoco fueron registrados elementos óseos asignables a especies de animales extintos (Neves et al., 2003; Kipnis, 2002).

Del total de la muestra, el 36,1\% representa elementos óseos quemados. La mayoría de ellos (más del 90\%) estaba totalmente carbonizado, pero no resultó un impedimento para su identificación (Kipnis, 2002).

La evidencia de huesos quemados demuestra el tratamiento cultural de este material, que fue asociado en forma parcial a actividades de preparación de alimentos diversos (Kipnis, 2002). Un detallado estudio tafonómico, sin embargo, ha demostrado intervención humana exógena en las muestras.

Este conjunto muestra que no se verificaron diferencias estadísticas respecto de la abundancia, diversidad y uniformidad de especies, entre el Pleistoceno final y el Holoceno Temprano, con los niveles del Holoceno Medio de Santana do Riacho (Neves et al., 2003). Esta evidencia sugiere que las estrategias de los cazadores fueron consistentes, a pesar de los cambios ambientales que ocurrieron durante el Pleistoceno Final y comienzos del Holoceno (Kipnis, 2002).

En cuanto a las marcas de corte, sólo se registraron cuatro huesos con esta evidencia, dos se hallaron en el estrato 1 (un fémur de un mamífero de gran tamaño y un hueso largo de un taxón no identificado), y dos en el estrato 3 (una costilla de armadillo y un hueso sin identificar).

Esta pequeña muestra hace imposible su cuantificación, dado que representa el $0,4 \%$ del total, no obstante, las presencias de estas marcas indican actividad humana (Kipnis, 2002). Por otra parte, este autor afirma que la fragmentación del material se asocia, principalmente, a un origen cultural más que tafonómico (Kipnis, 2002).

\subsubsection{Etnobotánica}

A pesar de la poca acidez de los suelos la muestra vegetal colectada fue relativamente pequeña en comparación a otros sitios situados en regiones calcáreas. 
Los estudios de los vestigios vegetales del abrigo revelaron la presencia de semillas y carozos junto a los enterratorios.

El registro vegetal nos indica la existencia especies de frutos representados por cáscaras y carozos de pequí (Caryocar brasiliense), jatobá (Hymenaea stilbocarpa), fruto de Symplocosy sp. y de cocos (sin identificar), en los distintos niveles estratigráficos (Tabla 5.3) (Resende y Prous 1991). Estos frutos, que corresponden a estaciones estivales, pueden haber sido enterrados durante estaciones lluviosas (Neves et al., 2003).
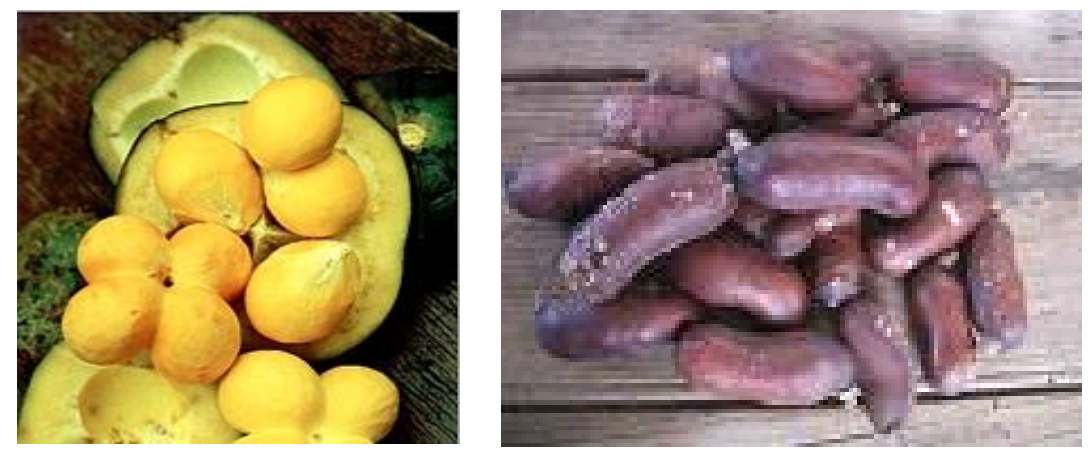

Figura 5.3 A. Pequí (Caryocar brasiliense. B. jatobá (Hymenaea stilbocarpa

Para Prous (1991), casi la totalidad de las rocas recuperadas en las excavaciones fueron trabajadas. Dominaban las rocas silíceas frágiles, silex, cuarzo y cuarcita, en menor importancia rocas semi resistentes o resistentes. Las primeras, fueron utilizadas principalmente para la confección de instrumentos por presión y las segundas, fueron transformadas en recipientes o morteros (Prous, 1991).

Las rocas de cuarzo presentan un radio de dispersión de 1 a 2 kilómetros del sitio. En un radio más cercano se encuentra cuarcita y calcedonia. Las canteras de silex se hallan a $40 \mathrm{Km}$, y la calcedonia se considera exótica para este lugar, ya que proviene de localidades situadas a no menos de $60 \mathrm{~km}$ de Sierra do Cipó (Neves et al., 2003)

Se piensa que las rocas silíceas provenían de lugares muy lejanos, lo cual se apoya en la ausencia de material derivado de la primera fase de 
procesamiento. Este material corresponde a un período temprano, haciéndose más escaso en ocupaciones recientes.

TABLA 5.3. Especies Vegetales Halladas En El Registro Representadas Por Nivel. (Adaptada de kipnis, 2002).

\begin{tabular}{|c|c|c|c|c|c|}
\hline T-mon & 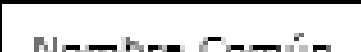 & & & & \\
\hline Iaxon & Nambre tamun & 0 & 1 & 2 & 3 \\
\hline Astracaryum 5 . & Coos & 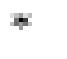 & $=$ & 7 & 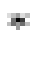 \\
\hline Caryocar brasiliense & Fe=ุuli & & $=$ & & 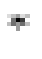 \\
\hline Coocs caronata & Coos Lieuri & & & & $F$ \\
\hline Convolvulsases (?) & & & & & 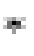 \\
\hline $\begin{array}{l}\text { Hymenos } \\
\text { stibocerp }\end{array}$ & Jatobá & 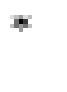 & $F$ & & $F$ \\
\hline Legenaria vilgenis & Gourd & & - & & \\
\hline Macova affinis & Tayúba & & & 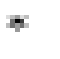 & 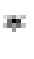 \\
\hline Myrtecea & Frute & 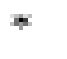 & & & \\
\hline Cow indsterminads & Coos & $\rightarrow$ & $=$ & & $=$ \\
\hline Fruta iindetenminada & & $\rightarrow$ & F & & \\
\hline Oenocarpus boteus & Coos patauǵ & & $=$ & & \\
\hline Phenodon pubercens & $\begin{array}{l}\text { Susecpirg } \\
\text { genrado }\end{array}$ & & $F$ & & 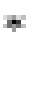 \\
\hline Solerio sp. & & & & & 7 \\
\hline Symplocos sp. & Frute & & $=$ & & \\
\hline Ventenes sp. & & & $=$ & & \\
\hline Zes mays & maix & & $=$ & F & \\
\hline & Carela de ems & & & & F \\
\hline
\end{tabular}




\subsubsection{Instrumental Lítico}

Las rocas básicas, a pesar de su origen cercano, no se encuentran tan representadas como el silex. Estas servían, sobre todo, para la confección de instrumentos por percusión (Prous, 1991).

Hasta el momento suman 12 los fragmentos artefactuales.

De acuerdo con Prous (1991) la mayoría de las lascas fueron obtenidas por percusión bipolar.

La fabricación de raspadores es típicamente del Holoceno Temprano, haciéndose cada vez más rara, en tanto, la obtención de puntas bifaciales perduró por los menos hasta cerca del 6000 AP. En el período siguiente, la técnica del retoque quedaría en desuso.

\subsubsection{Material Artefactual Óseo}

La industria ósea del sitio es escasa, a pesar de las buenas condiciones para la preservación de este material. Se hallaron en las excavaciones unos pocos artefactos de material óseo y uno de asta, de los cuales algunos probablemente corresponden a puntas y otros a perforadores (Prous, 1991).

El instrumental de origen malacológico, tan común en la región, se encuentra representado sólo por un fragmento de Strophocheilidea, manchada en el exterior y pintada en interior, que podría interpretarse, según Prous (1991), como parte de un recipiente para pigmentos.

Los elementos de hueso son raramente asociados a prácticas funerarias.

Tres fragmentos de punta de hueso (enterratorio IV), dos fragmentos de espátula (enterratorio II), un fragmento trabajado en asta de ciervo (enterratorio XXIII) (Neves et. al., 2003). Asociado al enterratorio XVII, fue hallado un anzuelo de pesca trabajado en hueso, datado en al menos 8000 años A.P. (Prous, 1991). 


\subsubsection{Material Textil}

Los grupos humanos que habitaban la región poseían conocimiento de tejido hacia el 10.000 AP. Se encontraron tres fragmentos de tejido de fibra de madera (Lara y Moresi, 1991).

Algunos individuos fueron probablemente envueltos en hamacas. El individuo $\mathrm{XVI}$ fue envuelto en una manta textil tejida con la técnica de enrosque (Lara y Moresi, 1991). Esta técnica es comúnmente usada entre las comunidades nativas actuales de Brasil (Ribeiro 1986, 1988 en Neves et. al., 2003).

\subsubsection{Pigmentos}

Los pigmentos preparados por los hombres de Santa do Riacho se obtenían de óxidos e hidróxidos de magnesio y de hierro. Hasta el momento fueron identificados seis distintos tipos de materiales de rocas, minerales y pigmentos concentrados (Prous, 1991).

Uno de los usos que se infieren de estos pigmentos rojizos ha sido en la cobertura de los cuerpos de los difuntos, como una práctica mortuoria de origen ritual.

Algunos de los individuos infantiles fueron cubiertos con pigmentos rojos extraídos de las formaciones lateríticas, facil de hallar en la cima de la roca donde se ubica el abrigo (Neves et al. 2003). 


\subsection{LOS ENTERRATORIOS}

Se exhumaron 28 enterratorios primarios y secundarios, concentrados en 12 m2 alrededor de una gran laja, posiblemente caída hace unos 11.000 años atrás (Junqueira 1992/93, Prous 1992/93). Para Prous (1991), la laja central sirvió de referencia para que los hombres de la región sepultaran la mayoría de los cuerpos a su alrededor, cavando pequeñas fosas, retirando el material arenoso y separando los bloques de piedra. Algunos de los bloques mayores (40 a $50 \mathrm{~cm}$ ) servían para efectuar los enterratorios, como en el caso de los niveles $\mathrm{V}, \mathrm{VI}, \mathrm{X}$ y XI.

La cueva era tapada por bloques menores después del depósito del cuerpo y el espacio vacío era cubierto por sedimentos mixtos, carbón vegetal y cenizas. Algunos de estos últimos elementos estaban aún calientes al momento de la depositación, debido a que dejaron evidencias de marcas de quemaduras en algunos de los huesos (Neves et al. 2003).

Algunas estructuras de enterratorios aisladas forman como un círculo periférico (enterratorios III, IX, XVI y XX). Como no se presentan pisos de ocupaciones continuas para esta época, la estratigrafía arqueológica no permite verificar las relaciones cronológicas entre los conjuntos (Prous, 1991). Las actividades de entierro, en algunos casos dañaron y desplazaron de su lugar original a los cuerpos que habían sido enterrados con anterioridad y que se encontraban debajo de estas sepulturas. Muchos de los cuerpos se encontraban superpuestos (ver Figuras 5.2. y 5.3.) y fueron enterrados en posición fetal y lateral, con diferentes orientaciones.

Algunos de ellos fueron expuestos a altas temperaturas, como evidencia el grado de alteración térmica de los materiales y la presencia de tierra cocida alrededor de los cuerpos. Muchos fueron recubiertos por pigmentos rojos. También se registraron concentraciones de ocre, que aparece como pigmentos esparcidos, alcanzando a cubrir también a los elementos asociados (Prous, 1991).

Se hallaron además collares realizados con cuentas de madera, instrumentos líticos como raspadores y puntas, así como fragmentos de instrumentos óseos. 


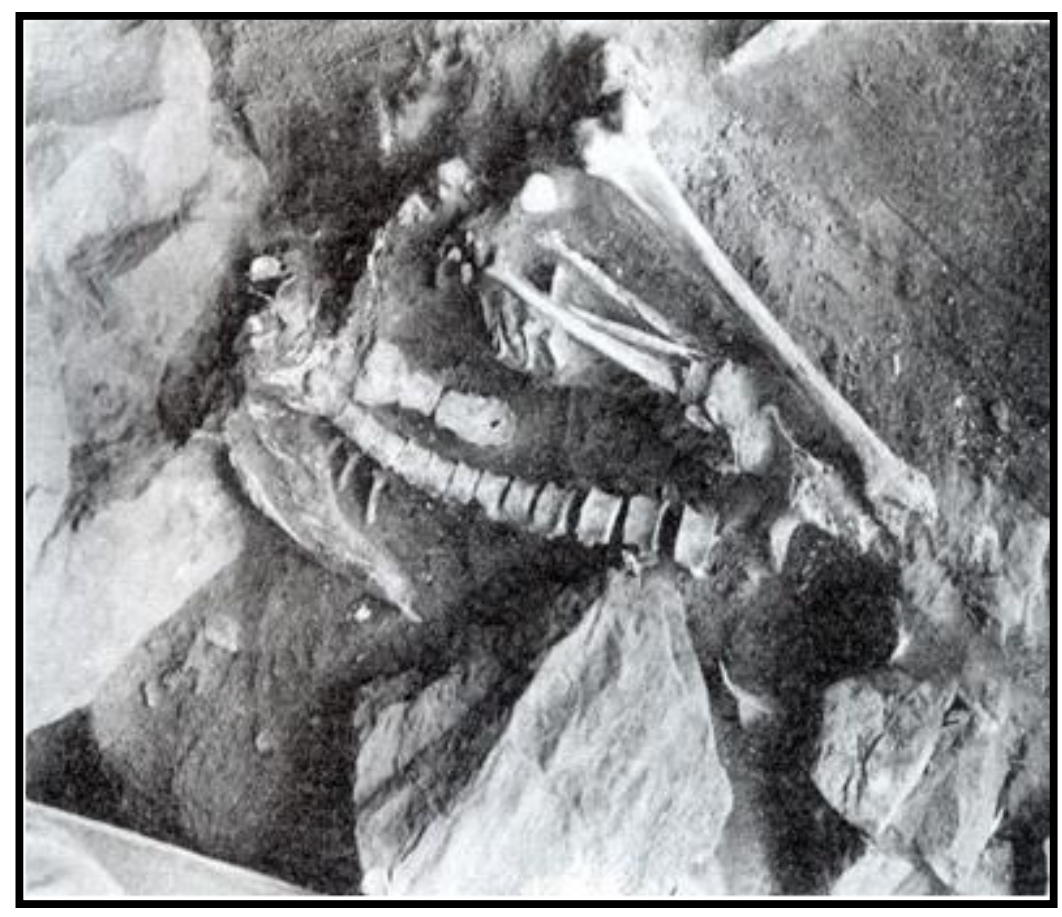

Figura 5.2a Enterratorio XII. (Junqueira, 1991: 90).

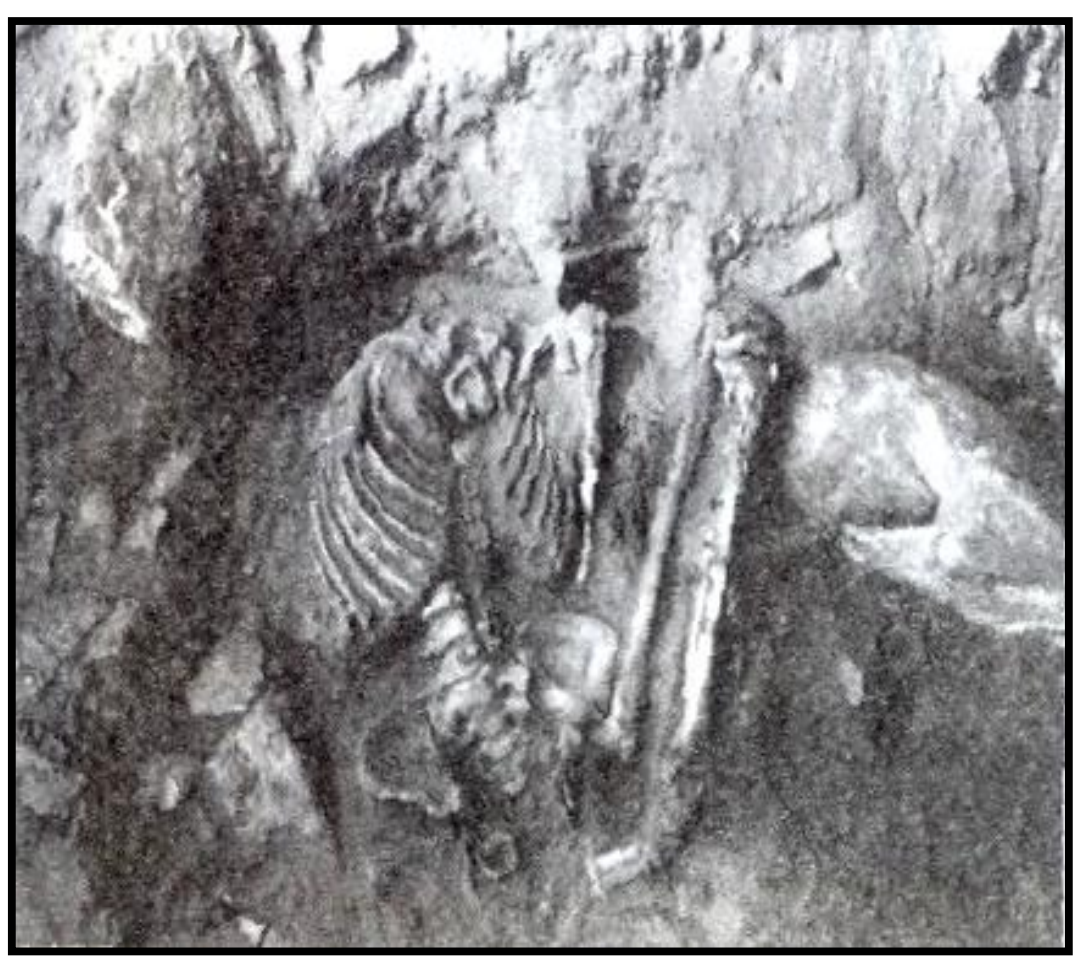

Figura 5.2b. Enterratorio XVI. (Junqueira, 1991: 89). 


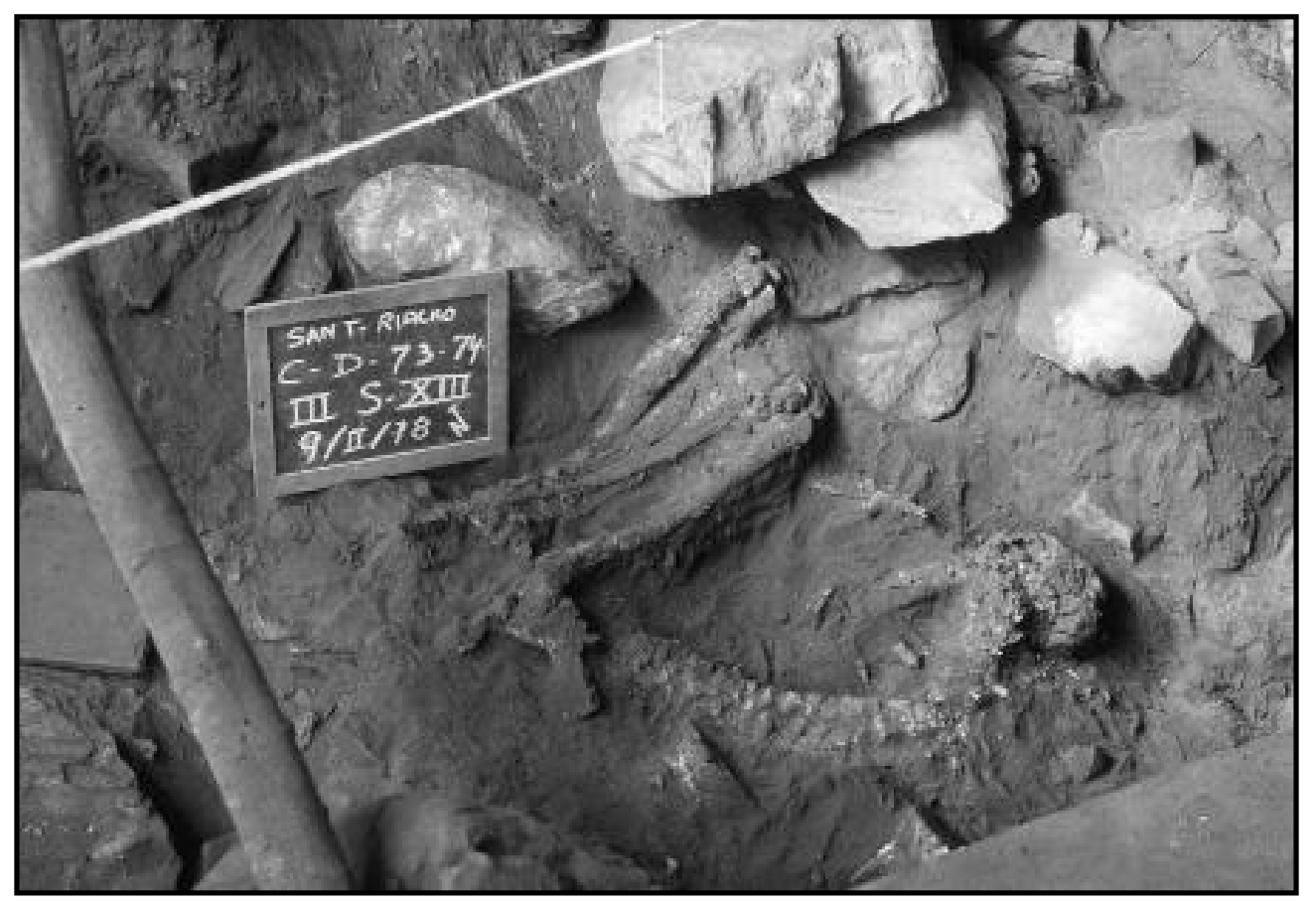

Figura 5.2c. Enterratorio XIII, Foto Cortesia A. Prous

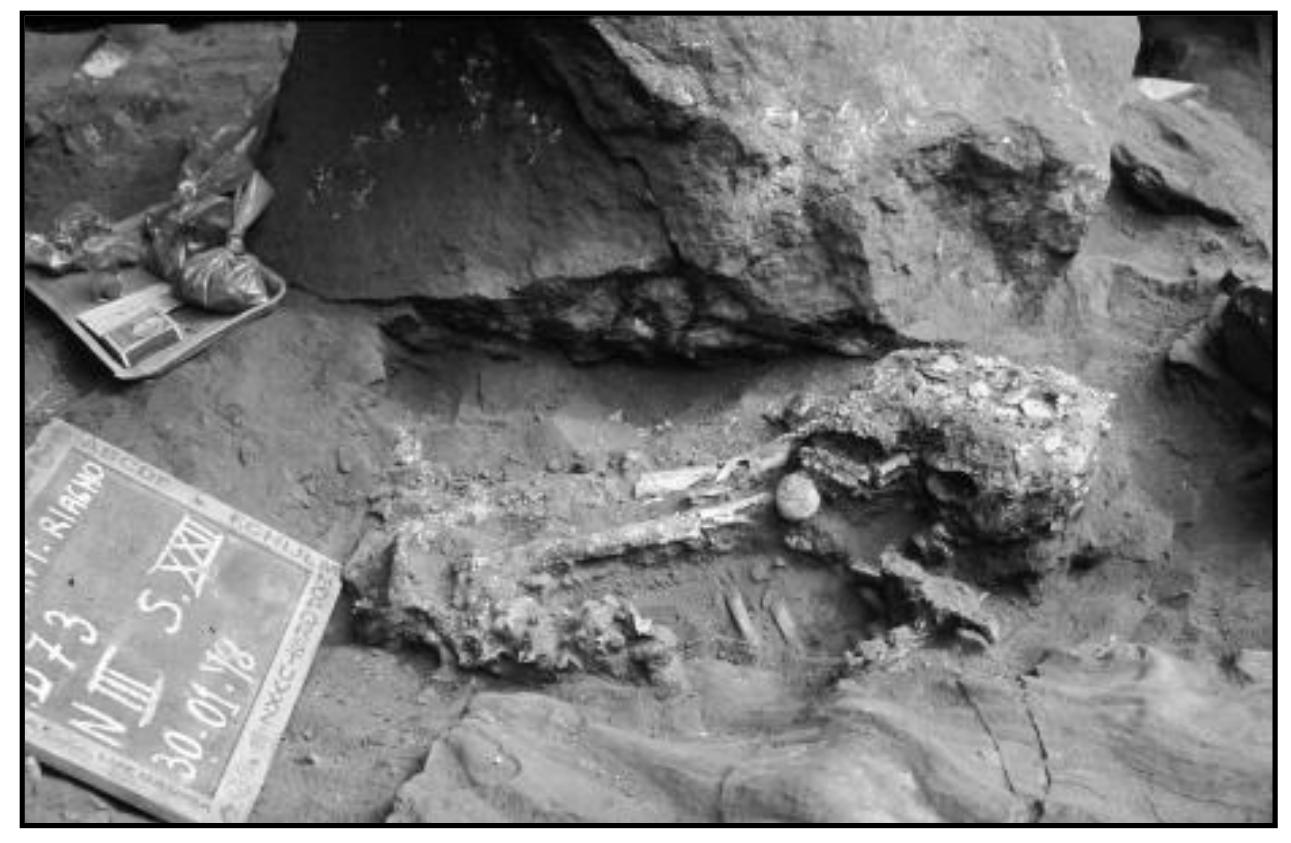

Figura 5.2c. Enterratorio XXI. Foto Cortesia A. Prous 
Estos elementos no podrían considerarse directamente como ajuar funerario, pues para Prous los elementos asociados a los esqueletos no evidencian criterios claros relacionados con prácticas funerarias (Prous, 1992-1993).

La presencia de individuos de ambos sexos y correspondientes a diversos grupos etarios, indica que los entierros de este sitio no fueron discriminados, ni tampoco se correlacionan las orientaciones y posiciones. Entre la diversidad de posiciones que presentan los enterratorios de SR1, encontramos 16 esqueletos en posición decúbito lateral (9 derechos y 7 izquierdos), 5 individuos en posición decúbito dorsal y 5 flexionados. Respecto a las orientaciones, los individuos se hallan de acuerdo al eje de su columna vertebral ubicados en todos los sentidos cardinales, tal como ise ndica en las figuras 5.4 y 5.5 y en la Tabla 5.4.

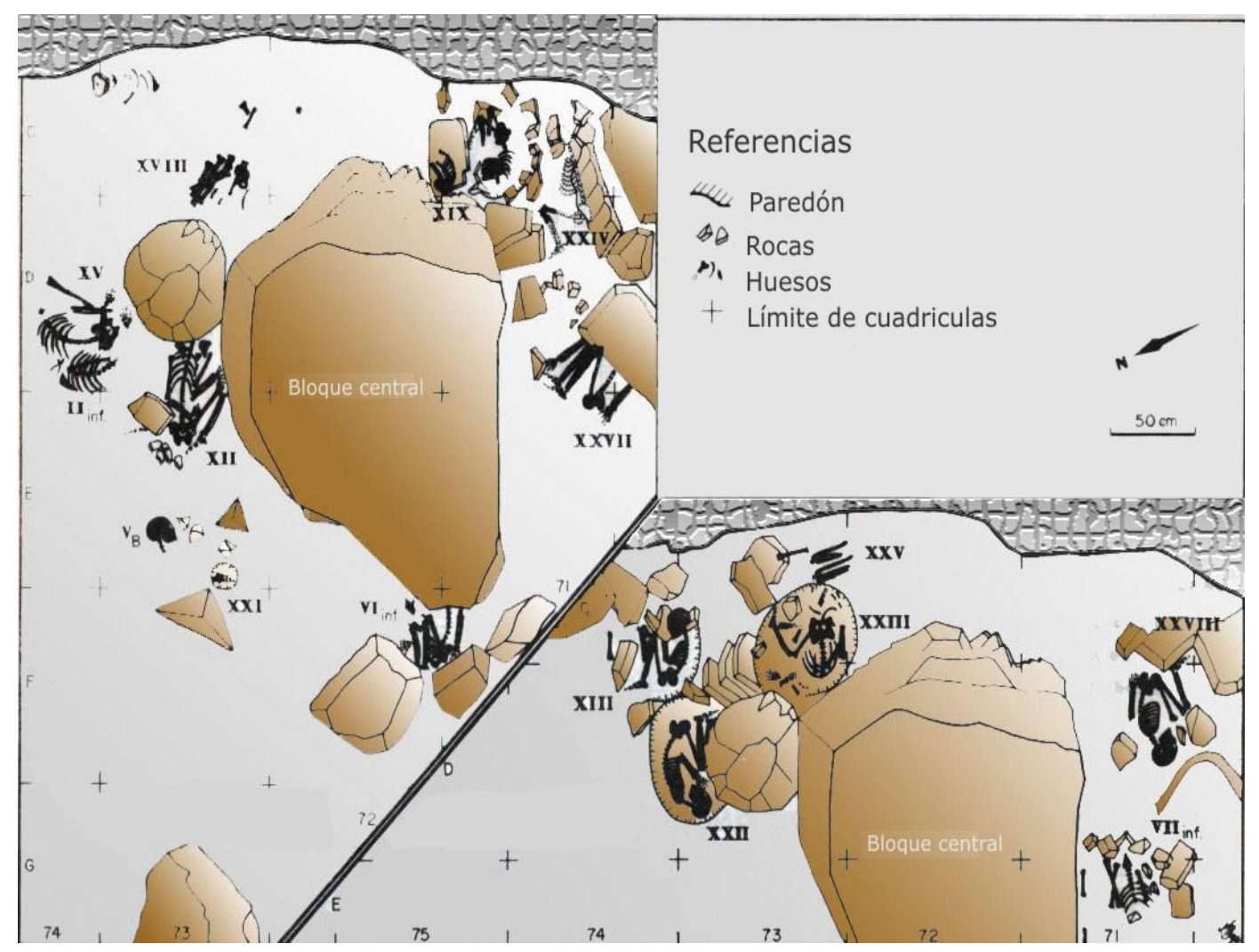

Figura 5.4. Distribución de los enterratorios en el sitio. Adaptado de Prous y Malta (1991: 24-25). 
Prácticas mortuorias similares a las de Santana do Riacho fueron descriptas en otros sitios arqueológicos de la región, en entierros de una antigüedad entre 10.000 años A.P. y 8.000 años AP (Neves et al., 2003).

Las figuras siguientes (5.4. y 5.5.) ilustran lo que Prous denomina tres momentos de inhumación, por lo que además representa la superposición que exponían los enterratorios ubicados alrededor del bloque macizo central.

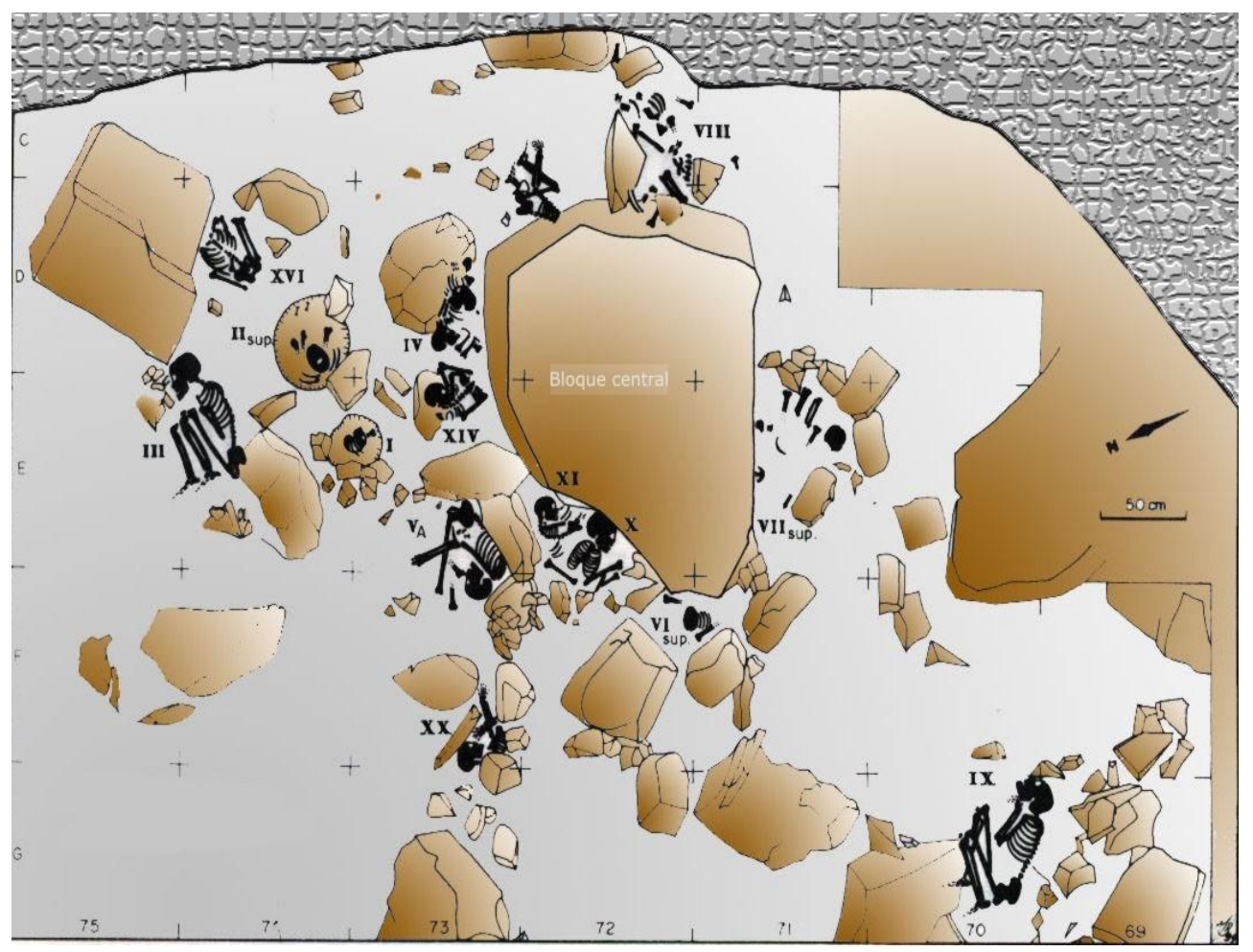

Figura 5.5 Distribución de los enterratorios en el sitio. Adaptado de Prous y Malta (1991: 24-25). 
TABLA 5.4. Orientación Y Posición In Situ de los Esqueletos. Adaptada de Prous 1992-1993:64-76

\begin{tabular}{|c|c|c|}
\hline ENTEFRATORIO & POSICION & DRIENTACION \\
\hline ! & Mismbra, Plexignadeu & Indeteriminada \\
\hline $31 \mathrm{G}\lrcorner \mathrm{F}$. & 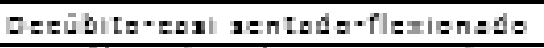 & HE \\
\hline II :-1'= ' & 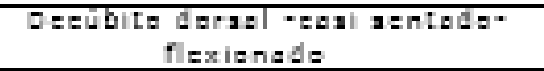 & \\
\hline$m$ & 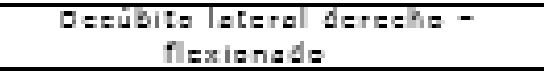 & $\mathbf{E}$ \\
\hline IV A & 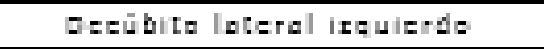 & HE \\
\hline $1 \mathrm{~W}=$ & 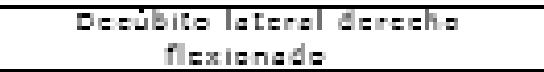 & $\mathbf{5}$ \\
\hline IA & Deajbita lateral teragha & $w$ \\
\hline$y \mathbf{E}$ & Desubita laterall inaularda & E \\
\hline vi: 1 an'. & Deadbite lateral detakha & \\
\hline VI: Patia & Dacubia derual d'laxianada & \\
\hline Wus. & 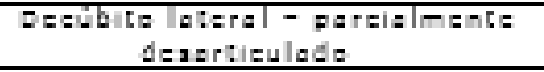 & He \\
\hline wat $\operatorname{tinf} . \mathrm{A}$ & & $\bar{w}$ \\
\hline Wat $\operatorname{tin} f . \mathrm{E}$ & - Iezienade & \\
\hline Wu $x u=$ Hada & Erazar rlexignadar & \\
\hline 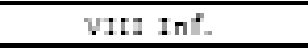 & Zzeübita lateralirauierds & $\mathrm{gn}$ \\
\hline $1 x$ & Dabibita lateral derablia & EI \\
\hline$x$ & 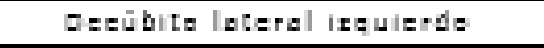 & IE \\
\hline$x 1$ & 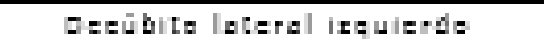 & HES \\
\hline$x+1$ & Zzeiubita lateralirauierde & \\
\hline$x=1$ & Dasubibe lateral dataklia & E \\
\hline xtu & 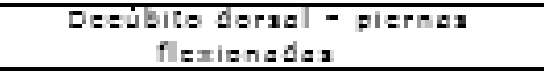 & 4 \\
\hline$x y$ & 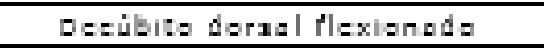 & \\
\hline xut $A$ & Decubita deranl & HE \\
\hline \multicolumn{3}{|l|}{ xint } \\
\hline xvit: & resienade & $\mathrm{N}$ \\
\hline $\mathrm{man}$ & Eagubita latarallixauierda & $\mathrm{W}$ \\
\hline $\mathrm{mag}$ & - Ireilenade & NVE \\
\hline$x x$ & - lezisnade & \\
\hline \multicolumn{3}{|l|}{$x \times t$} \\
\hline gent & 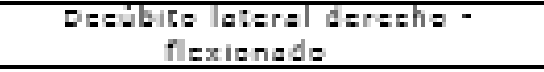 & $w$ \\
\hline ratu & & E \\
\hline$x x t a 14$ & $\operatorname{Sen}:=d \theta$ & FE \\
\hline xay & Dadibita lateral derablia & WE \\
\hline$x x y$ & Deaubita lateral deregha & $\mathrm{M}$ \\
\hline mout: & & EI \\
\hline xxutat & - Irais na 4 s & $\mathbf{E}$ \\
\hline
\end{tabular}




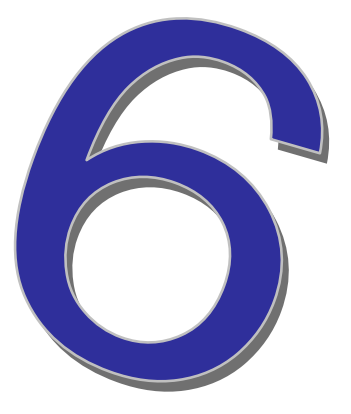

MATERIALES Y

METODOS 


\subsection{RELEVANCIA DE LA COLECCIÓN}

En América del Sur numerosos esqueletos son asignados a la edad del Pleistoceno tardío o del Holoceno temprano a pesar de que muchos de ellos nunca fueron datados. Muchos de estos individuos constituyen hallazgos aislados, en mal estado de preservación o en sitios sin clara información contextual. En este sentido, los esqueletos humanos recuperados en el sitio Santana do Riacho 1 son una excepción (Neves et al., 2003).

El material de SR1 es de importante interés para el estudio de las características biológicas de los primeros americanos y de sus implicaciones para el poblamiento del continente, como así también para el conocimiento del estilo de vida de los cazadores del Holoceno temprano para el área del Brasil Central.

Esta colección contiene un riquísimo potencial informativo, debido a su buen estado de preservación y a una importante cantidad de individuos de todas las edades que representan el grupo.

La muestra esqueletal encontrada en SR1 representa la mejor muestra del Paleoindio tardío disponible en el Nuevo Mundo para el estudio de afinidades biológicas y estilo de vida de los primeros americanos (Neves et al., 2003).

Para Neves y Atui (2004), luego del descubrimiento de los restos esqueletales de la Gruta de Sumidouro, los hallazgos de Lagoa Santa resultan de suma importancia para los estudios evolutivos humanos en el continente americano.

Esta afirmación se basa en dos interesantes eventos, por un lado en que la afirmación realizada por Peter Lund en 1844 de que los restos óseos de este sitio se encuentran asociados a fauna extinta procedente de los finales del Pleistoceno; y, por otro lado, una reciente demostración de que los restos óseos humanos antiguos de Lagoa Santa (incluyendo Luzia) muestran gran afinidad morfológica con los actuales africanos sub-saharianos y australianos, sin perjuicio del origen asiático, de acuerdo a las últimas investigaciones realizadas (Neves et al. 1998, 1999, 2003, Powell y Neves 1999). 


\subsection{ANTECEDENTES DE INVESTIGACIÓN DE LA COLECCION}

La colección de Santana do Riacho 1, después de su hallazgo en 1979, había sido cubierta en campo, durante el proceso de extracción, por una densa película oscura de cola de isopor y vendajes realizados con tela de gazas, que cubrió la superficie de los elementos, ocultando los marcadores biológicos tal como puede observarse en la Figura 6.1.

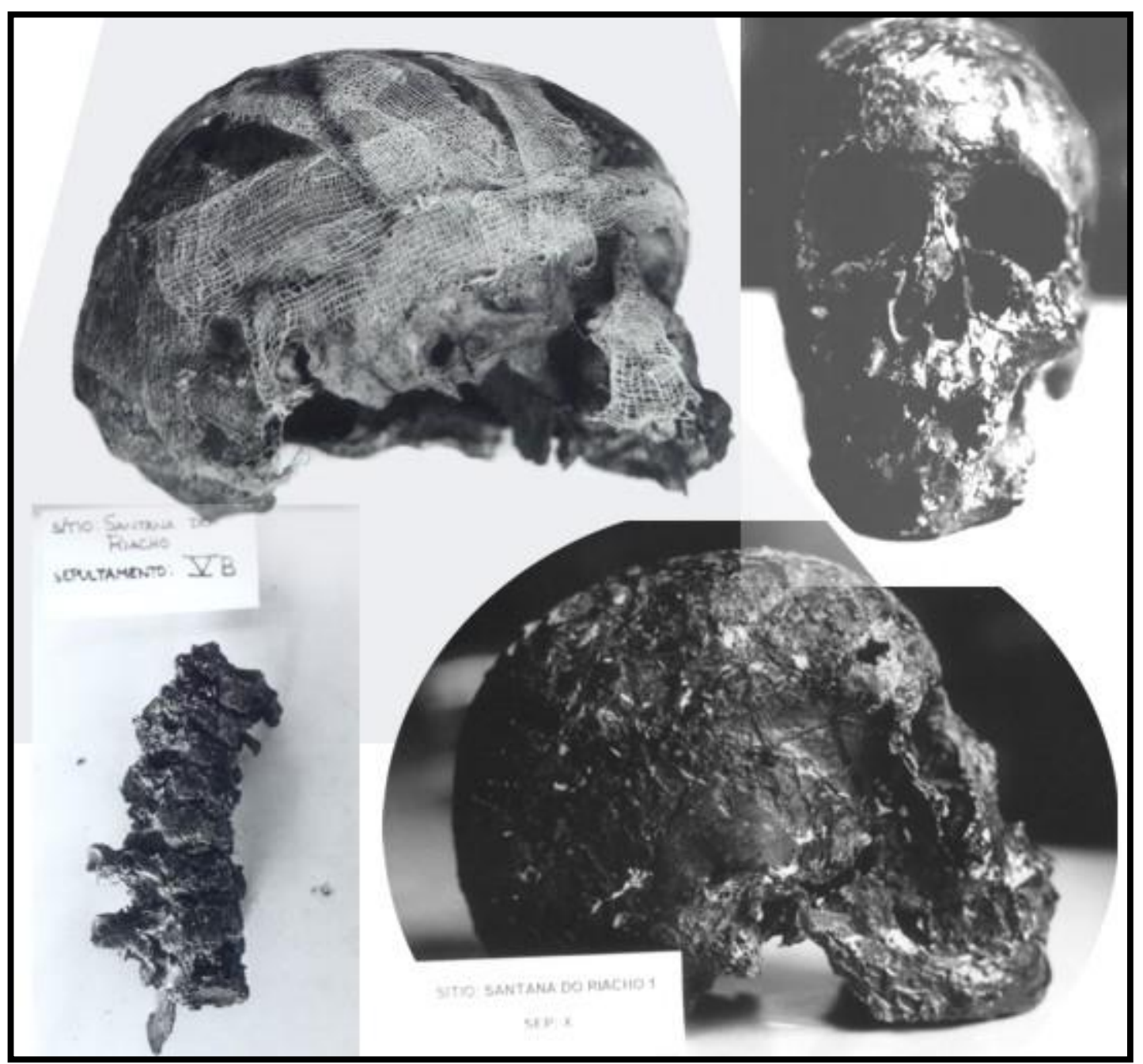

Figura 6.1. Cráneos de la colección Santana do Riacho con cobertura de cola de Isopor en el campo antes del tratamiento de curadoría. Fotografías de Verónica Wesolowski.

A pesar de esta condición, que como puede verse en la Figura 6.1., la cola y la gasa cubren la superficie ósea, a comienzos de los años '90, M. Alvin llevó a cabo un estudio morfológico preliminar y de Souza realizó observaciones 
destinadas al relevamiento de indicadores patológicos (de Souza 1992-1993). El estilo de estos trabajos se contextualiza en los paradigmas de la antropología física tradicional, dado que se demuestra más preocupación por la obtención y descripción de los diagnósticos individuales, que por las etiologías que pudieran dar cuenta de los procesos adaptativos. Ese estudio no presenta un tratamiento cuantitativo de los datos, orientado al análisis de la distribución de frecuencias, sino que expone algunas descripciones organizadas por individuo, sin considerar un análisis de población desde un enfoque evolutivo.

\subsection{PROGRAMA DE CURADORIA}

La colección de Santana do Riacho I ha sido rescatada de un crítico estado de deterioro gracias a un programa de curadoría de Walter Neves realizado en 1994, posibilitando recién ahora el emprendimiento de un análisis que contemple el relevamiento de datos inéditos del registro, para su interpretación. Los problemas que presentaba la colección Santana do Riacho 1 fueron planteados por Neves (com. pers.) y se resumen de la siguiente manera:

1- La densidad del registro óseo humano in situ, dificultó la asignación en el laboratorio de algunos elementos a individuos determinados.

2- El trabajo de curadoría se realizó casi quince años después de las exhumaciones. Desde entonces, algunos antropólogos físicos examinaron la colección sin preparación del material.

3- El consolidante que había sido aplicado en campo, de coloración oscura (cola de isopor), cubrió toda la superficie de los huesos ocultando información osteológica.

4- El desfasaje existente entre el número de individuos por enterratorios atribuido en campo y el atribuido en laboratorio.

Por estos motivos, se gestionó, en el marco del Proyecto "Origens y Microevolução do homem na América: uma abordagem paleoantropológica", la obtención de recursos para la preparación y curadoría de las colecciones SR1 y SR3.

El trabajo de las colecciones esqueletales de Santana do Riacho I y III siguieron, en líneas generales, las recomendaciones dadas en la propuesta 
pragmática para curadoría y recuperación de colecciones esqueletales humanas de Neves (1988).

Teniendo en cuenta el estado de preservación in situ, todos los fragmentos fueron consolidados después de su limpieza y remoción de cola de isopor, con acetato de polivinil (PVA) con excepción de costillas y falanges, que fueron conservadas para posteriores investigaciones bioquímicas y/o moleculares (Figuras 6.2.y 6.3.). Cada individuo fue rotulado -considerando para el siglado la designación original asignada por los arqueólogos- e inventariado y depositado en cajas de madera individuales, especialmente diseñadas para esta ocasión.

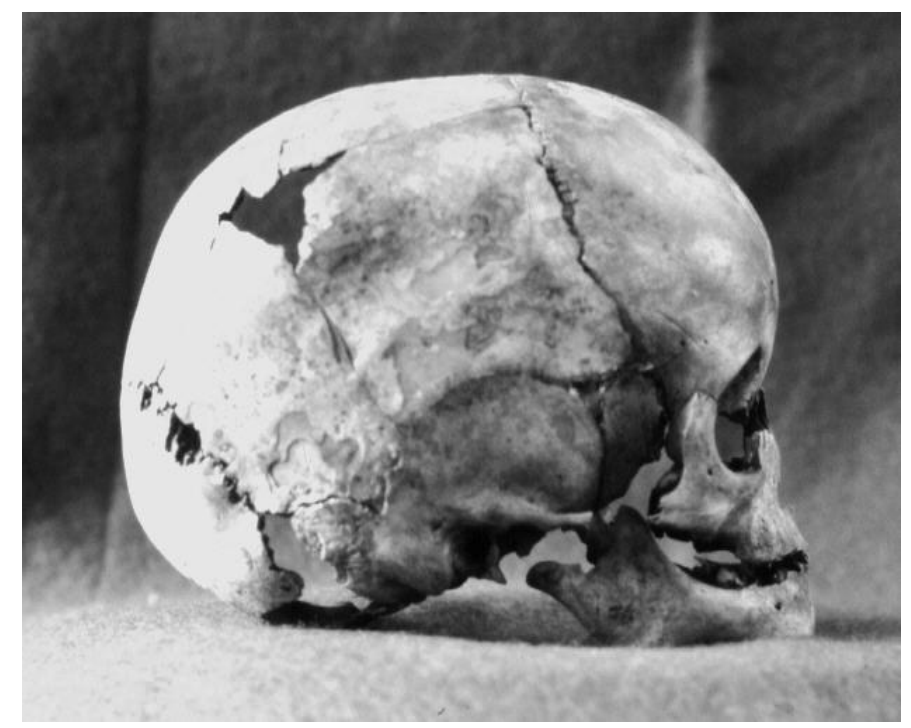

Figura 6.2. Cráneo infantil de SR1 recuperado después del proceso de curadoría

\subsection{LA MUESTRA}

La colección Santana do Riacho I constituye el $100 \%$ del universo de la muestra colectada. Para considerar válido el muestreo de esta colección establecemos, de acuerdo a la propuesta de Yacobaccio (1987), las condiciones mínimas de confiabilidad para controlar en la formación de colecciones: 


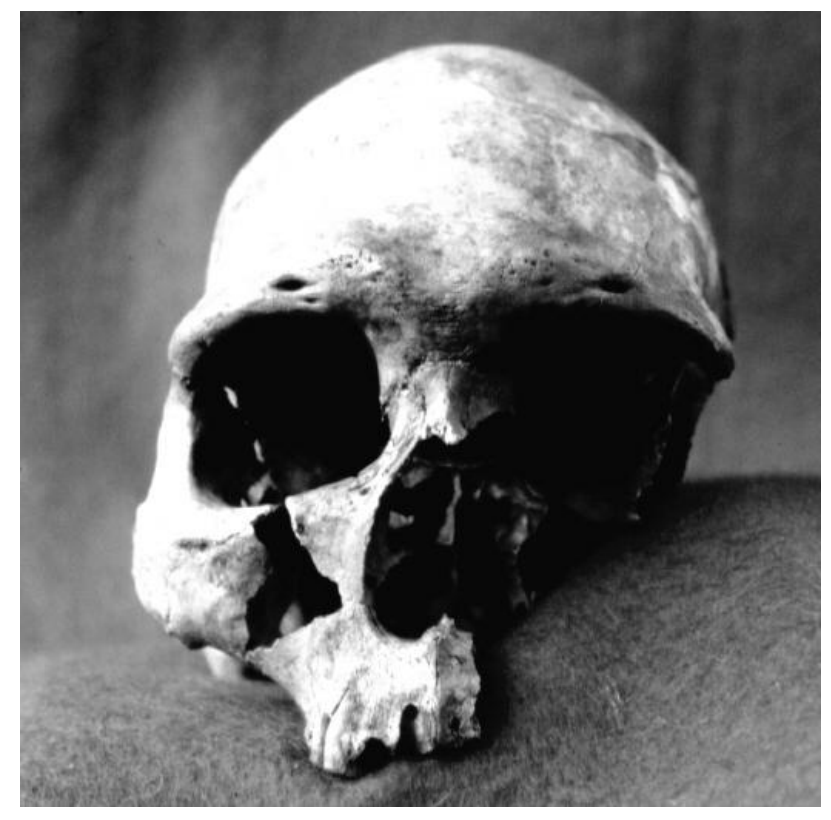

Figura 6.3. Calvaria de un adulto masculino de SR1 recuperado después del proceso de curadoría

a ) Aspectos relacionados con las distorsiones ocurridas en el sistema cultural. En este caso, la constitución de la muestra representa todos los intervalos etarios y diferentes sexos, de modo que todas las variantes de la estructura poblacional están presentes.

b ) Problemas relacionados con la recolección.

En este sentido, la metodología de relevamiento no ha descartado objetos pequeños o fragmentados, no hallándose alterada la composición original del registro (Figura 6.4.) 


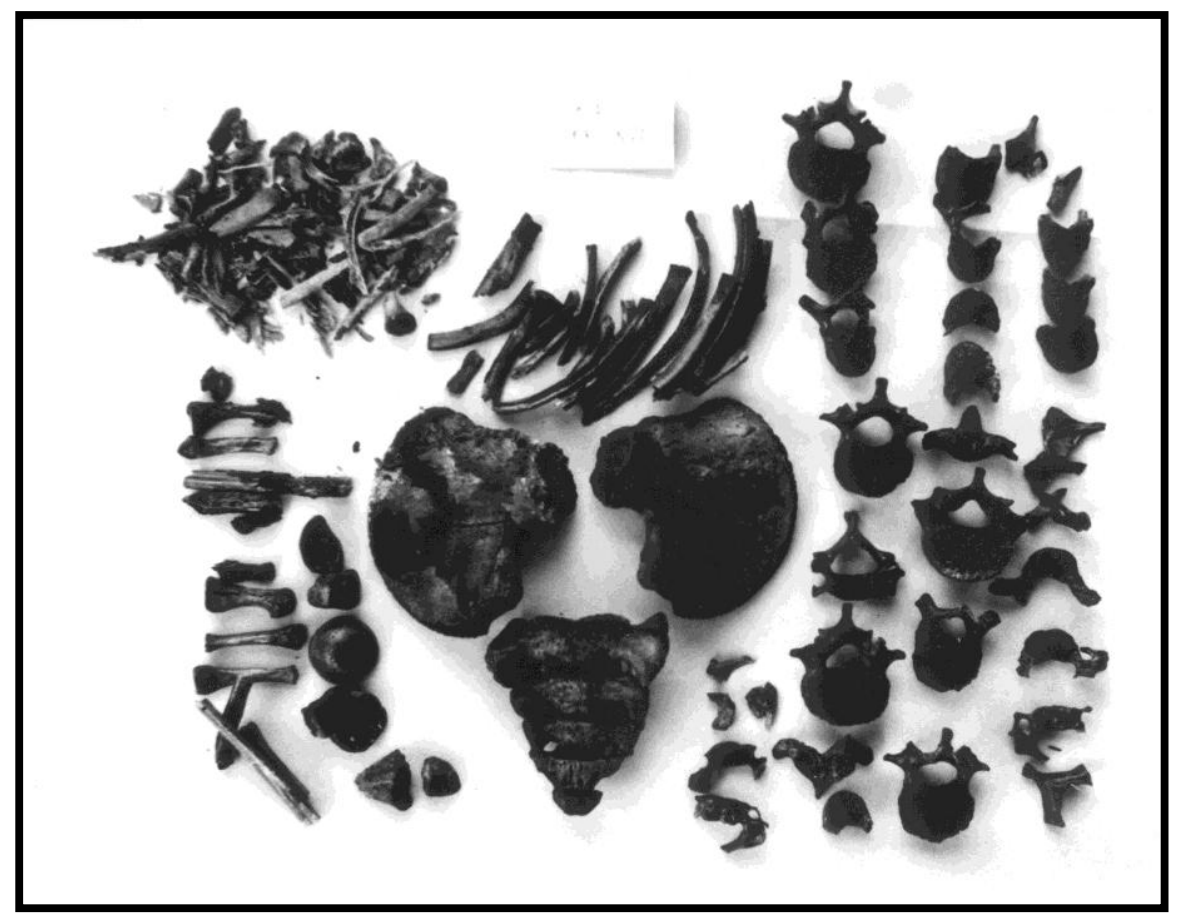

Figura 6.4. Esqueleto infantil proveniente de SR1

La muestra de una colección debe centrarse sobre aspectos definidos de la población y, a partir de ahí, la técnica de muestreo debe diseñarse en relación con los elementos no ambiguos que representa. Sólo así, al decir de Yacobaccio (1987), podemos realizar inferencias válidas a partir de los resultados del muestreo en relación a la población y afinar la formulación de los enunciados acerca de pasado.

A los fines del procesamiento estadístico, se considera a la colección como un universo poblacional.

\subsection{CARACTERIZACION, ESTRUCTURA Y COMPOSICIÓN DE LA MUESTRA}

La colección se compone de 40 individuos, los cuales fueron asignados etaria y sexualmente por Neves et al. cuando realizaban las tareas de curadoría (Walter Neves, com. pers.). De modo que el material se encontraba dispuesto y en condiciones aptas para el relevamiento de información (Figura 6.6). 
En líneas generales, la muestra presenta en el examen una discernible diferenciación de los caracteres sexuales, tendencia que se advierte en la observación de la morfología craneal y pélvica, y el esqueleto poscraneal se muestra con marcadas inserciones musculares, alcanzando los adultos una estatura normal. El sexo masculino presenta notable robustez, en tanto que las mujeres muestran elementos levemente más gráciles.

De los 40 individuos hallados en SR1 sólo seis cráneos se encuentran suficientemente bien conservados para ser medidos. Estos individuos están datados entre 8200 y 9500 años de antigüedad (Neves et al., 2003). La muestra quedó constituida por 1.808 elementos óseos completos y parciales, identificados por individuo, sexo, edad y lateralidad.

El $30 \%$ de la muestra corresponde a individuos masculinos, $20 \%$ a femeninos y el $50 \%$ restante no ha podido ser sexado, por cuanto el $87,5 \%$ corresponde a individuos infantiles.

El $82,5 \%$ de los individuos de la muestra pudo ser identificado en un rango etario definido, el resto sólo pudo ser asignado a la categoría adulto (siete individuos) (Ver Figuras 6.5. y 6.6.). 


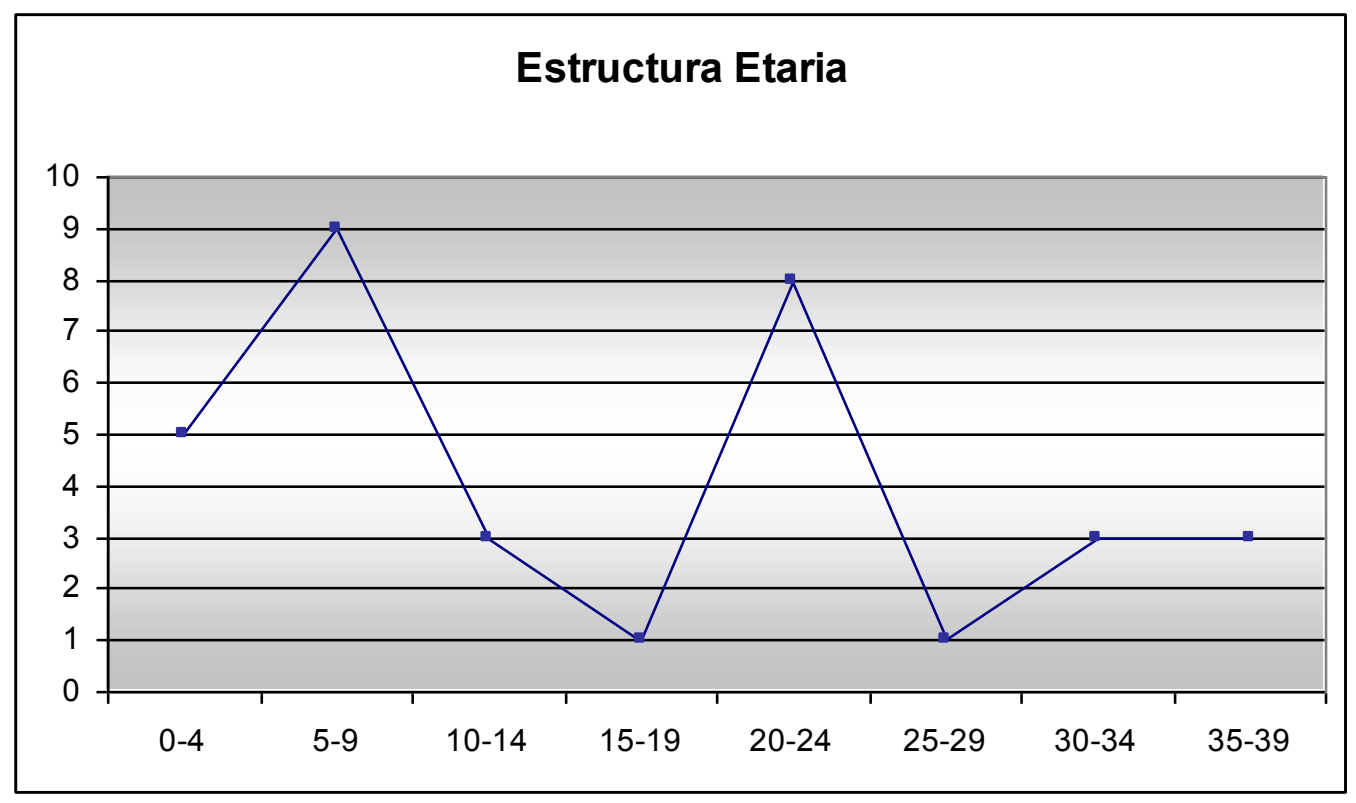

Figura 6.5. Estructura etaria de la muestra de SR1 por valores absolutos

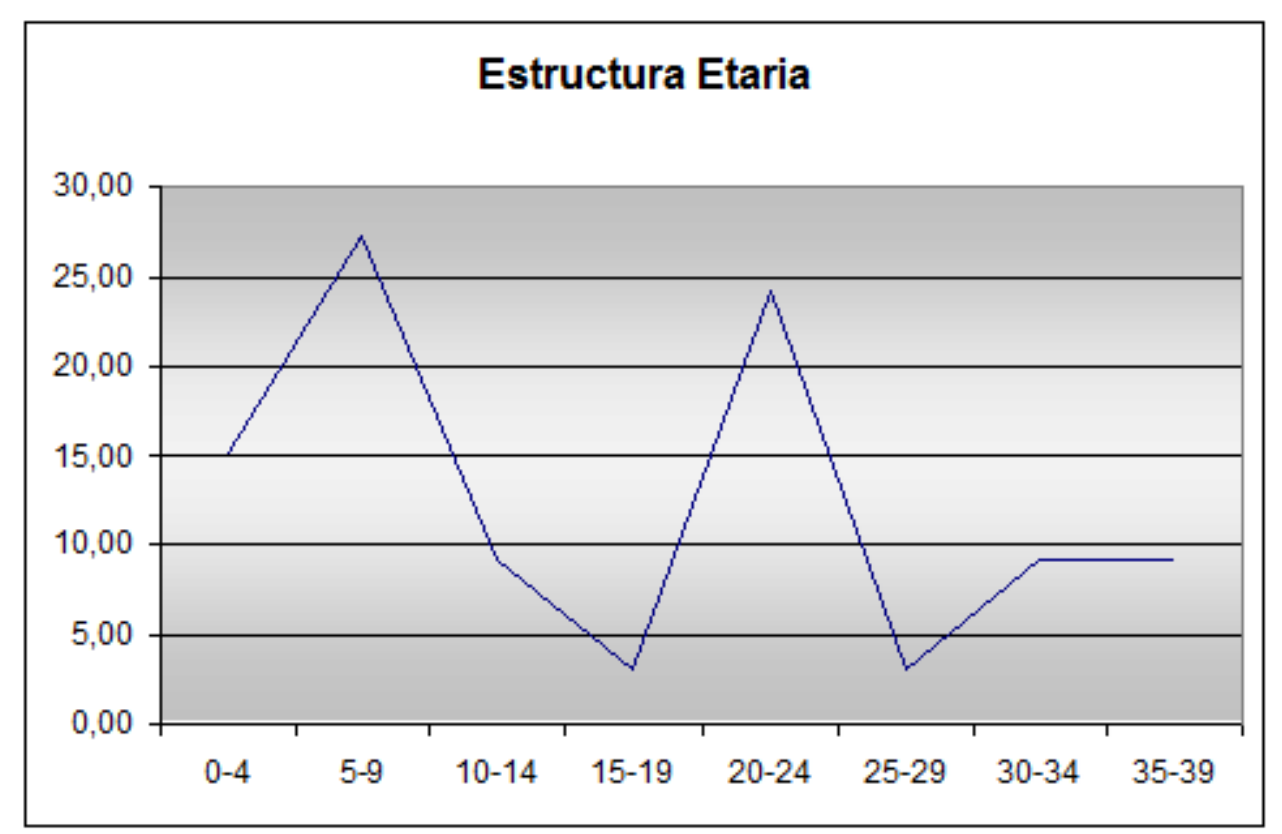

Figura 6.6. Estructura etaria de la muestra por valores porcentuales 
TABLA 6.1. Distribución de la Muestra por Sexo y Edad

\begin{tabular}{c|c|c|c|c}
\hline Edad/Sexo & Masculino & Femenino & Indeterminado & Total \\
\hline $0-4$ & & & 5 & 5 \\
$5-9$ & & & 9 & 9 \\
$10-14$ & 1 & 1 & 1 & 3 \\
$15-19$ & & 1 & & 1 \\
$20-24$ & 5 & 3 & & 8 \\
$25-29$ & & 1 & & 1 \\
$30-34$ & 2 & 2 & & 3 \\
$35-39$ & 1 & & 4 & 3 \\
Sdultos & 3 & & 20 & 40 \\
\hline Tinestimables & 12 & 8 & & 7 \\
\hline Total & & & & \\
\hline
\end{tabular}

De acuerdo a las Tablas 6.1. y 6.2., existe una presencia ligeramente mayor de individuos masculinos (30\%) respecto de los femeninos (20\%).

Hombres y mujeres se concentran en la faja etaria de 20 a 24 años, careciendo de representación en el intervalo siguiente.

TABLA 6.2. Distribución Porcentual por Sexo y Edad

\begin{tabular}{l|l|l|l|l}
\hline Edsd/Sexo & Masculino & Femenino & Indeterminado & Total \\
\hline 0.4 & & & 12.5 & 12.5 \\
5.9 & & & 22.5 & 22.5 \\
$10-14$ & 2.5 & 2.5 & 2.5 & 7.5 \\
$15-19$ & & 2.5 & & 2.5 \\
$20-24$ & 12.5 & 7.5 & & 20.0 \\
$25-29$ & & & 2.5 & 2.5 \\
$30-34$ & 5 & 2.5 & & 7.5 \\
$35-39$ & 2.5 & 5 & & 7.5 \\
Adultos & 7.5 & & 10 & 17.5 \\
insstimables & & & 50 & 100 \\
\hline Total & 30 & 20 & & \\
\hline
\end{tabular}


El grupo de edad máxima estimada (35 a 39 años de edad), se compone de 2 individuos femeninos y uno masculino.

Los resultados obtenidos de los análisis de los esqueletos de Santana do Riacho 1 (Neves et al., 2003) indican que su morfología no es única en el Nuevo Mundo. De hecho, los estudios realizados sobre muestras de esqueletos paleoindios indican que los primeros sudamericanos fueron marcadamente diferentes en términos de morfología craneal en comparación con los nordasiáticos y con los esqueletos amerindios Neves y coautores (2003) han caracterizado a los cráneos de Santana do Riacho 1 como de neurocráneo largo y angosto, y rostro bajo y fino.

\subsection{ESTADO ACTUAL DE CONSERVACIÓN}

La colección se encuentra actualmente depositada en el Museo de Historia Natural e Jardim Botanico de la Universidad Federal de Minas Gerais en Belo Horizonte.

Los esqueletos presentan diferente grado de conservación, siendo en algunos casos la exposición al fuego una de las principales causas de deterioro óseo. Algunos elementos exponen evidencias pseudopatológicas, provocadas por acción química de los insectos sobre los huesos. Este efecto posdeposicional modificó algunos sectores de los huesos dejando trazas de alteración química.

Los efectos causados por la infección de insectos comúnmente producen cambios en los huesos fácilmente confundibles con procesos infecciosos o de reabsorción (Buikstra y Ubelaker, 1994). Tal no sería el caso de SR1, debido a que las marcas de perturbación entomogénicas son claras (como áreas de coloración oscura, corrosión y canales incisos) y no se prestan a confusión.

La observación y relevamiento de la información se realizó en los gabinetes del área de arqueología del Museo de Historia Natural de la Universidad Federal de Minas Gerais en Belo Horizonte (Figura 6.7.).

El procesamiento de la información, el análisis y la discusión de los resultados se llevó a cabo en el Laboratorio de Estudos Evolutivos Humanos de la Universidad de Sao Paulo y la estructura, diseño y contenido de la investigación fue realizada en el Museo Universitario "Florentino y Carlos 
Ameghino" de la Facultad de Ciencias Exactas, Ingeniería y Agrimensura de la Universidad Nacional de Rosario.

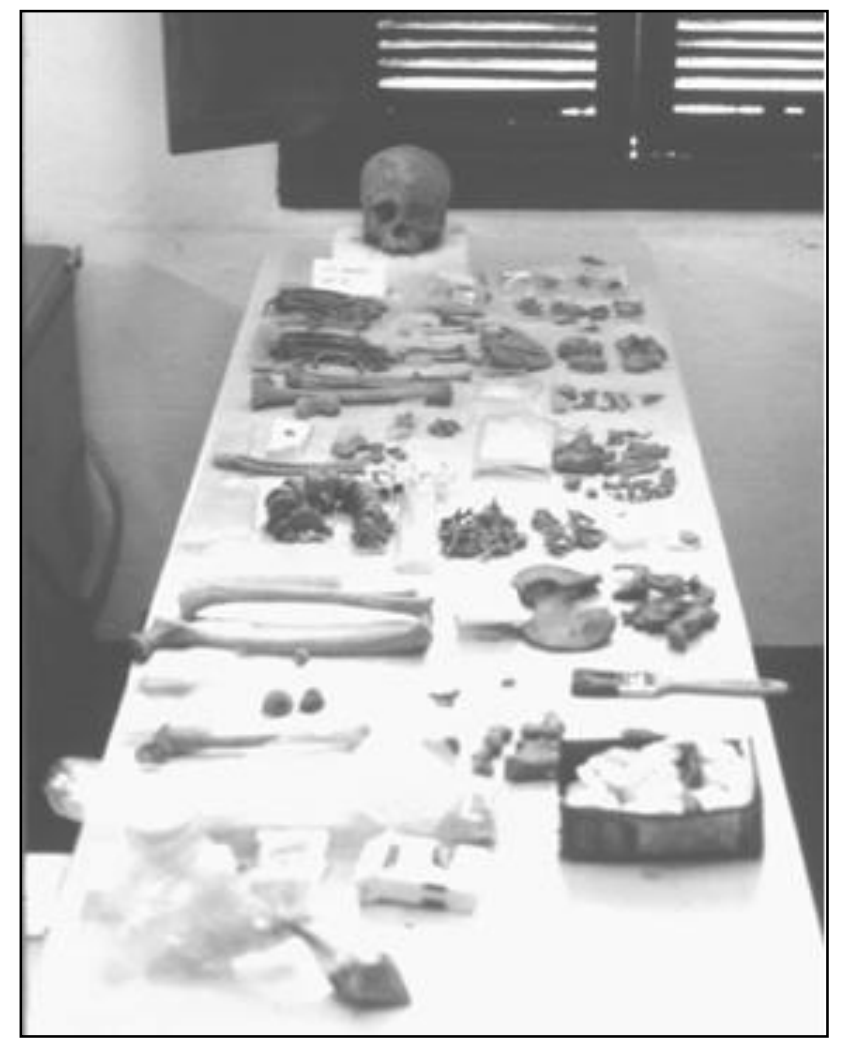

Figura 6.7. Materiales en el Museo de Historia Natural e Jardim Botánico de la Universidad Federal de Minas Gerais, Belo Horizonte

\subsection{EL RELEVAMIENTO DE DATOS}

El relevamiento de datos se llevó a cabo de manera sistemática y bajo supervisión. El trabajo se realizó en dos etapas de estadía en el Museo de Historia Natural de la Universidad de Minas Gerais, en Belo Horizonte, donde se halla depositada la colección.

El método seguido fue por observación macroscópica directa, de acuerdo con la propuesta metodológica de condiciones de observación de White (1992).

El relevamiento de patologías se hizo de acuerdo con la lista de elementos esenciales propuesta por Ortner y Putschar (1985:36), tales como uso de terminología no ambigua y precisión en la ubicación, distribución y descripción morfológica. 
La terminología, en descripciones de apariencia obvia, se basó en la referencia del Glosario de términos técnicos del Apéndice I del "Standards for data collection from human skeletal remains" (Buikstra y Ubelaker, 1994:108).

Los datos relevados fueron vertidos en 8 fichas osteológicas especialmente diseñadas y confeccionadas por Walter Neves y María Antonieta Costa para cada marcador biológico.

Los items considerados fueron antropometría odontológica básica consistente en: presencia, pérdida ante y postmortem de piezas, agénesis congénita, pieza no erupcionada, caries, retención alveolar, periodontitis y desgaste dental; indicadores nutricionales o metabólicos: hiperostosis, hipoplasia; indicadores ocupacionales: trauma, artropatías, osteofitos, y nódulos de Schmorl) y enfermedades infecciosas inespecíficas.

De modo que para la realización de este trabajo fueron relevados y procesados un conjunto de 669 atributos óseos por individuo, incluidos los datos de ausencia de registro.

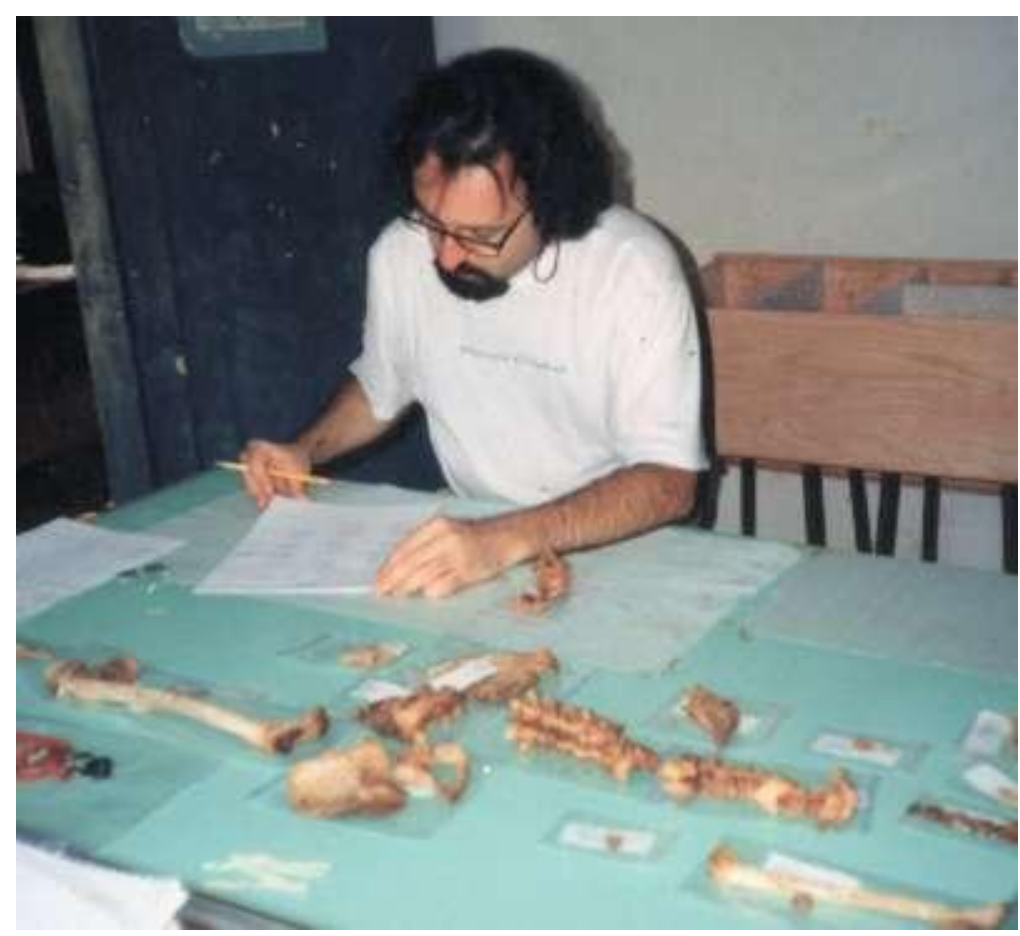

Figura 6.8 Walter Neves trabajando en el Gabinete del Museo Universitario de Bello Horizonte, Minas Gerais. 
La información individual obtenida se volcó en planillas de MS Excel para la confección del banco de datos.

\subsection{PROCEDIMIENTO CUANTITATIVO Y ESTADÍSTICO}

Aunque la muestra total para cada marcador analizado sea pequeña, teniendo en cuenta la gran recurrencia de datos ausentes, adoptamos como estrategia presentar los resultados de manera cuantificada, dado que éste es el primer estudio sistemático de una colección de esqueletos paleoindios en términos de población. Aun en virtud de la pequeña muestra, restringimos nuestra cuantificación a la presentación de estadísticas descriptivas de frecuencias y medidas de tendencia central.

\subsection{METODOLOGIA}

\subsubsection{Indicadores de Salud}

\subsubsection{Talla}

La estatura es inferida considerando la longitud de los huesos largos. Muchos son los métodos que desde la antropología se proponen para la estimación de la estatura.

El procedimiento para estimación de talla, utilizado en este trabajo, deriva de la aplicación de técnicas antropométricas sobre fémures, basado en el método propuesto por M. Feldesman, G. Kleckner y J. Lundi (1990). Este método ha sido empleado, tanto en las colecciones homínidas de Atapuerca, como en registros históricos (US Army). Dicho método consiste en obtener la longitud anatómica femoral (LAF) mediante el uso de una tabla osteométrica.

La LAF se mide desde el punto superior de la cabeza al punto más distante de los cóndilos, siguiendo el eje de la diáfisis, cifra que se multiplica por cien y se la divide por 26.74 . 


\subsubsection{Dimorfismo Sexual}

El dimorfismo sexual (DS) ha sido calculado de acuerdo con fórmula propuesta por Hamilton (1975):

DS $=$ media masculinos - media femeninos $X 100$

media femeninos

se proponen hasta seis medidas del esqueleto postcraneal para la aplicación de esta fórmula, tomando siempre los valores de la media (Powel, 1988):

1. diámetro máximo de la cabeza humeral,

2. diámetro máximo de la cabeza femoral,

3. circunferencia media de la diáfisis femoral,

4. diámetro máximo anteroposterior de la diáfisis femoral,

5. largo máximo femoral, y

6. largo máximo de la tibia.

Las primeras cuatro medidas propuestas han documentado un mayor grado de dimorfismo sexual que las dos últimas, motivo por el cual son empleadas más frecuentemente en estudios forenses para determinación sexual.

En términos generales, la selección de estas variables corresponde a las condiciones de conservación en que se encuentran los materiales osteológicos. En este trabajo se consideró como referente para este indicador la medida del diámetro máximo de la cabeza femoral (DMF), que posibilita la obtención de un mayor tamaño de muestra.

\subsubsection{Condición general de la dentición}

Se observaron las piezas dentales mandibulares, maxilares y aislados y se realizaron 184 registros dentales correspondientes a 16 individuos (tres masculinos, seis femeninos y siete infantiles). La distribución de los elementos dentales de los adultos, por categorías, se expone en la Tabla 7.4.

La muestra dental infantil conserva muy pocos ejemplares completos. La muestra dental de los adultos está mayormente representada por elementos presentes completos, de los cuales 49 elementos dentales corresponden a individuos masculinos y 63 a femeninos. 


\subsubsection{INDICADORES PATOLÓGICOS}

\subsubsection{Hipoplasias Dentales}

Para el relevamiento de este indicador se tomó la propuesta metodológica de Goodman, Armelagos y Rose (1980), quienes proponen una técnica para determinar patrones poblacionales a partir del registro de diferentes elementos dentales, considerando el canino mandibular y los incisivos centrales como los elementos dentales más sensibles. Se consideraron a tales fines, tanto elementos temporarios, como permanentes.

\subsubsection{Cribra Orbitalia - Hiperostosis Porotica}

La porosidad en bóveda craneana y órbita demostró presencia de anemia. Generalmente, la hiperostosis porótica se presenta en la superficie orbital del hueso frontal y/o en las áreas adyacentes de las suturas sagitales y lamboidea $y$, ocasionalmente, en la sutura coronal. En casos más severos, esta porosidad aparece también en lo parietales y en el hueso occipital (Buikstra y Ubelaker, 1994). 
Tabla 6.3. Distribución Por Categorías de los Elementos Dentales Adultos de la Colección Santana Do Riacho 1

\begin{tabular}{|c|c|c|c|c|c|c|c|}
\hline \multirow{4}{*}{$\underline{y}$} & \multirow{2}{*}{$\underline{z}$} & $\rightarrow$ & & $\mid \rightarrow$ & $\Rightarrow$ & $\rightarrow$ & \\
\hline & & 0 & & $\rightarrow$ & $\rightarrow$ & & \\
\hline & \multirow{2}{*}{$\stackrel{亏}{\bar{\prime}}$} & $\because$ & & $\cdot \vec{\theta}$ & & & \\
\hline & & 0 & & $\mathrm{ra}$ & $\mathrm{ra}$ & & \\
\hline \multirow{4}{*}{$\Rightarrow$} & \multirow{2}{*}{$\stackrel{\sharp}{\rightleftarrows}$} & $\Rightarrow$ & & $\rightarrow$ & $\rightarrow$ & & \\
\hline & & 0 & & & $\mathrm{rH}$ & & \\
\hline & \multirow{2}{*}{ 㥯 } & $\Rightarrow$ & & $\rightarrow$ & & & \\
\hline & & $\mathrm{a}$ & & $m$ &. & & \\
\hline \multirow{4}{*}{$u$} & \multirow{2}{*}{ 㟒 } & $\rightarrow$ & & $\rightarrow$ & $\rightarrow$ & & \\
\hline & & $\square$ & & & & & \\
\hline & \multirow{2}{*}{ 㥯 } & $\Rightarrow$ & & & $\rightarrow$ & & \\
\hline & & $\square$ & & $\rightarrow$ & & & \\
\hline \multirow{4}{*}{$\frac{7}{2}$} & \multirow{2}{*}{ 背 } & $\because$ & & $\Rightarrow$ & $\Rightarrow$ & & \\
\hline & & 0 & & & $r$ & & \\
\hline & \multirow{2}{*}{ 言 } & $\because$ & & 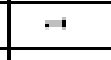 & 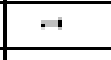 & & \\
\hline & & 0 & & & $r$ & & \\
\hline \multirow{4}{*}{$\sum_{i}^{2}$} & \multirow{2}{*}{ 尝 } & $\because$ & & $\Rightarrow$ & $\Rightarrow$ & & \\
\hline & & 0 & & & $\vec{r}$ & & \\
\hline & \multirow{2}{*}{ 㥯 } & $\square$ & & $\because$ & $\because$ & & \\
\hline & & 口 & $\Rightarrow$ & & $\vec{r}$ & & \\
\hline \multirow{4}{*}{$\vec{z}$} & \multirow{2}{*}{ 플 } & $\because$ & & $\Rightarrow$ & $\mathrm{rat}$ & & \\
\hline & & 口 & & 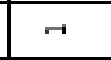 & 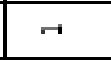 & & \\
\hline & \multirow{2}{*}{ 言 } & $\because$ & & $\mathrm{rA}$ & $\mathrm{rA}$ & & \\
\hline & & 口 & $\vec{H}$ & $\vec{r}$ & $\vec{r}$ & & \\
\hline \multirow{4}{*}{ 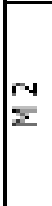 } & \multirow{2}{*}{ 吾 } & $\because$ & & & $\mathrm{rat}$ & & \\
\hline & & 0 & & & $r$ & & \\
\hline & \multirow{2}{*}{ 혹 } & $\rightarrow$ & & $\mathrm{r}$ & $\mathrm{r}$ & & \\
\hline & & 口 & $\Rightarrow$ & $\rightarrow$ & $\rightarrow$ & & \\
\hline \multirow{4}{*}{$m$} & \multirow{2}{*}{ 焗 } & $\because$ & & & $\Rightarrow$ & $\mathrm{rat}$ & \\
\hline & & $\Delta$ & & & & & $\mathrm{ra}$ \\
\hline & \multirow{2}{*}{ 禀 } & 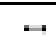 & & $\Rightarrow$ & 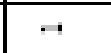 & 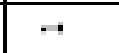 & $\mathrm{ri}$ \\
\hline & & 口 & & $\mathrm{m}$ & & $\rightarrow$ & $\mathrm{ra}$ \\
\hline & & & 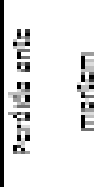 & 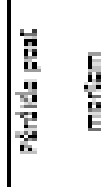 & 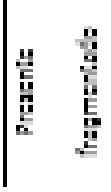 & 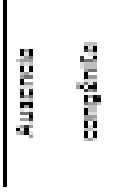 & 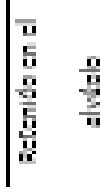 \\
\hline
\end{tabular}


No todos los cráneos de la colección estudiada se encontraban en condiciones idóneas para la observación de esta patología. De modo que para evaluar este indicador se seleccionó una muestra compuesta por 9 elementos, de los cuales 4 corresponden a individuos adultos - 3 femeninos y 1 masculino- de un rango etario entre 17 y 37 años; y 5 cráneos corresponden a individuos infantojuveniles con una edad que va entre los 3 y los 12 años.

La observación se realizó macroscópicamente, con asistencia de una lente de aumento (X10).

\subsubsection{Patologías de Origen Infeccioso: Infecciosas Inespecíficas}

Se consideraron las siguientes categorías: periostitis localizada, periostitis extensa, osteomielitis localizada, osteomielitis extensa y lesiones reabsorbidas. Las lesiones periostíticas, o periostitis, son aquellas que afectan a la superficie del hueso. Se entiende por osteomielitis al conjunto de lesiones que involucran al tejido cortical y a la médula (Goodman, et al., 1984).

Las infecciones pueden ser sistémicas o localizadas. Las primeras se manifiestan en diferentes regiones del esqueleto y las segundas son producto de eventos que se centran en un área ósea determinada y que generalmente son producidos por el impacto de lesiones traumáticas (Ortner y Putschar, 1985). En el presente trabajo se consideró como de grado extenso a aquellas lesiones que afectaron a más de un $30 \%$ del hueso.

\subsubsection{PATOLOGIAS INFECCIOSAS ESPECÍFICAS}

\subsection{Caries}

La dentición permanente de los individuos de Santana do Riacho I fue examinada para determinar caries, por observación visual macroscópica mediante la asistencia de un explorador odontológico, para la identificación de infecciones cariogénicas. 
Las lesiones halladas se relevaron por su localización (oclusal, medial, distal, bucal y lingual) y su grado de severidad se determinó de acuerdo a una escala de 1 a 8 .

La presencia de caries se hizo visible en los casos de orificios de bordes redondeados, cuya profundidad pasara la capa esmaltaria, comprobando este hecho por medio de instrumental odontológico. Fueron excluidos del análisis los individuos infantiles, para permitir la comparación con otros grupos estudiados y publicados en la literatura internacional (Powel, 1985).

Mediante la información obtenida (tabla 7.7.) se calculó el total de dientes cariados (TDC) presentes sobre el total de dientes observados (TDO), siguiendo con la propuesta metodológica de Powell (1985).

\subsection{Periodontitis}

Se consideró como criterio diagnóstico la retracción del tejido alveolar, la formación de una cresta horizontal que acompaña la línea del contorno alveolar (Larsen, 1996) y/o la presencia de una porosidad macroscópica de origen periostítica (Lukacs, 1989).

\subsubsection{Traumas}

Lovell (1997) organizó las categorías de daño traumático propuestas por varios autores, con la intención de clarificar y estandarizar la terminología, así como para reducir inconvenientes a la hora de interpretar las causas de daño. Para este estudio nos basamos en las asignaciones terminológicas allí propuestas y, de acuerdo con Jurmain (2001), se buscaron los siguientes atributos: asimetría bilateral, deformación angular y callosidad ósea.

Siguiendo la metodología de Lovejoy y Heiple (1981), sólo fueron incluidos para este estudio los huesos largos que tuvieran más de los $2 / 3$ presentes y alguna de sus áreas articulares bien preservadas. De esta manera, se seleccionó una muestra de individuos adultos de ambos sexos, de acuerdo con la recomendación para estudios de trauma de Edynak (1976), quedando conformada por 18 individuos (10 masculinos y 8 femeninos).

Los traumas de ruptura en el esqueleto ocurren como consecuencia de fracturas y fisuras. El diagnóstico de este tipo de traumas se efectuó por 
observación macroscópica siguiendo las propuestas de Lovell (1997) y Jurmain (2001).

Los datos contenidos en la muestra de SR1 fueron volcados en una base de datos de acuerdo a la lateralidad y a la localización (proximal, medial y distal) de cada lesión (amputación, fractura, cicatriz de fractura, luxación y trepanación) por elemento óseo.

Fracturas por Compresión

Se analizaron 224 vértebras completas o fragmentadas, correspondientes a 16 individuos adultos de la colección SR1.

\subsubsection{Nódulos de Schmorl}

Los nódulos de Schmorl se reconocen por presentar una pequeña depresión irregular, de bordes redondeados, en el área central del cuerpo vertebral. Esta afección puede aparecer en forma simultánea en la cara superior e inferior del cuerpo vertebral, o sólo en una de sus superficies articulares. Generalmente, este hundimiento manifiesta una coloración oscura que facilita su identificación. Sobre una muestra de siete columnas adultas observadas (tres correspondientes a individuos masculinos y cuatro a femeninos, con un rango etario de 22 a 38 años) se realizaron 185 observaciones sobre las superficies superior e inferior de 93 cuerpos vertebrales.

\subsubsection{Artropatías}

Para el estudio de este indicador, se consideraron todas las articulaciones disponibles de los adultos de la colección y se organizaron los datos según su grado de afección, de acuerdo a las categorías elaboradas por Walter Neves y María Antonieta Costa (1999a):

Trazo: inicio de porosidad sobre la superficie de la articulación, en áreas puntuales.

Moderado: margen afectado por la porosidad hasta el $50 \%$ de la superficie.

Acentuado: margen afectada por una porosidad superior al $50 \%$ de la superficie del hueso.

Severo: superficie deformada por la porosidad, la exostosis y lo anquilosis. 
Se analizaron 306 superficies articulares, correspondientes a 11 individuos adultos de ambos sexos, 5 masculinos y 6 femeninos, de un rango etario que ocupa entre los 17 y 38 años.

\subsection{Osteofitos}

Se organizó la columna en sus tres segmentos cervical, toráxico y lumbar y se recuperó macroscópicamente la información, de acuerdo a los bordes superiores e inferiores, considerando los siguientes grados de afección:

Trazo (1): formación de labios discretos en el margen Moderado (2): labio que ocupa hasta la mitad de extensión del margen;

Acentuado (3): osteofitos generalizados horizontales;

Severo (4): osteofitos grandes, verticales o entrecruzados y/o anquilosados. 


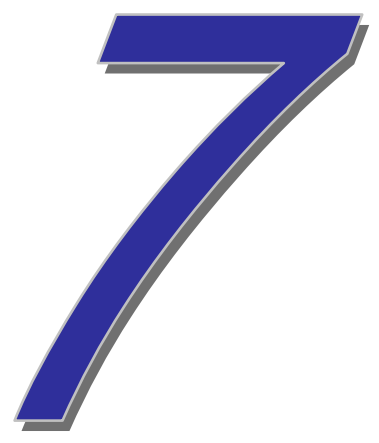

RESULTADOS 


\subsection{RESULTADOS}

\subsubsection{Indicadores de Salud}

\subsubsection{Talla}

De acuerdo a los autores Feldesman, Kleckner y Lundi, la longitud femoral corresponde al $26,74 \%$ del total de la talla (Feldesman et al. 1990), pudieron registrarse estas medidas en sólo dos individuos, los resultados se exhiben en la tabla siguiente (Tabla 7.1).

TABLA 7.1. Longitud Femoral (En Mm) Por Sexo Y Edad.

\begin{tabular}{c|c|c|c|c}
\hline INDIVIDUO & SEXO & EDAD & LONG.FEM & \multicolumn{1}{|l}{ TALLA } \\
CSLCULADA
\end{tabular}

\subsubsection{Dimorfismo Sexual -DS-}

Sobre 15 fémures adultos de ambos sexos (8 masculinos y 7 femeninos), se obtuvieron los valores expresados en la Tabla 7.2.

El Dimorfismo Sexual obtenido según el método de Hamilton (1975) es de 13,5.

TABLA 7.2. Medidas De La Cabeza Femoral (en mm)

\begin{tabular}{c|c|c|c}
\hline $\begin{array}{c}\text { Individuos } \\
\text { Masculinos }\end{array}$ & DMF & $\begin{array}{c}\text { Individuos } \\
\text { Femeninos }\end{array}$ & DMF \\
\hline II & 45 & III & 37 \\
Vii & 41 & Va & 36 \\
VIIIs & 45 & VIIIs & 37 \\
VIII0 & 40 & IX & 39 \\
X & 40 & XII & 36 \\
XVIII & 40 & XIII & 38 \\
XX & 45 & XXII & 36 \\
XXVII & 40 & & \\
\hline
\end{tabular}

Los valores del DMF, por grupo sexual, se representan gráficamente en la Figura 7.1. 


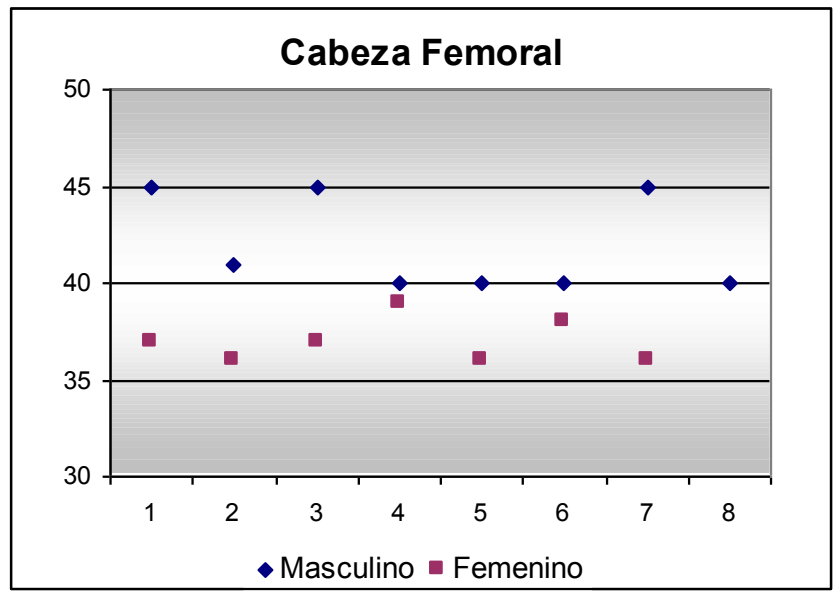

Figura 7.1. Diámetro máximo de la cabeza Femoral

Se observa que existe una diferencia en los valores medios, según la variable sexo, correspondientes al diámetro máximo de cabeza femoral (Figura 7.1. y Tabla 7.3.).

En cuanto a las medidas de valores máximos y mínimos para los valores de las variables según el sexo, no existe solapamiento, siendo menor (en un rango igual a 1) el valor máximo correspondiente a los individuos femeninos menor al valor mínimo de los individuos masculinos.

TABLA 7.3. Estadística Descriptiva Dmf

\begin{tabular}{l|cc}
\hline \multicolumn{1}{c|}{ Medidas } & M & F \\
\hline Medias & 42 & 37 \\
Mediana & 40,5 & 37 \\
Desviación estándar & 2,51 & 1,15 \\
Rango & 5 & 3 \\
Mínimo & 40 & 36 \\
Măximo & 45 & 39 \\
\hline
\end{tabular}

Para analizar la igualdad de las distribuciones de estos datos se aplicó el test U Mann Withney para muestras independientes. Este test fue aplicado debido a que ambas muestras presentan un tamaño reducido (menos que 10 elementos 
cada una, $\mathrm{n} 1=8$ y $\mathrm{n} 2=7$ ) y no pudiendo garantizarse el supuesto de la distribución normal de la variable. El resultado de la variable PIVOTAL fue $W=28$, con $p<0,0003$, es decir, que ambos sexos presentan diferencias significativas en cuanto a sus distribuciones con una confianza del 99,97\%. En otras palabras, indicaría que la población de Santana do Riacho presentaba un dimorfismo sexual significativo.

\subsubsection{Condición General de la Denticion}

Las categorías de pérdidas post mórtem y piezas fragmentadas corresponden a perturbaciones de origen tafonómico con una prevalencia de $15,22 \%$ en el primer caso y de un $17,93 \%$ en el segundo.

Vinculada parcialmente a esta patología consideramos las pérdidas ante mortem de elementos dentales y observamos que de 9 adultos -3 masculinos y 6 femeninos- solo un masculino presenta pérdida ante mortem en 3 elementos dentales.

La categoría de ausencia congénita o agenesia, se presentó en dos individuos adultos sobre 16 observados. Estos individuos, estimados en una edad esqueletal de 22 años, sugieren que, por su edad podrían tratarse de casos con molares aún no erupcionados, pero para verificar esta posibilidad se hubiera requerido de la realización de placas radiográficas, lo que no fue posible de hacer.

No se presentaron casos de pérdida de coronas por caries, ni se evidenciaron antiguos tratamientos de terapias odontológicas.

\subsubsection{Indicadores Patológicos}

\subsubsection{Hipoplasias Dentales}

Conforme se muestra en la Tabla 7.5., se observaron diez individuos de ambos sexos y de todos los grupos etarios. De los 10 niños, sólo un caso - un niño de seis años- presentó hipoplasias lineales (individuo XIXb). En este individuo las hipoplasias de esmalte dental se presentan de manera simétrica, afectando solamente a caninos e incisivos centrales permanentes en erupción. Los adultos por otro lado, no presentaron evidencia de ésta afección. 
TABLA 7.4. Frecuencias De Hipoplasia De Esmalte Dental

\begin{tabular}{|c|c|c|c|c|c|c|c|c|c|c|}
\hline \multirow{3}{*}{ INDIVIDUO } & \multirow{3}{*}{ SEXO } & \multirow{3}{*}{ EDSD } & \multicolumn{4}{|c|}{ c } & \multicolumn{4}{|c|}{ IC } \\
\hline & & & \multicolumn{2}{|c|}{ SUP } & \multicolumn{2}{|c|}{$\mathrm{IN}=$} & \multicolumn{2}{|c|}{ SUP } & \multicolumn{2}{|c|}{$\mathrm{IN}=$} \\
\hline & & & 0 & $I$ & 0 & $I$ & 0 & I & 0 & $I$ \\
\hline II & $M$ & A & 0 & - & - & - & - & - & - & - \\
\hline III & $F$ & A & - & - & 0 & - & 0 & - & - & - \\
\hline$V a$ & $F$ & A & 0 & 0 & 0 & 0 & 0 & 0 & 0 & 0 \\
\hline VIIb & I & J & - & 0 & - & - & 0 & 0 & - & - \\
\hline$x$ & $F$ & J & 0 & 0 & 0 & 0 & 0 & 0 & - & - \\
\hline$x / 1=$ & $F$ & J & - & - & - & - & 0 & 0 & - & - \\
\hline XVIII & I & I & - & - & - & - & 0 & - & - & - \\
\hline $\mathrm{XIX}=$ & I & I & 0 & - & - & 0 & 0 & - & 0 & 0 \\
\hline$x \mathbb{X x b}$ & I & I & 1 & 1 & 0 & 0 & 1 & 2 & 0 & 0 \\
\hline XxII & $F$ & I & 0 & 0 & - & - & 0 & 0 & - & - \\
\hline
\end{tabular}

Referencias de la tabla 7.4

$\mathrm{C}=$ canino, $\mathrm{IC}=$ incisivos centrales, $\mathrm{D}=$ derecho, $\mathrm{I}=$ izquierdo

Sexo: $M=$ masculino, $F=$ femenino, $I=$ indeterminado

Edad: $\mathrm{A}$ = adulto, $\mathrm{J}=$ juvenil, $\mathrm{I}=$ infantil

0 =ausencia de patología, =presencia de patología,

- =ausencia de registro

\subsubsection{Cribra Orbitalia - Hiperostosis Porotica}

Dos individuos exponen evidencias claras de estas afecciones. Solo un individuo adulto de sexo femenino (Va) presentó hiperostosis porótica sobre la bóveda craneana (Figura 7.2.) y un individuo infantil (XI), cribra orbitalia, lo cual corresponde a una prevalencia del $22,2 \%$ en la población. 


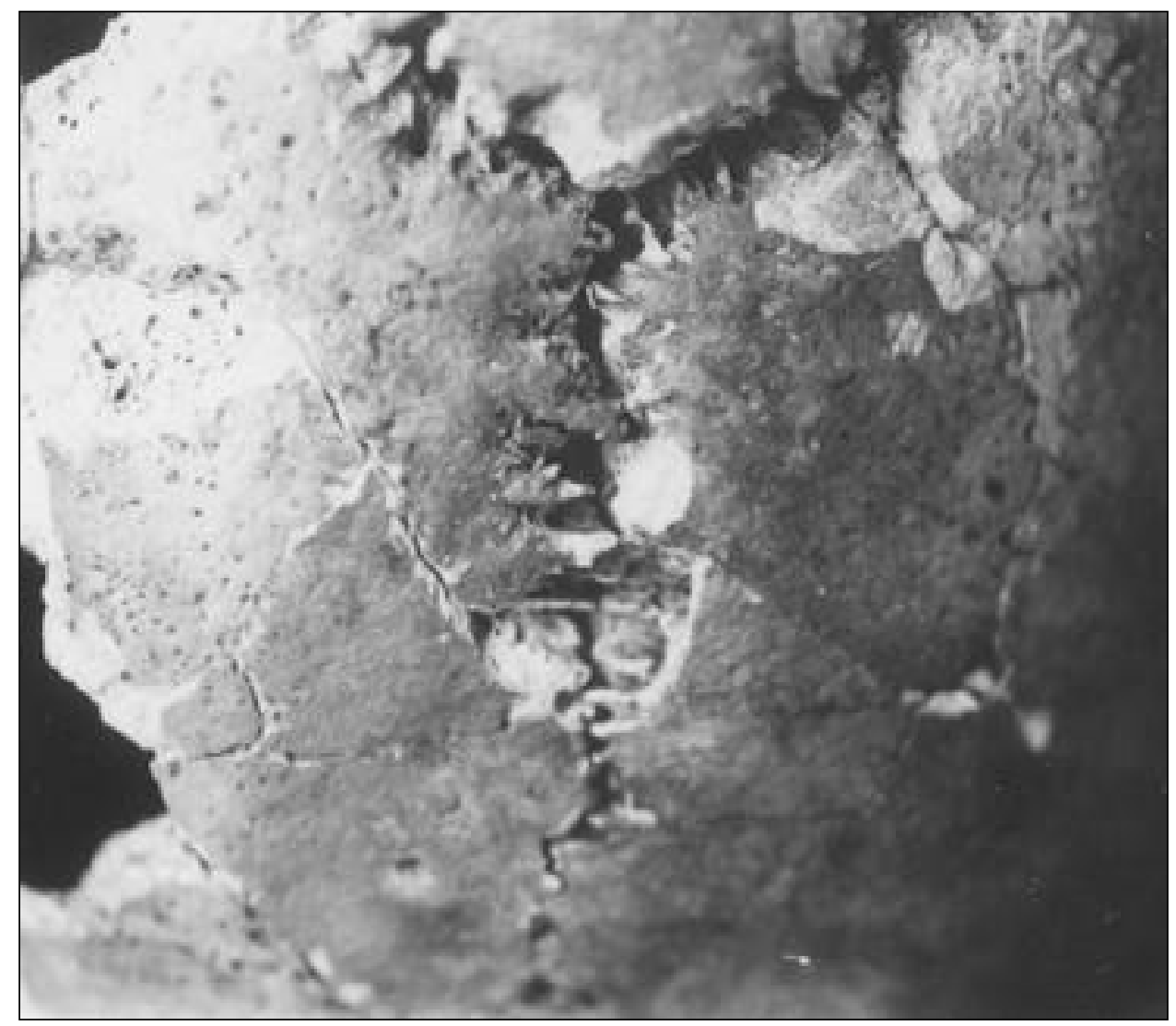

Figura 7.2. Individuo Va. Hiperostosis porótica sobre el parietal izquierdo

Los individuos analizados no presentan evidencias de raquitismo, osteomalacia, escorbuto o cualquier otro desorden de origen nutricional.

\subsubsection{Patologías de Origen Infeccioso: Infecciosas Inespecíficas}

Las lesiones reabsorbidas representan lesiones en el disco vertebral, en los cuales se ha dado un proceso de remodelación ósea a través de la actividad osteogenética que evidencia un período de supervivencia después del episodio de infección. Los grados de prevalencia hallados pueden verse en la Tabla 7.6. De los 21 individuos observados, 12 corresponden a adultos, de los cuales cuatro de los que presentan afecciones corresponden al grupo de adultos maduros y uno al grupo de adultos jóvenes. 
TABLA 7.5. Distribución de Afecciones por Individuo, Sexo, Edad y Localización Anatómica.

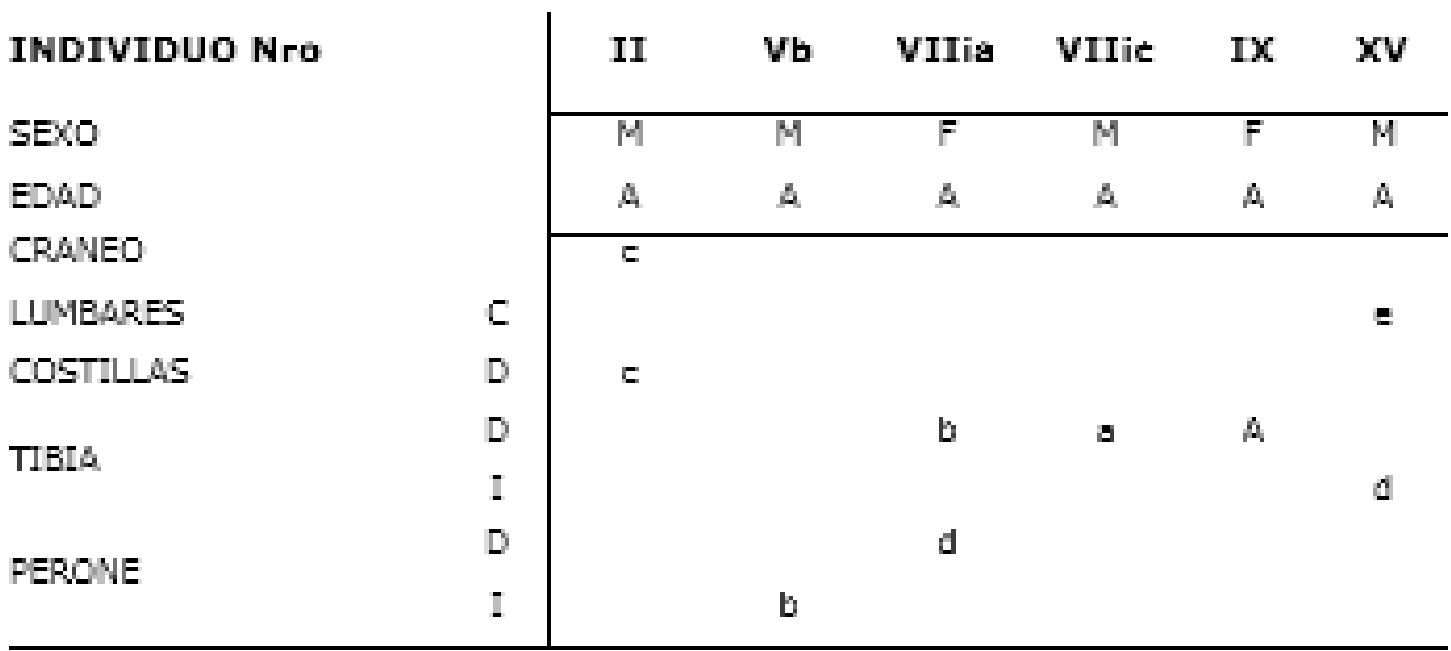

Respecto de los nueve infanto-juveniles observados, sólo uno presentó lesiones. Es decir que, de los 21 individuos observados, 6 presentaron lesiones, lo que corresponde a un $28,6 \%$ sobre el total. Esto indica que la manifestación de este indicador en ambos sexos no constituyó diferenciación considerable ( 3 masculinos -2 femeninos -1 indeterminado).

De las nueve lesiones observadas en cinco individuos de ambos sexos, seis afectaron solamente a tibia y peroné.

El individuo masculino II (Figura 7.3.) expone una lesión osteomielítica en las costillas, en su articulación con el esternón, pero dado el grado de fragmentación de este material, sólo podemos decir que la afección lesionó moderadamente las caras anterior y posterior. En este mismo individuo se registra, también, la presencia de un proceso infeccioso localizado en el maxilar.

La Figura 7.4. representa a un adulto masculino, cuyo peroné izquierdo presenta una afección periostítica extensa. Desafortunadamente, de este individuo no se conservaron otros elementos de los miembros inferiores. 


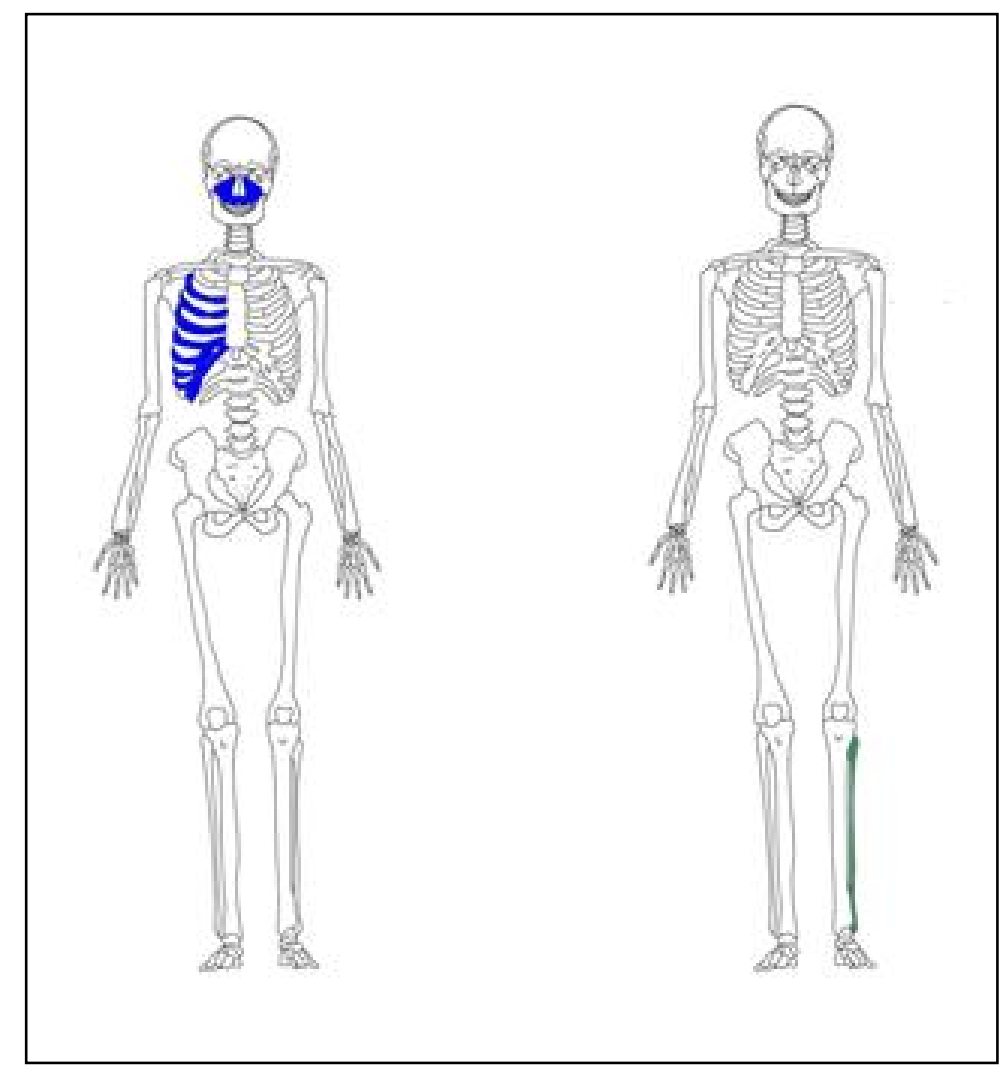

Figura 7.3 Izq. Afecciones Infecciosas en el individuo II. Figura 7.4 Der. Afeccion Infecciosa localizada en el individuo Vb.

La tibia y el peroné derechos del individuo VIlia, (Figura 7.5.) correspondiente a un hombre de una edad estimada en los 37 años, exponen un claro proceso inflamatorio, caracterizado por alteración morfológica, con superficie de aspecto rugoso y poroso compatible con periostitis y la presencia de orificios y cloacas de drenaje para la supuración, característicos de los casos de osteomielitis.

La tibia del mismo individuo (VIlia) presenta un engrosamiento del tejido cortical, notable además por su peso y por un aumento de volumen y remodelación. El peroné se presenta como un caso mas crítico, con aumento del diámetro diafisiario, presencia de cloacas y pérdida de la cavidad medular por depósito de materia ósea a causa de un incremento del tejido trabecular (Figuras 7.7 y 7.8 ). 


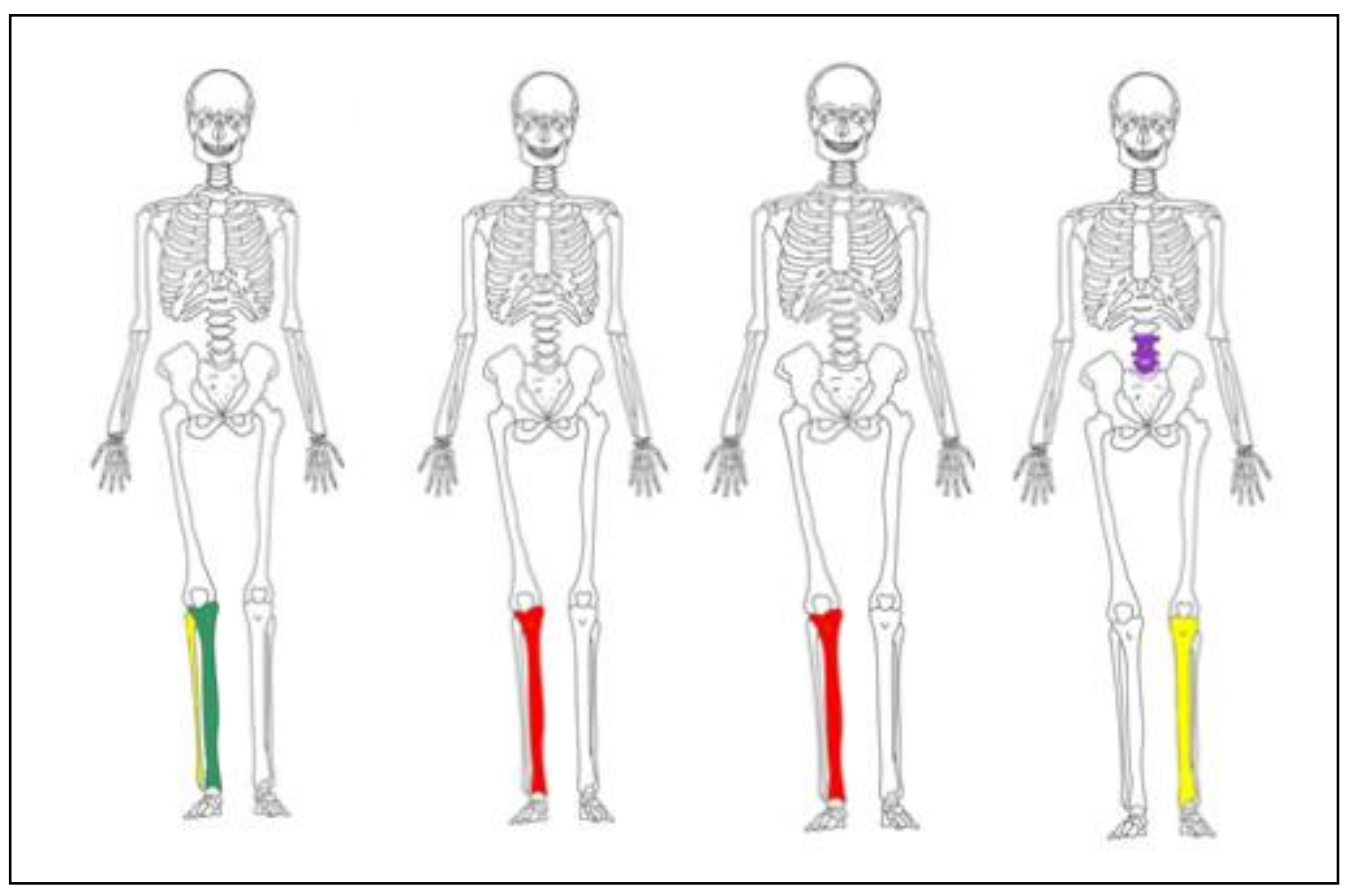

Figura 7.5 a. Afecciones Infecciosas en VIlia. b. Afecciones Infecciosas en VIlic C. afecciones infecciosas en IX d. Afecciones infecciosas en XV

Este cuadro infeccioso puede estar directamente relacionado con efectos postraumáticos. De acuerdo con Steinbock (1976), podría estar causado por Staphylococcus aureus, como en la mayoría de las infecciones de origen traumático.

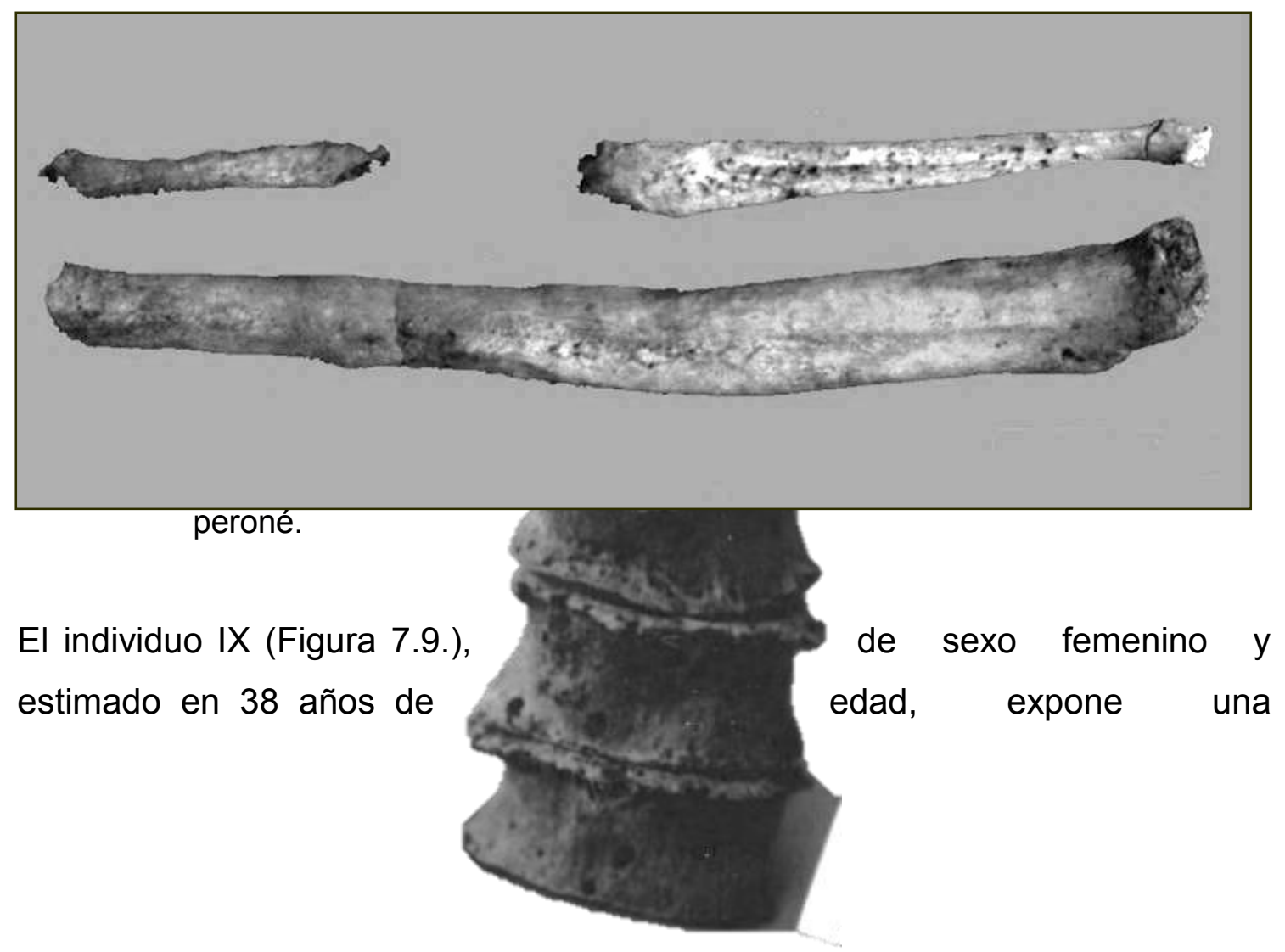


periostitis localizada en el tercio distal de la tibia derecha, sin claras evidencias de tratarse de un caso producido por consecuencias traumáticas. La ausencia del peroné derecho no nos posibilitó evaluar mejor el cuadro.

Figura 7. 7a. Osteofitos lumbares en el Individuo XV

El individuo XV (Figura 7.10.), un hombre adulto de 33 años estimados, presenta una osteomielitis extensa en la tibia izquierda, sin vinculación traumática aparente. En la columna, los cuerpos vertebrales de las lumbares exponen signos de un proceso de reabsorción.

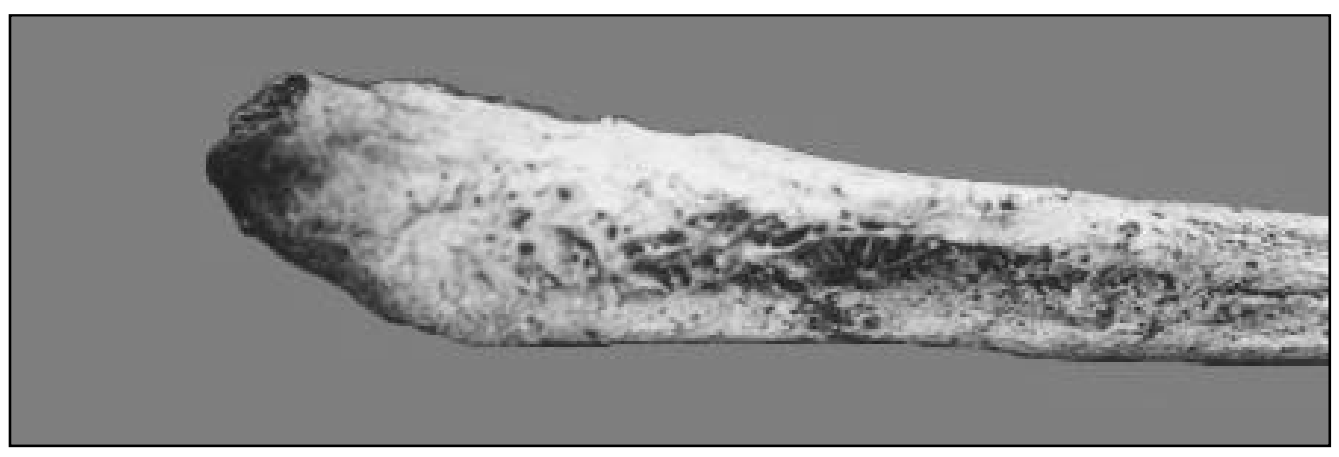

Figura 7.8 Individuo Vllia. Detalle del peroné.

Según las consideraciones de Larsen (1997), que preveen una mayor sensibilidad de afección en tibias, vemos que la muestra de Santana do Riacho 
I no escapa a lo esperado, dado que el $44,5 \%$ de las afecciones infecciosas se expresa en el hueso tibial.

Los individuos observados no evidencian signos de haber padecido enfermedades infecciosas de tipo sistémico.

\subsubsection{Patologias Infecciosas Específicas}

No se registraron evidencias osteológicas de afecciones sistémicas compatibles con patologías como treponematosis, tuberculosis o neumonía.

\subsection{Caries}

La prevalencia cariogénica que resulta de la distribución porcentual de frecuencias de la muestra, fue del $10,5 \%$.

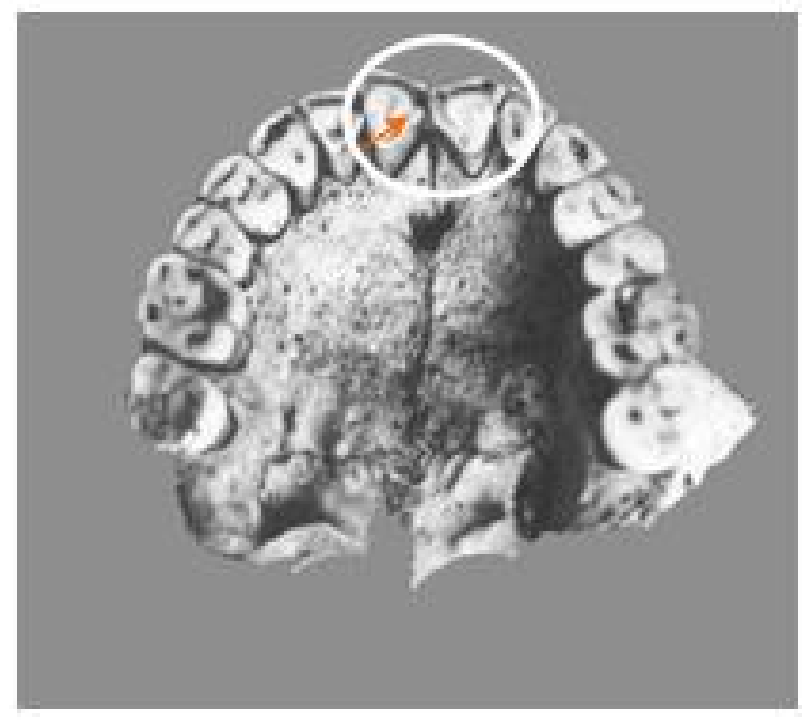

Figura 7.11. Caries oclusal del incisivo central izquierdoen el Individuo Va.

La mayor representación se encuentra entre los adultos jóvenes, no siendo distintiva la diferencia entre los sexos (Neves y Cornero, 1997). No se registraron otras lesiones infecciosas como el caso de abscesos alveolares.

TABLA 7.6 Distribución de Caries por Elemento Dental 


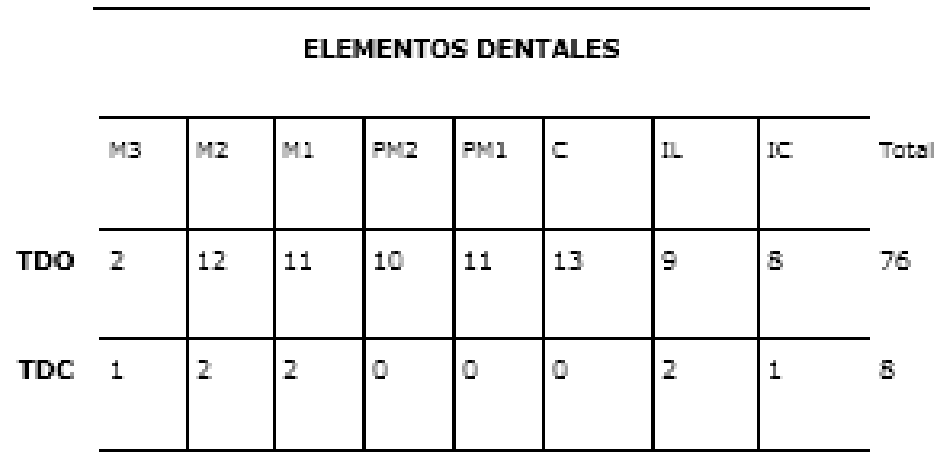

Referencias de la Tabla 7.6

TDO $=$ total de dientes observados - TDC $=$ total de dientes cariados

\subsection{Periodontitis}

Se observaron las dentaduras de 7 individuos adultos de ambos sexos, de los cuales solo un masculino adulto presentó, en grado incipiente, evidencias de lesiones periodontales.

\subsubsection{Traumas}

Se analizaron 1219 huesos adultos de sexo conocido. Se observó que el total de los traumas correspondió a fracturas, las cuales se presentaron con una frecuencia del $1 \%$ de elementos observados.

Sobre 18 individuos analizados 6 casos presentaron lesiones traumáticas, lo cual equivale al 33,3\% de individuos de la muestra.

La Tabla 7.8. presenta la distribución de frecuencias de lesiones traumáticas sobre, el total de elementos por región anatómica.

TABLA 7.7. Distribución Porcentual De Lesiones Traumáticas 


\begin{tabular}{l|c}
\multicolumn{1}{c|}{ Región anatómica } & Porcentajes \\
\hline Cabezs $\gamma$ cuello & 0,16 \\
Tórax & 0,25 \\
Cinturs escopular $\gamma$ brazos & 0,16 \\
Manos & 0,10 \\
Pelvis & 0,10 \\
Piernss & 0,25 \\
Pies & 0 \\
\hline
\end{tabular}

El $41,6 \%$ del total de huesos que presentan lesiones, corresponden al grupo masculino y el $58,3 \%$ al grupo femenino.

El individuo Va corresponde al sexo femenino y se estima una edad media esqueletal de 22 años. Representa un caso de politraumatismo en esternón, cráneo y falange.

Los traumas no otorgan evidencias suficientes que puedan asociarlos al mismo evento de origen.

El manubrio esternal expone una línea irregular de fractura transversa en la región inferior. Se trata de una fractura incompleta, cicatrizada con efectos de remodelación poco deformantes (Figura 7.12.).

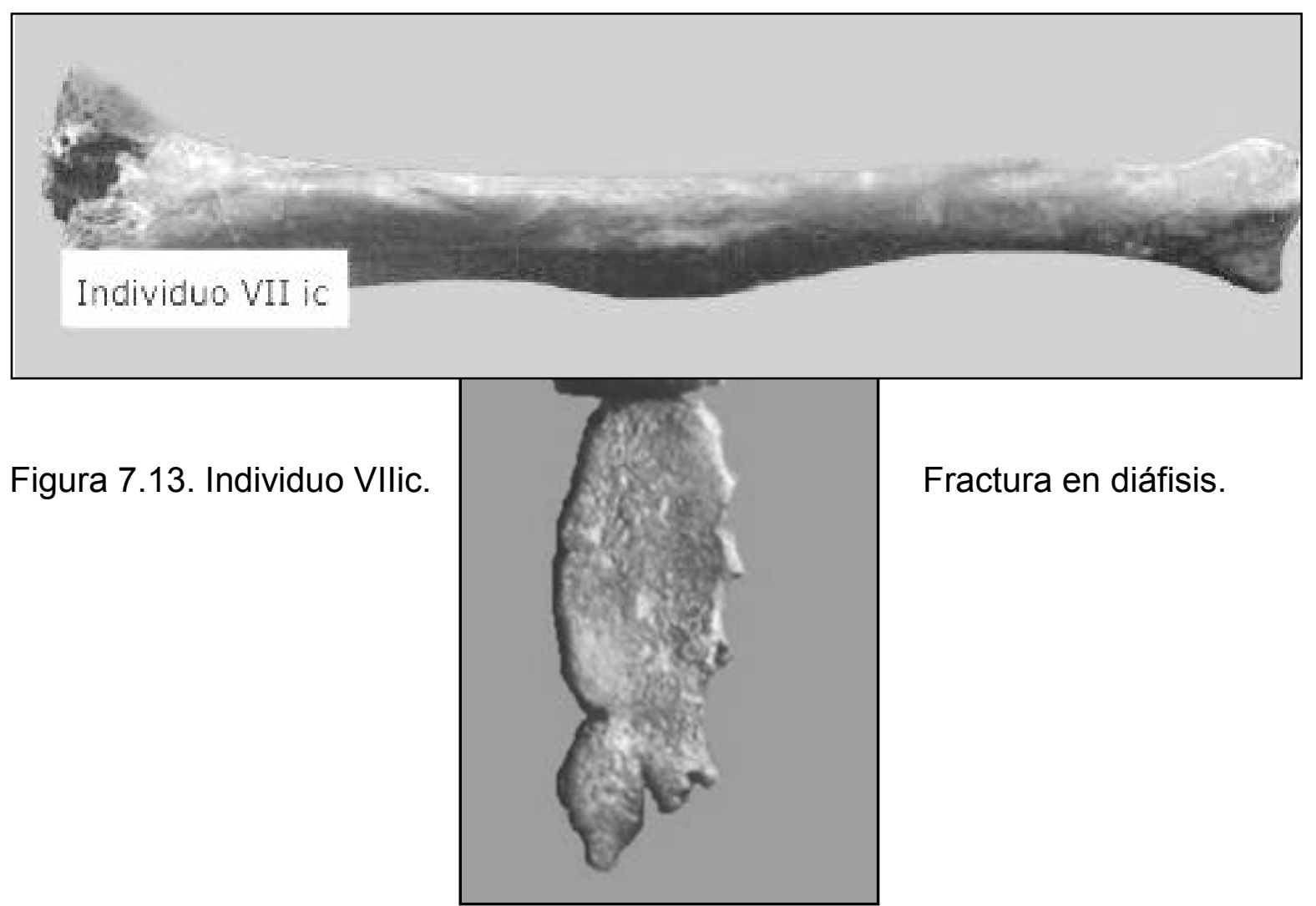


Figura 7.12. Esternón afectado en el Individuo Va

El proceso xifoideo presenta una alta variabilidad epigenética (White, 2000). Expone, en este caso, una fisura de fusión incompleta, de acuerdo a la tipología que presenta Barnes (1994). La relación entre fracturas y huesos largos es de 1,6\% (1/62) para masculinos y del 5,6 \% (3/53) para femeninos, resultando un total del 3,5\% (4/115) de lesiones.

La muestra está representada por individuos cuyo rango etario estimado oscila entre los 14 y los 38 años. Se observa un incremento en la presencia de fracturas, en relación directa con el incremento en edad. No se observan fracturas específicas relacionadas con grupos de edad, ni asociadas con la madurez, como las fracturas de cuello femoral o intertrocantéricas (Cornero y Neves, 1999).

Dos de los individuos lesionados (el XV de sexo masculino y el IX de sexo femenino), presentan fracturas múltiples. El individuo VIlic (Figura 7.13.) presentó una fractura en tibia derecha, con subsecuente remodelación ósea.

El individuo VIlia presentó fracturas en tibia y peroné, con infección localizada en la tibia. La distribución de frecuencias de individuos afectados es similar en ambos sexos. El Test Exacto de Fisher (Tabla 7.9) indica que las fracturas no estuvieron asociadas al sexo $(P=1,000)$. 
TABLA 7.8. Distribución de Fracturas por Sexo

\begin{tabular}{l|c|c|c}
\hline SEXO & $\begin{array}{c}\text { FRECUENCIA } \\
\text { ABSOLUTA }\end{array}$ & $\begin{array}{c}\text { FRECUENCIA } \\
\text { PORCENTUAL }\end{array}$ & $\mathrm{N}$ \\
\hline MASCULINO & 3 & 30 & 10 \\
FEMENINO & 3 & 37.5 & 8 \\
TOTAL & 6 & 50 & 18 \\
\hline
\end{tabular}

Lovejoy y Heiple (1981) también observan en los cazadores del sitio Libben, que la distribución de daños traumáticos entre sexos es igualitaria, por lo que las atribuyen a causas accidentales en cacerías y traslados. En este caso, por sus características, todas las evidencias de fracturas encontradas indican un origen no intencional.

No existe un patrón común a determinado elemento anatómico, ni se presentan reincidencias en el tipo de fracturas. La muestra tampoco expone evidencia de lesiones ocasionadas por agresión interpersonal como indicarían los marcadores de violencia conocidos en la literatura americana, tales como los percussion pit, crushing, cutmarks, chopmarks e indicadores de hundimiento craneal, fracturas de Parry, escalpe, amputación, mutilación o canibalismo.

\section{Fracturas por Compresión}

Se reportaron tres casos de fracturas por compresión, una en el individuo II y las otras dos en la columna del individuo XV. El individuo II tiene afectada la primera cervical. Las fracturas del individuo $\mathrm{XV}$, de compresión mínima, se localizan sobre los cuerpos vertebrales de la décimosegunda toráxica y sobre la segunda lumbar (Figura 7.14.). 


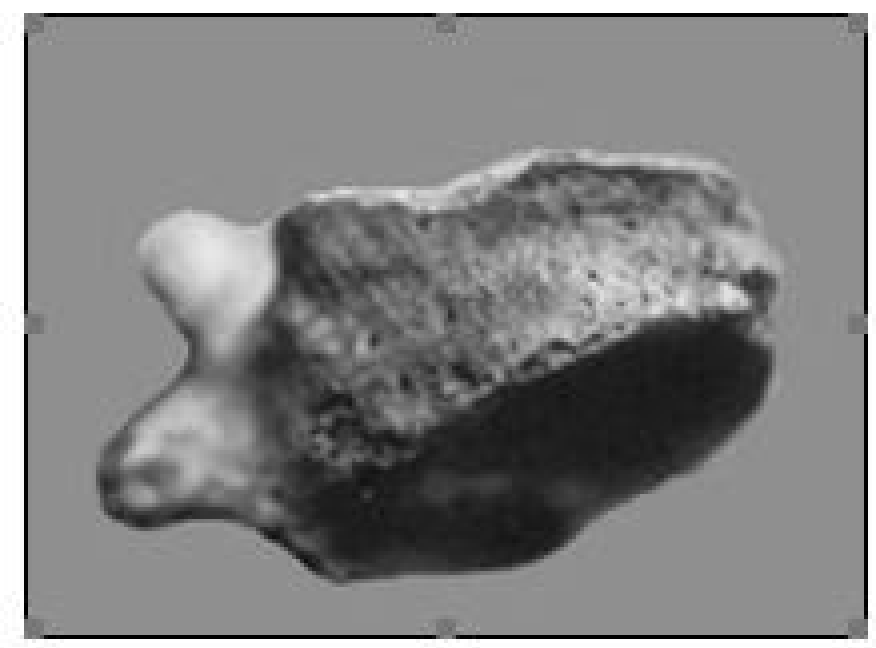

Figura 7.14. Vértebra toráxica con fractura de compresión del Individuo XV

\subsubsection{Nódulos de Schmorl}

Sólo se detectó la presencia de nódulos de Schmorl en un individuo - Va, femenino de 22 años (Figura 7.15)-.

Estos nódulos se localizan entre la décima toráxica y la tercera lumbar. Se presentan como pequeñas depresiones irregulares en las superficies centrales de los cuerpos vertebrales y, en algunos casos, se acompañan de una coloración más oscura en su contorno.

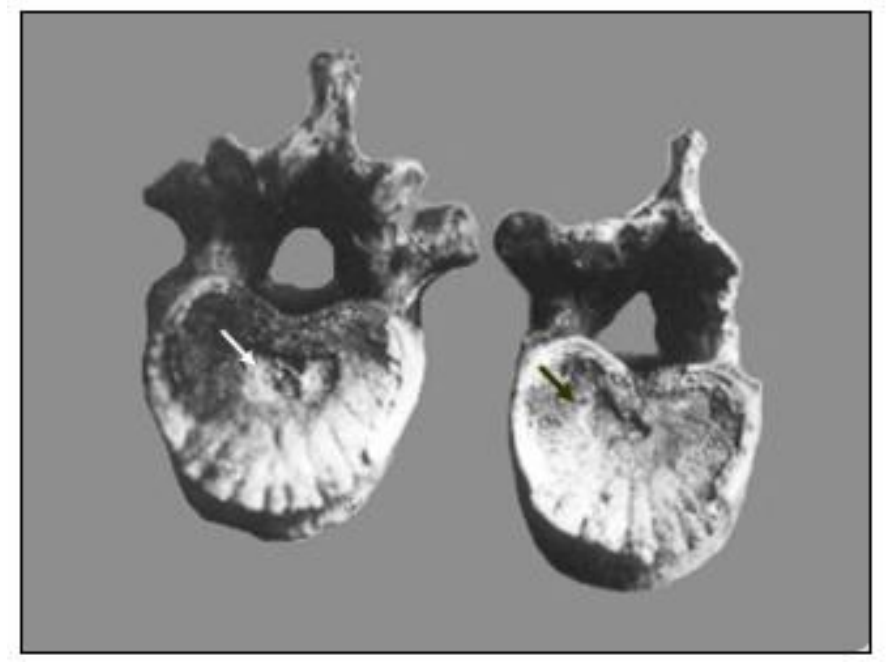

Figura 7.15 Nódulos de Schmorl en el Individuo Va 
No se detectaron nódulos de Schmorl en individuos masculinos, como así tampoco en los individuos de mayor edad.

\subsubsection{Artropatías}

De las 306 superficies articulares observadas el 11,11\% (34/306) presentaron evidencias artropáticas asignadas a casos de osteoartritis, correspondientes a cinco individuos, 2 femeninos (IX y XII), y 3 masculinos (II, VIlic y XV). Los individuos afectados pertenecen al grupo de adultos mayores de 33 años. Dos individuos de edad madura (IX y XV), exponen evidencias de osteoartritis generalizada, de distribución lateral simétrica, manteniendo un grado incipiente de afección en la mayoría de los elementos afectados.

Las afecciones artrósicas observadas en Santana do Riacho 1 se distribuyen, principalmente, en el esqueleto apendicular involucrando especialmente a las rodillas y codos (Figura 7.16.).

El $42 \%$ de las artropatías exponen un grado de afección inicial, el 18,2\% moderadas, el $3 \%$ acentuadas y el $6 \%$ severas.

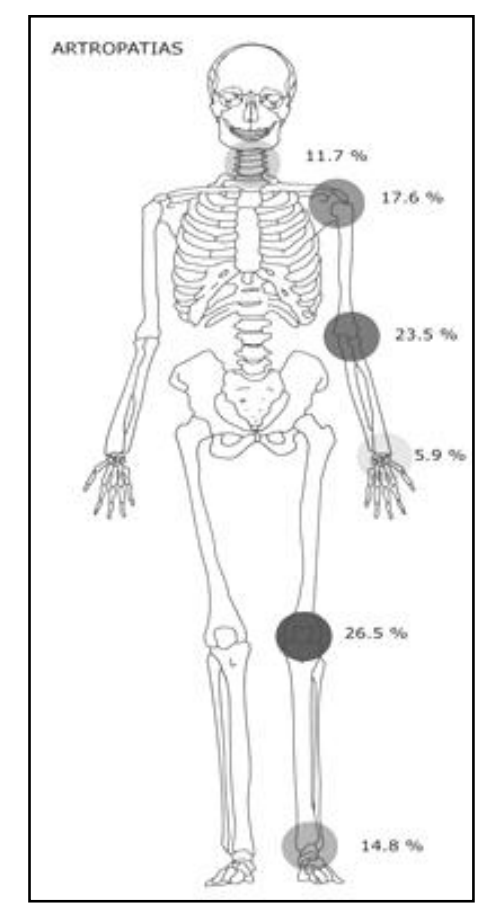

Figura 7.16 Distribución de las lesiones artropáticas por articulación 
A su vez, la distribución sexual de esta patología en SR1 se representa afectando mayormente la articulación del hombro y muñeca en los individuos masculinos, y el resto de las afecciones se observan distribuidas equilibradamente en ambos sexos, como puede verse en la Tabla 7.10.

TABLA 7.9. Distribución De Afecciones Artrósicas por Sexo

\begin{tabular}{|c|c|c|c|c|}
\hline \multirow[t]{2}{*}{$\begin{array}{c}\text { PARTE } \\
\text { ANATOMICA }\end{array}$} & \multirow[t]{2}{*}{$\begin{array}{l}\text { INDIVIDUOS } \\
\text { OBSERVADOS }\end{array}$} & \multicolumn{3}{|c|}{$\begin{array}{l}\text { INDIVIDUOS } \\
\text { AFECTADOS }\end{array}$} \\
\hline & & $F$ & $M$ & $\mathrm{~T}$ \\
\hline Cóndilo, atlas y axis & $\mathrm{s}$ & 1 & 1 & 2 \\
\hline Hombro & 9 & 0 & 3 & 3 \\
\hline Codo & 8 & 1 & 1 & 2 \\
\hline Muñeca & 7 & 0 & 2 & 2 \\
\hline Cadera & 5 & - & - & - \\
\hline Rodills & 11 & 1 & 2 & 3 \\
\hline Tobillo & 9 & 1 & 1 & 2 \\
\hline
\end{tabular}

\subsection{Osteofitos}

Se realizaron observaciones sobre 192 vértebras correspondientes a 7 individuos adultos entre 17 y 38 años de edad, de ambos sexos (2 masculinos y 5 femeninos) (Tabla 7.11).

TABLA 7.10. Distribución de Osteofitos por Segmentos Vertebrales

\begin{tabular}{ccccc}
\hline \multirow{2}{*}{ GRAdOS } & Vertebras & Vertebras & Vertebras & TOtal \\
& CERViCALES & TORAXICAS & Lumbares & \\
\hline 0 & 39 & 79 & 40 & 158 \\
1 & 7 & 10 & 5 & 22 \\
2 & 3 & 3 & 3 & 9 \\
3 & 3 & 0 & 0 & 3 \\
4 & 0 & 0 & 0 & 0 \\
\hline
\end{tabular}


De los siete individuos adultos observados, cuatro resultaron afectados, de los cuales dos corresponden al sexo femenino y dos al masculino. Los cuatro se estimaron entre 22 y 38 años de edad.

Las vértebras cervicales se vieron más afectadas en el grupo femenino. Los osteofitos se manifestaron más en los sectores dorsales y en los sectores lumbares de los individuos masculinos. 


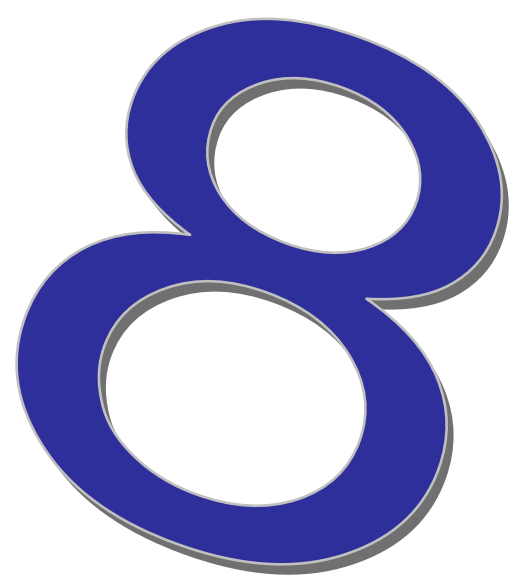

DISCUSION Y

CONCLUSIONES 
Los hombres de Lagoa Santa han sido motivo de estudio desde los tiempos en que Peter Wilhelm Lund descubriera sus restos a mediados del siglo XIX. Desde entonces y hasta el momento, el presente trabajo constituye el primer esfuerzo en comprender de una manera cuantitativa el costo biológico de las relaciones de estos grupos con su ambiente, medido en términos del status de salud y calidad de vida. Esto fue logrado a partir de los resultados obtenidos de la biología esqueletal, que posibilita inferir, a través del registro osteológico, la magnitud de las fuerzas que ejercieron las presiones selectivas y el modo en que el ambiente pudo haber impactado sobre la población de Santana do Riacho (SRI).

Durante el proceso adaptativo, y debido a las posibles fluctuaciones ambientales, los grupos pudieron variar su grado de eficiencia adaptativa adquirida, que como habíamos visto, puede medirse en términos de salud. Ésto si consideramos que la salud constituye un efecto de la relación poblaciónmedio y por lo tanto ser un factor significativo para analizar la calidad de vida de las poblaciones.

En este sentido las patologías y alteraciones óseas fueron analizadas exhaustivamente, pero considerando en especial aquellas que reflejan aspectos adaptativos en términos sanitarios, funcionales, económicos, laborales o culturales, útiles para la interpretación del estilo de vida de cada grupo involucrado.

Se ha procurado tener en cuenta los parámetros e indicadores de tensión ambiental posibles de ser evaluados en la muestra de SRI, seleccionando aquellos que el registro nos posibilita trabajar, para volcar los resultados con un enfoque integral que pueda dar cuenta de una mayor aproximación al conocimiento del costo adaptativo particular del grupo en estudio y de sus implicancias en el estilo de vida local.

Los 13 marcadores óseos empleados permitieron estimar la fuerza del impacto ambiental y la resistencia que opusieron los hombres y las mujeres de esa población en pos de su supervivencia, durante la transición PleistocenoHolocénica. 
En este sentido se observa, en primer lugar, una discernible diferenciación de los caracteres sexuales secundarios, los cuales expresan, a través de rasgos como el ancho máximo de la cabeza femoral, un notable dimorfismo sexual. Esta tendencia dimórfica, que también se advirtió en la morfología craneal y pélvica, habla en este caso, en favor de un normal proceso de crecimiento y desarrollo, ya que como fue visto, la alteración, insuficiencia o inadecuación nutricional severa impacta significativamente en el normal proceso de crecimiento y desarrollo. Tal como lo demuestran estudios realizados en diversas poblaciones actuales, como por ejemplo, los estudios realizados en poblaciones marginales modernas por Pucciarelli et al. $(1995,2005)$.

La influencia del estrés ambiental sobre el dimorfismo sexual se manifiesta claramente sobre la variación estatural, cuya potencialidad es sexualmente selectiva e inversamente proporcional al grado de estrés nutricional. De los dos casos de adultos observados en Santana do Riacho I, el individuo masculino alcanzó una estimativa, estatural notablemente mayor (12\%) que el femenino.

Otras manifestaciones actúan en forma directamente proporcional respecto del potencial grado de estrés. En éste rango se ubican afecciones que padecieron las poblaciones primitivas y parte de las cuales fueron detectadas en la población aquí estudiada. En líneas generales, el esqueleto apendicular en Santana do Riacho se muestra sano y fuerte, según se observa por el relieve de sus inserciones musculares, lo cual indica un normal proceso de desarrollo esquelético.

Si bien no es sencillo pensar en una distribución del trabajo por sexos por causa de las limitaciones que ofrece el registro, algunas inferencias útiles pueden ser realizadas. En términos de una aproximación, esta división podría verse reflejada por diferencias entre dos biomarcadores analizados de la columna vertebral: los osteofitos, que sólo presentan una afección levemente mayor en el segmento toráxico masculino respecto del femenino y más sutilmente en las afecciones de osteoartrosis (dos veces mayor en masculinos). Como se ha visto, los hombres de Santana do Riacho I presentan una notable robustez, que no alcanza un desarrollo entesopático.

En suma, estos elementos parecerían indicar un compromiso corporal con el medio levemente mayor en los hombres que en las mujeres. 
Asimismo, las patologías de origen metabólico, que pueden dar cuenta de alteraciones nutricionales, se representan con una baja prevalencia en la muestra.

Si tenemos en cuenta el rango de prevalencias observadas de patologías nutricionales en grupos de diferentes hábitats y sistemas económicos, podemos ubicar comparativamente los resultados observados en el grupo de Santana do Riacho con valores de prevalencia moderada.

A modo de comparación, la población arcaica de cazadores-recolectores de Punta Teatinos (Chile) presentó un 6\% de frecuencia de hiperostosis porótica, mientras que una población agrícola del mismo lugar careció por completo de esta afección (Quevedo, 1998). Asimismo, en un grupo de cazadores recolectores de la región pampeana (Argentina) se reportó ausencia de casos para la afección mencionada (Barrientos, 1994). Lo mismo ocurre con los cazadores de la región de Cuyo (Novellino et al., 1996) que se muestran como modelos de poblaciones con prevalencias bajas de afecciones de origen metabólicos.

Si a la vez consideramos a los grupos agro-alfareros del sitio de Las Pirguas (57\%) (Baffi y Cocilovo, 1989) y a los cazadores pescadores del litoral fluvial de los pantanales del río Paraná, en su sector medio (> 50 \%) (Cornero y Puche, 2002) como prevalencias elevadas, podríamos establecer que los indicadores de estrés nutricional en Santana de Riacho I alcanzaron valores moderados, con un $11 \%$ de hiperostosis porótica y cribra orbitalia (Figuras 8.1. y 8.2.).

El modelo etiológico de infecciones parasitarias supone que la deficiencia de hierro es responsable, causando a modo de consecuencia, graves infecciones parasitarias. La parasitosis intestinal es de amplia distribución, especialmente en áreas tropicales y subtropicales (Layrisse y Roche, 1964). Asimismo, se registraron casos en el litoral brasilero de acuerdo a la información suministrada por Walter Neves. 


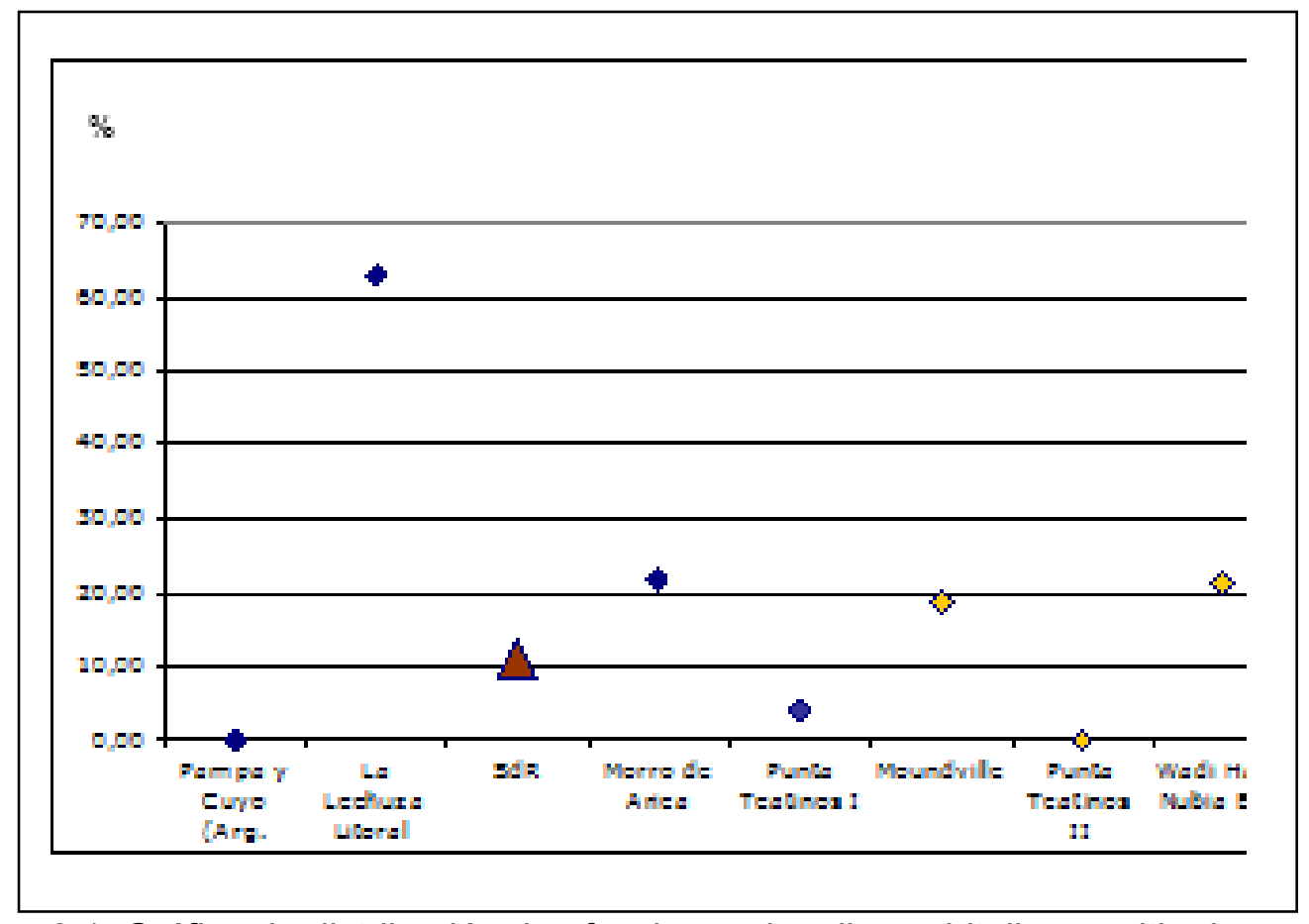

Figura 8.1. Gráfico de distribución de afecciones de cribra orbitalia por sitio de acuerdo a sus estrategias económicas (Cazadores- recolectores=u y Agricultores=u)

Inferimos a modo de conclusión, que las condiciones higiénicas y sanitarias en Santana do Riacho fueron lo suficientemente aceptables como para no comprometer a la población con efectos patológicos graves.

Los marcadores dentarios son de suma importancia en los estudios de calidad de vida. En el caso de nuestra muestra, la hipoplasia de esmalte dental se evidenció sólo en un individuo y, dado que se trata de un marcador cuyo origen puede deberse a múltiples causas, su presencia podría atribuirse a un episodio particular, posiblemente vinculado con detención de crecimiento por alteración nutricional o con padecimiento eventual de altas fiebres, a consecuencia de un posible cuadro infeccioso.

Otro indicador sensible, en términos de calidad sanitaria ambiental, fue la baja frecuencia de muertes perinatales $(5 \%)$ y durante la primera infancia $(7,5 \%)$. 


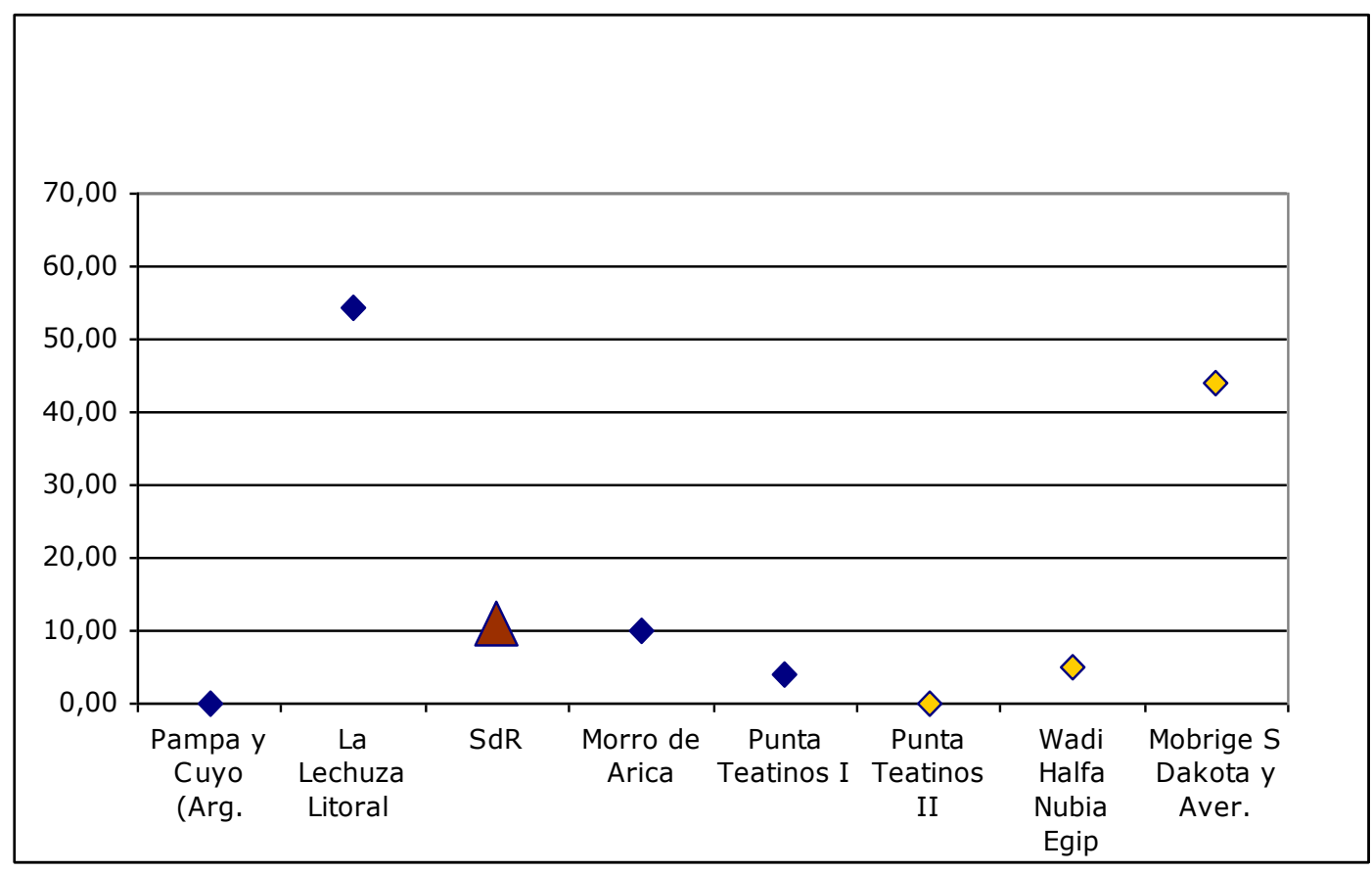

Figura 8.2. Gráfico de distribución de afecciones de hiperostosis porótica por sitio de acuerdo a sus estrategias económicas (Cazadores- recolectores $=u$ y Agricultores $=u$ )

Esto último, unido al hecho que no se manifiestan patologías nutricionales severas y que se carece de evidencias de enfermedades como raquitismo, osteomalacia, escorbuto u otro desorden de origen nutricional, pensamos que el grupo de SRI no padeció la influencia de factores de tan grave incidencia como para ocasionar disturbios crónicos en salubridad, capaces de afectar la supervivencia del grupo.

No obstante, la frecuencia de caries en Santana do Riacho I resultó ser del $10,5 \%$ lo cual es mayor a las expectativas planteadas por los modelos propuestos para economías cazadoras recolectoras, por cuanto Turner (1979) propone frecuencias entre 0,0 y $5,3 \%$ a la vez que, Larsen (1987) sugiere un rango entre $0,4 \%$ y $7,8 \%$. Nuestros resultados podrían estar vinculados, como veremos más adelante, con una dieta mixta que consideraría la ingesta de azúcares y carbohidratos naturales.

El registro arqueofaunístico llevado a cabo a partir de los trabajos sistemáticos de Kipnis $(1998,2002)$, comienza a aportar una valiosa contribución a los estudios de paleodieta. 
Por Velosos y Prous (1991) sabemos originalmente que parte del registro recuperado corresponde a una fauna mediana y pequeña compuesta por venados, roedores, dasipódidos y marsupiales, peces, aves, reptiles y anfibios.

Durante las excavaciones no se hallaron restos de grandes mamíferos actuales, ni de megafauna, aunque sí existen evidencias de su presencia en regiones cercanas al sitio, para los mismos momentos (Piló y Neves, 2002).

La economía de SRI, vista desde el registro arqueológico, no está por lo tanto de ninguna manera relacionada con megafauna.

El material procedente de los niveles más antiguos es en su mayoría una fauna pequeña, como armadillos, primates, roedores y lagomorfos. Queda claro entonces que la caza de mayor porte es más prominente en los niveles posteriores que en los más antiguos, registrándose restos de venado, pecaríes (puercos del monte) y tapires (Kipnis, 1998).

La edad de los más antiguos vestigios humanos y las nuevas dataciones presentadas por Piló y Neves (2002) para megafauna en la región confirman la convivencia del hombre con al menos dos especies de megamastofauna pleistocénica en Lagoa Santa: Catomyx cuvieri y Smilodon populator. Sin embargo, hasta el momento no hay registro arqueológico que evidencie la explotación de esta fauna como recurso alimenticio o de otro tipo por el ser humano de la región.

No sería éste el primer antecedente de sitios tempranos con preferencia por la recolección en los grandes bosques o sabanas, pesca y/o caza de pequeños y medianos mamíferos. En este sentido, también podrían citarse casos asignados al paleoindio en contextos como Sur Patagonia (Argentina) (Borrero, 1984), Piedra Pintada (Brasil) (Roosevelt et al., 1996), o Monte Verde (Chile) (Dillehay, 1986) y Meadowcrof Rockshelter (USA) (Fagan, 1989) con nula o escasa representación de megamamíferos en fechas tempranas. 


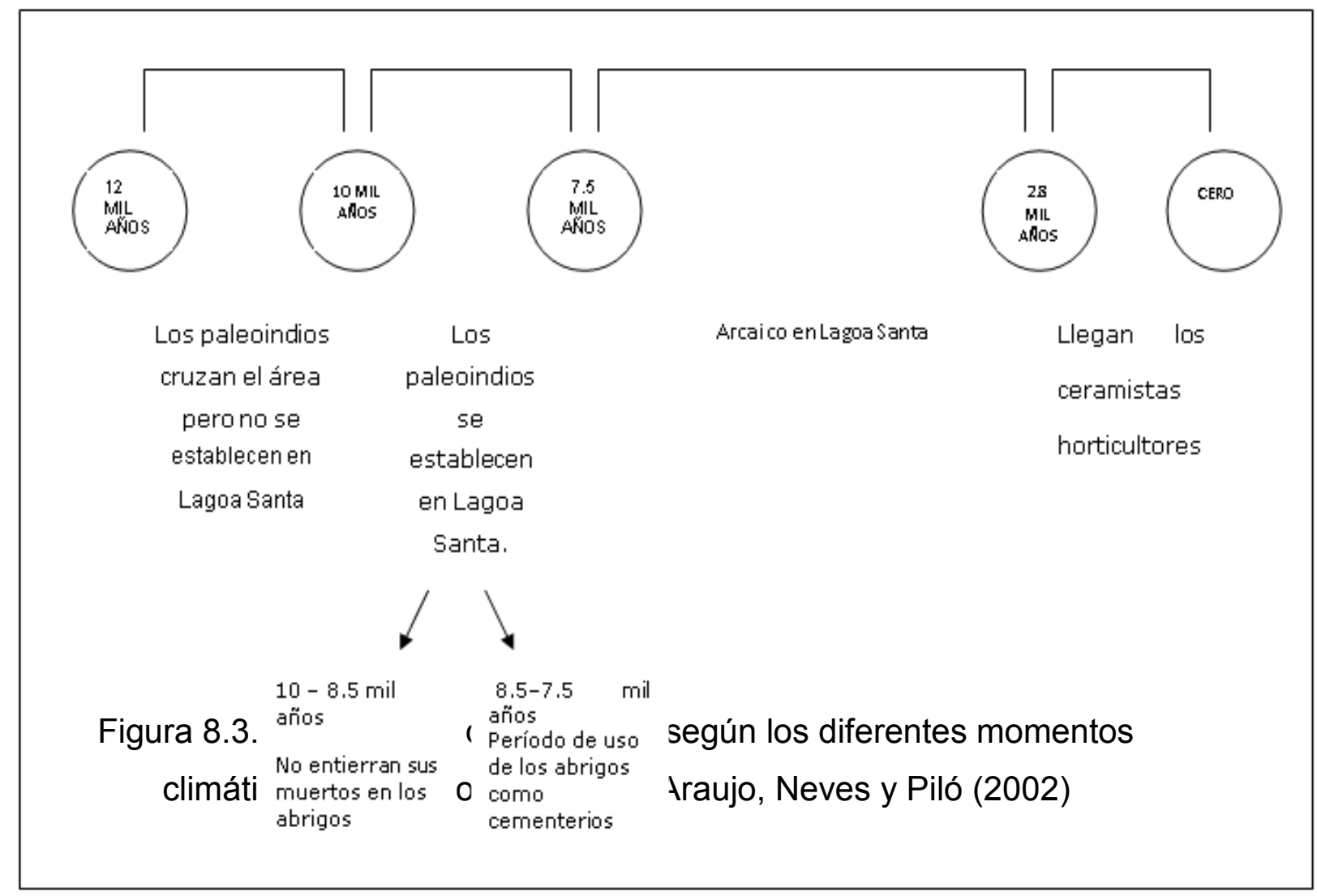

Que la región de Brasil Central fue escenario de marcadas oscilaciones climáticas, lo demuestran también los estudios de paleoclimas basados en los análisis polínicos que llevaron a cabo Ledru (1993) y van der Hammen (1974). En esta región se realizaron estudios en los últimos años que sugieren eventos de estación seca constante durante el Holoceno medio (Araujo et al., 2002).

Un análisis de la bibliografía reciente respecto de los paleoclimas en el Cuaternario soporta la hipótesis de que los eventos de mayor humedad habrían ocurrido entre el final del Pleistoceno y el inicio del Holoceno (Behling 1998, Ledru 1993, Rodríguez - Filho 2002, en Araujo et al., 2002). Este clima habría favorecido la ocupación humana en varias regiones del Brasil habiéndose sucedido por períodos de menor pluviosidad durante el Holoceno Medio (Araujo et al., 2002).

Los restos de vegetales asociados a los enterratorios indican la presencia de una variedad de frutos como Caryocar brasiliense, Astrocaryum sp y Hymenaea stilbocarpa, entre otros (Resende y Prous, 1991). De modo que podría pensarse en el grupo de cazadores recolectores paleoindio de Santana do Riacho I, como posibles consumidores de una dieta de alto contenido en componentes ricos en carbohidratos de origen vegetal, resinas arbóreas y 
mieles y complementada con componentes proteicos derivados de elementos cárneos, producto de la caza de presas pequeñas y medianas. Reforzarían esta idea los resultados del análisis de oligoelementos realizados, para lograr una aproximación a la reconstrucción de paleodietas (Ocian, 1999, com. pers.) que sugieren que hubo dieta omnívora compuesta por carnes y vegetales en un $70 \%$ de los 30 individuos analizados del sitio Santa do Riacho I.

Las dietas con alto contenidos de carbohidratos constituyen importantes factores de actividad cariogénica, producto de una actividad de recolección y/o de elaboración de alimentos, lo cual condice con la prevalencia de caries observadas. Estas consideraciones están de acuerdo con Borrero (1984), Gibbons (1996), y Roosevelt et al. (1996), quienes proponen, desde diferentes enfoques analíticos, que la subsistencia de cazadores paleoindios sudamericanos no estaba basada en la obtención de recursos megamamíferos (Cornero, et al., 1999).

Los resultados obtenidos de los indicadores de estrés funcional u ocupacional (fracturas por comprensión, osteofitos y nódulos de Schmorl) sugieren que el uso de la columna vertebral en ocupaciones asociadas al levantamiento, carga y/o transporte de materiales pesados no habrían demandado exigencias biomecánicas suficientes como para provocar lesiones que afectaran significativamente la movilidad corporal de los individuos. Aunque las afecciones traumáticas se manifestaron en el 33\% de los adultos, demostrando la posterior remodelación y supervivencia de los individuos lesionados, que por sus características indican un origen accidental que podrían vincularse con las actividades laborales u ocupacionales, como la cacería.

Por último, debe citarse otro hecho significativo que es la ausencia de casos de amputaciones, luxaciones o trepanaciones. Tampoco hubo lesiones que respondieran a patrones de daño intencional, motivo por lo que no vinculamos al grupo con situaciones de violencia endémica, lo que nos posibilita descartar eventos de gran tensión social intra o intergrupales, al menos entre los 9.000 y 8.000 años AP en la región. Sin embargo, la observación comparativa (ver Tabla 2.1.) ubica a la frecuencia de traumas de Santana do Riacho 1 en una situación por encima de la media entre otros grupos cazadores recolectores y por sobre el total de los grupos horticultores y agricultores. 
La gran prevalencia de traumas accidentales sugiere que la obtención de recursos demandaba una importante inversión física en esa región específica. Esto concuerda tanto con el trabajo de Kipnis (1998), como con las investigaciones de Prous et al., (1992/1993) y con el modelo Araujo, et. al., 2002 (Figura 8.3).

La escasa presencia de enfermedades infecciosas, como en el caso de la periostitis, refleja un mesurado y no agresivo impacto de microorganismos en general, así como una adecuada respuesta inmunológica postraumática, evidenciada por la supervivencia de los individuos al impacto traumático. La ausencia de marcadores diagnósticos de enfermedades infecto- contagiosas, refleja una fuerte respuesta inmunológica ante las infecciones endémicas que pudieron haber existido en la región.

Se podría considerar, ya que la región de Lagoa Santa es tradicionalmente conocida por una densa ocupación paleoindia (Neves, 1990, Prous, 1978, Prous y Fogaça, 1999 y Silva et al. 2000), que el grupo en estudio habitó un ambiente con amplia capacidad de sustento alimenticio y de recursos generales, que no hicieron necesarias situaciones de conflicto, al menos en términos de tensión social.

Una evaluación crítica de los resultados obtenidos hasta el momento exhibe una coherencia interna entre las variables analizadas y vemos que la mayor parte de la muestra presenta que las condiciones de salud resultaron buenas y las condiciones patológicas se han demostrado entre bajas y moderadas. Por lo que a modo de una evaluación general pensamos que, de acuerdo a los resultados obtenidos a través de los indicadores de estres funcional y nutricional, éstos son sugerentes de un bajo impacto ambiental negativo y de una calidad de vida apropiada, capaz de garantizar la reproducción, la supervivencia del grupo en Lagoa Santa constituyendo un modelo de éxito adaptativo.

\section{BIBLIOGRAFIA}

Alvarenga Junqueira, $P$. 
1992/1993 Os sepultamentos da excavaçao n III. En Archivos do Museu de Historia Natural Minas Gerais, Brasil. XIII/XIV:78-90

Angel, L.

1984 Health as Crucial Factor in the Changes from Hunting to Developed Farming in the Mediterranean. En Paleopathology and Origins of Agriculture, editado por G. J. Armelagos y M. N. Cohen. pp. 51-69. Academic Press.

Angel, L., J. Kelley, M. Parrington y S. Pinter

1987 Life stresses of the Free Black Community as Represented by the first African Baptist Church, Philadelphia, 1823-1841. Am. Journal Physical Anthropology 74(2):200-213.

Araujo, A. W. Neves y L. Piló

2002 Eventos de seca no Holoceno e suas implicações no povoamento préhistórico do Brasil Central. En II Congresso sobre Planejamento e Gestão das Zonas Costeriras dod Países de Expressão Portuguesa.

Armelagos, G.

1988 Biocultural Aspects of Food Choice. En Food and Evolution: Toward a Theory of Human Food Habits, editado por M. Harris y E. Ross. pp. 579-594. Temple University Press, Philadelphia.

Armelagos, G. J.

1998 Introduction: sex, gender and health status in prehistoric and contemporary populations. En Sex and Gender in Paleopathological Perspective, editado por A. L. Grauer y P. Stuart-Macadam. pp. 1-9 Cambridge University Press, Cambridge.

Armelagos, G., D. Carlson y D. Van Gerven

1982 The Theoretical Fundations and Development of Skeletal Biology. En A History of American Physical Anthropology, editado por F. Spencer, pp. 305328. Academic Press Inc. New York.

Baffi, E. y T. Cocilovo

1989 Evaluación del Impacto Ambiental en una Población Prehistórica: El caso de las Pirguas (Salta, Argentina). Rev. Antropología. 8:39-43. 
Baffi, E., M. F. Torres y J. A. Cocilovo

1996 La población prehispánica de las Pirguas (Salta, Argentina). Un enfoque integral. Revista Argentina de Antropología Biológica. 1(1):204-218.

Baker, P. T.

1965 Multidisciplinary Studies of Human Adaptability: Theoretical Justification and Method. En Yearbook of Physical Anthropology, editado por S. Genovés 13: 1-12. American Association of Physical Anthropologists, México.

Barnes E.

1994 Developmental Defects of the Axial Skeleton in Paleopathology. University Press of Colorado.

Barrientos, G.

1994 Análisis del estado nutricional y dieta de las poblaciones aborígenes prehispánicas de las Areas Interserrana y Serrana de Ventania. Estado de avance de las investigaciones. En Los Primeros Pasos, editado por D. Olivera y J. Radovich. pp. 43-52. INAPL, Buenos Aires.

Baynes, R. D. y T. H. Bothwell.

1990 Iron deficiency. Annual Review of Nutrition. 10:133-48.

Biddle, W.

1995 Germs. Henry Holt \& Co. New York

Bogin, B.

1988 Patterns of Human Growth. Cambridge Studies in Biological Anthropology. Cambridge University Press.

Borrero, L.

1984 Pleistocene extinctions in South America. En Quarternary of South America and Antartic Peninsula, vol. 2, editado por J. Rabasa pp. 115-125. A. A. Balkema, Boston.

Brandão, M. 
1993 A Cobertura Vegetal Circundante Do Grande Abrigo de Santa do Riacho. En Archivos do Museu de Historia Natural Minas Gerais, Brasil. XIII/XIV:401-408

Buikstra J. E. y D. H. Ubelaker

1994 Standars for data collection from human skeletal remains. Arkansas archeological survey research series NO. 44.

Carlson, D. S., G. J. Armelagos y D. P. Van Gerven.

1974 Factors influencing the etiology of cribra orbitalia in prehistoric Nubia. J. Hum Evol 3:405-410.

Cassidy, C.M.

1980 Nutrition and Health in Agriculturalist and Hunter-Gatherers: A Case Study of Two Prehistoric Populations. En Nutritional Anthropology. Contemporary Approaches to Diet \& Culture, editado por J. Norge, K. Randy y P. Gretel. pp. 117-145. Redgrave Pub. Co.

Civera, C. M. y L. Marquez Morfín.

1998 Tlatilco, Población aldeana del Preclásico en la Cuenca de México: Sus perfiles demográficos. En Perfiles Demográficos de Poblaciones Antiguas de México, editado por L. Márquez Morfín y J. Goméz de León. pp. 30-76. INAH, México.

Cocilovo, J. A.

1995 Biología de la Población Prehistórica de Pisagua. Continuidad y cambio cultural en el Norte de Chile. Tesis doctoral inédita, Facultad de Cs. Exactas, Físicas y Naturales. U.N.Córdoba.

Cocilovo, J. A.

2000 Evaluación de modelos demográficos de Poblaciones Nativas Antiguas. Manuscrito en archivo CONICET. Universidad de Río Cuarto.

Cocilovo, J. A y W. A. Neves.

1988-1989 Afinidades biológicas entre las poblaciones prehistóricas del Litoral del Brasil y de Argentina. Primera aproximación. Relaciones de la Sociedad Argentina de Antropología XVII(2): 31-56. 
Charlotte, R., M. Lewis y P. Boocock

1998 Infections disease, sex, and gender: the complexity of it all. En Sex and Gender in Paleopathological Perspective, editado por A. Grauer y P. StuartMacadam. pp. 93-113 Cambridge University Press.

Charlotte, R. y K. Manchester

1995 The Archaeology of Disease. Cornell University Press.

Cohen, M. y G. Armelagos (editores)

1984 Paleopathology at Origins of Agriculture. Academic Press, Inc.

Cook, D. y J. Buikstra.

1979 Heath and differential survival in prehistoric populations: Prenatal dental defects. American Journal of Physical Anthropology 51:649-664.

Cornero, S.

1993 Bioarqueología del Sitio Arroyo Aguilar: Evaluación de Status de Salud. Tesis de Licenciatura. Inédita, Escuela de Antropología, Universidad Nacional de Rosario.

Cornero S. y W. Neves

1999 Prevalencia de traumas en un Grupo Paleoindio de Lagoa Santa: Santana do Riacho I, Brasil Central. Coloquio Internacional “Juan Comas” México :73.

Cornero, S. y R. Puche.

2000 Diet and Nutrition of Prehistoric Populations at the Alluvial Banks of the Parana River (Middle Sector). Revista Medicina Vol. 60:109-114. Bs. As. ISSN 0025-7680.

Cornero, S. y R. Puche.

2002 Cribra Orbitalia - Hiperostosis Porótica en una Población Prehistórica del Paraná Medio. Medicina 62: 169-172.

Cornero, S., W. Neves y A. Prous.

1999 Prevalencia de caries en una muestra de la población de Santana do Riacho I o el mito del paleoindio cazador. Revista Argentina de Antropología Biológica 2: 301-306. 
Costa M., H. Varela, J.Cocilovo, S. Quevedo y S. Valdano.

2000 Perfil paleodemográfico de Morro de Arica, una población de pescadores arcaicos del norte de Chile. Bol. Museo Nac. Hist.Nat. 49:215-235.

Crawford, $M$.

1998 The Origns of Native Americans. Evidence from anthropological genetics. Cambridge University Press.

de Souza, S.

1993 Paleopatología Humana de Santana do Riacho Arquivos do Museu de Historia Natural Minas Gerais, Brasil XIII-XIV: 129-160.

Dillehay, T. D.

1986 The cultural relationshis of Monte Verde: A late Pleistocene Settlement Site in the Subantartic Forest of South-Central Chile. En New evidence for the Pleistocene peopling of the Americas. Editado por Alan Bryan, Center for the study of early man.

1992 Where are the Human Skeletal Remains of the Late Pleistocene Period? Problems and Prospects in Searching for the First Americans. Mecanografiado.

Duray S.

1992 Enamel Defect and Caries Etiology: An Historical Perspective. En Recent Contributions to the Study of Enamel Developmental Defects, editado por A. Goodman y L. Capasso. pp. 307-320. Teramo, Italy.

Edynak, G.

1976 Life-style from skeletal material: a medieval Yugoslav example. En The Measure of Man, editado por E. Giles e J. Frieddlaender. pp.408-432. Peabody Museum Press, Cambridge.

El-Najjar, M. Y., J. Andrews, J. G. Moore y D. G. Braga

1982 Iron deficiency anemia in two prehistoric American Indian skeletons: a dietary hipótesis. Plains Anthropologist 27:205-209.

Fagan, B. 
1989 The Great Journey. The Peopling of Ancient America. Thames and Hudson, NY.

Faiad, Y. y N. D'ercole.

2000 Aspectos Estáticos y Dinámicos de la Población. Universidad Nacional de Río Cuarto.

Farley, J.

1993 Schistosomiasis. En: The Cambridge World History of Human Disease, Editado por KF Kiple, pp. 992-997 Cambridge University Press, Cambridge.

Feldesman, M. Kleckner J. y J. Lundy.

1990 Femur/stature ratio and estimates os stature in mid and late Pleistocene fossil hominids. Am J Phy Anthropol 83: 359-372.

Gibbons, A.

1996 Firts American: not mammoth hunters, but forest dwellers?. Science 272:346-347

Gilbert, Jr. R.y J. Mielke (editores)

1985 Analysis of Prehistoric Diets. Academic Press.

Goodman A., G. Armelagos and J. Rose.

1980 Enamel hypoplasias as indicator of stress in three prehistoric populations from Illinois. Human Biology 52:515-528.

Goodman, A., J. Lallo, G. Armelagos and J. Rose.

1984 Health Changes at Dickson Mound, Illinois (A.D. 950-1300). In Paleopathology at Origins of Agriculture, editado por M. Cohen and G. Armelagos. pp. 271-301. Academic Press, Inc.

Goodman A., D. Martin, G. Armelagos, y G. Clark

1984 Indications of stress from bones and teeth. En Paleopathology at the Origins of Agriculture, editado por M. Cohen y G. Armelagos, pp. 13-39. Academic Press.

Granado Lara, E. y C. M. Dutra Moresi 
1991 Material textil de Santana do Riacho. En Arquivos do Museu de Historia Natural. Volumen XII: 179-183. Universidad Federal de Minas Gerais.

Guichón R.

1993 Antropología Física de Tierra del Fuego. Tesis Doctoral Inédita. Universidad de Buenos Aires.

Guimãraes, C.

1991 A ocupaçao historica da regiao de Santana Do Riacho. En Arquivos do Museu de Historia Natural. Volumen XII: 13-31. Universidad Federal de Minas Gerais.

Guimarey, L. M., F. R. Carnese y H. M. Pucciarelli

1995 La influencia ambiental en el crecimiento humano. Ciencia Hoy. $5(30): 41-59$.

Hassan F. A.

1981 Demographic Archaeology. Academic Press.

Hillson, S.

1996 Dental Anthropology. Cambridge University Press.

Hillson, S.

1990 Teeth. Manuals in Archaeology. Cambridge Univ. Press.

Holland, T. y M. O’Brien

1997 Parasites, Porotic Hyperostosis, and the Implications of Changing Perspectives. American Antiquity 62(2):183-193.

Hotez P. J. y D. I. Pritchard

1995 Hookworm infection. Scientific American 1995, 272:68-74.

Hrdlicka, A.

1914 Early Man in South America. Government Printing Office, Washington Hurt, W. R. y O. Blasi

1969 O projeto arqueológico "Lagoa Santa", Minas Gerais, Brasil (nota final)" Arquivos do Museu Paranaense (N. S.) Arqueología, vol. 4:1-63 
Huss-Ashmore, R., A. H. Goodman y G. J. Armelagos

1982 Nutritional inference from paleopathology. En Advances in Archaeological Method and Theory, vol 5, pp. editado por M. Shiffer. 5:395-474. Academic Press.

Inhorn, M. y P. Brown.

1990 The Anthropology of Infectious Disease. Annu.Rev.Anthropol. 19:89-117. Iscan, M.Y. y K. Kennedy.

1989 Reconstruction of Life from Skeleton. Alan Liss NY

Judd, M. y CH. Roberts.

1998 Fracture patterns at the medieval Leper Hospital in Chichester. Am. J. Phys. Anthropol. 105(1):43-55.

Junqueira P.A. 1992/1993 As estructuras aparentes (2): os sepultamentos do Grande Abrigo de Santana do Riacho - Os sepultamentos da escavacao No III. Arquivos do Museu de Historia Naturale da Universidade Federal de Minas Gerais 12, 33-41.

Jurmain $\mathrm{R}$.

2001 Paleoepidemiolgical Patterns of Trauma in a Prehistoric Population From Central California American Journal Of Physical Anthropology 115:13-23

Jurmain, R. y L. Kilgore.

1998 Sex-related patterns of trauma in humans and African Apes. En Sex and Gender in Paleopathological perspective. Editado por A. Grauer y P. StuartMacadam. pp. 11-26 Cambridge University Press.

Karfunkel J., C. Noce y H. Kohler.

1991 A Geologia do Grande Abrigo de Santana do Riacho e Vizinhascas, Sera do Cipó, Minas Gerais. Arquivos Do Museu do Historia Natural UFMG, XII:33-41

Kelley, M.

1989 Infectious Disease. En Reconstruction of Life from the Skeleton, editado por Y. M. Iscan y K. A. R. Kennedy. pp. 191-200 Alan R. Liss inc. New York. 
Kelley M. y L. Angel.

1987 Life Stresses of Slavery. Am. J. Phys. Anthropol. 74:199-211.

Kennedy, K.

1989 Skeletal Markers of Occupational Stress. En Reconstruction of Life from the Skeleton, editado por M. Y. Iscan y Kennedy. pp. 129-160 Alan Liss inc. New York.

Kipnis, R.

1998 Early hunter-gatherers in the Americas: perspectives from central Brasil. Antiquity 72:581-92.

Kipnis, R.

2002 Foraging societies of eastern central Brazil: An evolutionary ecological study of subsistence strategies during the terminal Pleistocene and Early/Middle Holocene. Ph. D. Dissertation, The University of Michigan.

Knowles, A.

1983 Acute traumatic lesions. En Diseases in Ancient Man, editado por G. Hart. Clarke Irwin. pp. 61-82. Toronto.

Lamine - Emperaire A., A. Prous, A. Vilhena de Moraes y M. Beltrao.

1975 Grottes et abris de la Region de Lagoa Santa, Minas Gerais, Brasil. En Cahiers D’Archéologie D’Amerique du Sud. 1. 1:185. Paris.

Larsen, C.

1987 Bioarchaeological Interpretations of Subsistence Economy and Beharvior from Human Skeletal Remains. En Advances in Archaeological Method and Theory, editado por M. Shiffer.:339-445. Academic Press.

Larsen, C.

1997 Bioarchaeology. Interpreting behavior from human skeleton. Cambridge Studies in Biological Anthropology 21. Cambridge University Press.

Larsen, C., C. Ruff, M. Schoeninger y D. Hutchinson. 
1992 Population Decline and Extinction in La Florida. En Disease and Demography in the Americas, editado por J. Verano y D. Uberlaker. pp. 25-40. Smithsonian Institution Press. Washington.

Ledru, M.P.

1993 Late Quaternary Environmental and Climatic Changes in Central Brasil. Quaternary Research 39:90-98.

Little, M.

1982 The Development of Ideas on Human Ecology and Adaptation. En A History of American Physical Anthropology. editado por F. Spencer, pp. 405433. Academic Press Inc. New York.

Lovell, N. C.

1997 Trauma Analysis in Paleopathology. Yearbook of Physical Anthropology. 40: $139-170$.

Lovejoy, O. and K. Heiple.

1981 The Analysis of Fractures in Skeletal Populations with an Example from the Libben Site, Ottowa County, OHIO. American Journal of Physical Anthropology. 55:529-541.

Lukacs, J.

1989 Dental Paleopathology: Methods for Reconstructing Dietary Patterns. En Reconstruction of Life from the Skeleton, editado por Y. Iscan y Kennedy. pp. 261-286. Alan Liss inc. New York.

Lund, P.W.

1950 Memorias sobre Paleontología Brasilera. Ministerio da Educacao e saude. Rio de Janeiro.

Malta, I. y H. Kohler.

1991 O cenario Geográfico e Geológico do Planalto de Lagoa Santa/MG. Arquivos Do Museu do Historia Natural UFMG, Vol XIl:3-11.

Márquez Morfín, L. 
1984 Sociedad Colonial y Enfermedad: Un ensayo de osteopatología diferencial. INAH. Colección Científica. México.

Martin, D, A. H. Goodman y G. J. Armelagos.

1985 Skeletal Pathologies as Indicators of Quality and Quantity of Diet. En The Analysis of Prehistoric Diet. editado por Jr. R. Gilbert y J. Mielke. pp. 227270 Academic Press.

Meiklejohn, C., C. Schentag, A. Venema and P. Key.

1984 Socioeconomic change and patterns of paleopathology and variation in the mesolithic and neolithic of western Europe: some suggestions. En Paleopathology at Origins of Agriculture, editado por M. Cohen and G. Armelagos. pp. 75-100. Academic Press, Inc.

Mello e Alvim, M.C.

1977 Os Antiguos Habitantes da Area Arqueológica de Lagoa Santa, Minas Gerais, Brasil. Estudo Morfológico. Arquivos Do Museu do Historia Natural UFMG, II:119-173.

Mena F. y O. Reyes

2001 Montículos Y Cuevas Funerarias en Patagonia: Una Visión desde Cueva Baño Nuevo-1, Xi Región. Chungar (Arica). Vol.33 Nro.1. Arica. OnlineISSN0717-7356.

Merbs, Ch.

1989 Trauma. En Reconstruction of Life from the Skeleton, editado por Y. Iscan y K. A. R. Kennedy. pp. 161-190.. Alan R. Liss. New York.

Merbs, Ch.

1992 A new world of infectious disease. American Journal of Physical Anthropology 35:3-42.

Miles, J.

1975 Orthopedic Problems of the Wetherill Mesa Populations. Publications in Archaeology 7G. Wetherill Mesa Studies. National Park Service. US.

Morán, E. 
1993 La Ecología Humana de los Pueblos de la Amazonia. Fondo de Cultura Económica, México.

Moreira, N. S., A. Araújo, U. Confalonieri, L. Ferreira y A. Prous.

1991 Os restos de invertebrados encontrados durante as escavaçoes do abrigo de Santana do Riacho. Arquivos do Museu Historia Natural Minas Gerais, Brasil. XII:155-176.

Neves, W.

1984a Incidencia e distibuicao de osteoartritis em grupos colectores do litoral de Parana: uma abordagem osteobiografica. Clio 6:47-62.

Neves, W.

1984b Estilo de Vida e Osteobiografía: a reconstituicao do comportamento pelos ossos humanos. Rev. Pre-Historia 6:287-291.

Neves, W.

1988 Uma proposta pragmatica 'para cura e recuperação de coleções de esqueletos humanos de origen arqueológica. Boletim do Museum Paranaense Emilio Goeldi. 4(1):3-26.

Neves, W.

1990 Dados cranianos de remannnenscentes osseos humanos da Gruta Sumidouro, Brasil, depositados em Instituicoes da Europa. Arq.Mus.Hist.Nat. UFMG Vol.11:301-311.

Neves, W.

1997 Lagoa Santa. History of Physical Anthropology. 1:598-599.

Neves W. y J. P. V. Atui

2004 O mito da homogeneidade biológica na população paleoíndia de Lagoa Santa: implicações antropológicas. En Revista de Antropología, São Paulo, V47 n¹:159-206

Neves W. y S. Cornero

1997 What did South American Paleoindians eat ? Current Research in the Pleistocene. Vol. 14. : 93-96. U.S.A. 
Neves W. y M. A. Costa

1998 Adult Stature and Standard of living in the prehistoric Atacama Desert. Current Anthropology. Vol. 39. 2 : 278-281

1999 a Fracture Incidence in San Pedro de Atacama. American Journal of Physical Anthropology 109:253-258.

1999 b Nutrition and quality of life in prehistoric San Pedro de Atacama, Chile. En Antropología Física Latinoamericana 2:23-40, Universidad Autónoma de México.

Neves, W., A. Prous, R. González-José, R. Kipnis y J. Powel

2003 Early Holocene human skeletal remains from Santana do Riacho, Brazil: implications for the settlement of the New World. En Journal of Human Evolution, vol. 45:19-42

Novellino P, Guichón R. y H. Lagiglia

1996 Indicadores Biológicos en Restos Humanos del Sur de Mendoza. Rev. Arqueología 6.:69-82.

Ortner, D.

1992 Skeletal Paleopathology. Probabilities, possibilities and impossibilities. En Disease and Demography in the Americas, eds. John W. Verano y Douglas Ubelaker. pp. 5-14. Smithsonian Institution Press, Washington and London.

1998 Male - female immune reactivity and its implications for interpreting evidence in human skeletal paleopathology. En Sex and Gender in Paleopathological Perspective, editado por A. Grauer y P. Stuart-Macadam. pp. 79-92 Cambridge University Press.

Ortner, D. y W. Putschar.

1985 Identification of Pathological Conditions in Human Remains. Smithsonian contributions to Anthropology No. 28. Washington.

Ortner D., N. Tuross y A. Stix.

1992 New Approaches to the Study of Disease in Archeological New World Populations. Human Biology, 64(3):337-360. 
Owsley D. y R. Jantz.

1994 Skeletal Biology in the Great Plains. Migration, Warfare, Health and Subsistence, editado por D. W. Owsley y R. L Jantz Smithsonian Institution Press Washington and London.

Pérez Pérez, A.

1995 Salud, enfermedad y muerte en el pasado. Patología oral, indicadores de stress y dieta en una muestra esqueletal de aborígenes de Tierra del Fuego. Actas III Congreso Nacional de Paleopatología de España, pp. 99-106. Barcelona.

Piló L. B. Y W. A. Neves

2002 A coexistência do homen com grandes mamíferos extintos e a origem do homen no novo mundo, segundo Peter Wilhelm Lund (1801-1880). En Cronos Revista de História, Facultad de Ciencias Humanas de Pedro Leopoldo. Junho. : 29-41

Polednak, A.

1987 Host Factors in Disease. Age, Sex, Racial and Ethnic Group. Ch.Thomas Pub., Illinois, U.S.A.

Powell J. y W. Neves.

1998 Dental diversityof early New World population: taking a bite out of the Tripartite Model. Am. J. Phys. Anthrop. 26 (Suppl.), 179-180.

Powell, J. y D. G. Steetel.

1994 Diet and Health of Paleoindians: An Examination of Early Holocene Human Dental Remains. En Paleonutrition. The Diet and Health of Prehistoric Americans, editado por Kristin Sobolik. Center for Archaeological Investigations. Occasional Paper No. 22. pp. 178-194. Southern Illinois University at Carbondale.

Powell, M.

1985 The Analysis dental Wear and Caries for Reconstruction Dietary. En The Analysis of Prehistoric Diet, editado por R. I. Gilbert y J. H. Mielke. pp. 307-335. Academic Press. 
Powell, M.

1988 Status and Health in Prehistory. A Case Study of the Moundville Chiefdom. Smithsonian Institution Press, Washington

Powell, M.

1991 Ranked Status and Heath in the Missisippian Chiefdom at Moundville. En What Mean These Bones?. Studies in Southeastern Bioarchaeology, editado por M. L. Powel, P. S. Bridges y A. M. Wagner Mires. pp. 22-51 University Alabama Press, Alabama.

Powell, M.

1993 Health and Diseases in Late Prehistoric Southeast. En Disease and Demography in the Americas. Smithsonian Press.

Powell, M., P. Bridges y A. Wagner Mires.

1991 What Mean These Bones?. Studies in Southeastern Bioarchaeology. University Alabama Press, Alabama.

Prous, A.

1991 Historico das pesquisas no abrigo de Santana do Riacho e nos arrededores. Arquivos do Museu de Historia Natural Minas Gerais, Brasil. Vol XII:61-66.

Prous A.

1993 Os Sepultamentos da escavação No 1. Arquivos do Museu de Historia Natural Minas Gerais, Brasil XIII-XIV: 21-77

Prous A. (editor)

1993 Santana do Riacho. Tomo II Arquivos do Museu de Historia Natural Minas Gerais, Brasil. Vol. XIII/XIV.

Prous, A. y M. Carsalad Schlobach.

1997 Sepultamentos pré-históricos do Valle do Peruaçu-MG. Rev do Museo de Arqueología e Etnologia. 7:3-21

Prous, André \& E. Fogaça 
1999 Archaeology of the Pleistocene-Holocene boundary in Brazil. Quaternary International 53/54:21-41.

Prous, A. y M. Malta (editores).

1991 Santana do Riacho. Tomo I Arquivos do Museu de Historia Natural Minas Gerais, Brasil. Vol. XII.

Prous, A. y T. P. G. Veloso.

1991 A Fauna de vertebrados de Santana do Riacho. Arquivos do Museu de Historia Natural Minas Gerais, Brasil. Vol. XII:113-153.

Pucciarelli, $\mathrm{H}$.

1991 Nutrición y Morfogénesis Craneofacial. Una Contribución de la Antropología Biológica Experimental. Interciencia. Vol 16 Nro 5: 248-252.

Pucciarelli, H. M., F. R. Carnese y L. M. Guimarey. 1996 Desnutrición y Dimorfismo sexual. Ciencia Hoy 6(34):53-59.

Quevedo Kawasaki, S.

1998 Punta Teatinos. Biología de una Población Arcaica del Norte Semiárido Chileno. Tesis Doctoral inédita, Universidad de Buenos Aires.

Quevedo Kawasaki, S. y J. A. Cocilovo.

1996 La población antigua de Pisagua. Caracterización bioantropológica del cementerio "C" de la colección Max Uhle. Fondo de apoyo a la investigación. 4:46-53.

Resende, E. T. y A. Prous.

1991 Os vestigios vegetais do Grande Abrigo de santana do Riacho. Arquivos do Museu de Historia Natural Minas Gerais, Brasil. XII: 87-112

Resnick, D. y G. Niwayama.

1988 Osteomyelitis, Septic, Artritis and Sofá Tissue Infecction: The Organisms. En Diagnostisis of Bone and Joint Disorders, Vol. 4, editado por D. Resnick y G. Niwayama. pp. 2647-2754. W.B. Saunders Company, HBJ, Inc. Robbins S. y M. Angell. 
1989 Patología Básica. Interamericana. México

Roberts, Ch. y K. Manchester.

1995 The Archaeology of Disease. Alan Sutton Pub. Cornell University Press, Ithaca, NY

Roosevelt, A., da Costa L., C. Machado, M. Michab, N. Mercier, H. Valladas, J. Feathers, W. Barnett, M. da Silva, A. Henderson, J. Silva, B. Chernoff, D, Reese, J. Holman, N.

Toth y K. Schick

1996 Paleoindian cave dwellers in the Amazon: The Peopling of the America. Science 272: 373-384.

Rose, J. C., K. W. Condon y A. H. Goodman.

1985 Diet and dentition: Developmental Distrubances. En The Analysis of Prehistoric Diets, editado por R. Gilbert Jr. y J. H. Mielke. pp. 281-306. Academia Press, Inc.

Rose, J. C., B. A. Burneo, M. S. Nassaney y M. W. Blaener

1984 Paleooathology and the Origins of Maite Agricultura in the Lower Mississippi Valleyand Caddoan Cultura Areas. En Paleopathology and the Origins of Agriculture, editado por M. N. Cohen y G. J. Armelagos. pp. 393-424. Academia Press Inc.

Saul, F. P.

1976 Osteobiography: life history recorded in bone. En The Measures of Man, editado por E. Giles y J. S. Firedlaender. Peabody Museum Press, Cambridge.

Smith, M.

1993 Genetic Adaptation. En Human Adaptation, editado por G. Harrison. pp. 154. Oxford Univ. Press.

Soto-Heim, P. 
1994 Les Homes de lagoa Sabta (Brésil). Caractères Anthropologiques et position Parmi D' Autres Populations Paléoindiennes D' Amérique. L'Anthropologie 1:81-109.

Steckel, R. H.

1995 Stature and the Standard of living. Journal of Economic Literature. XXXIII: 1903-1940

Steckel, R. H. y J. C. Rose

2002 Patterns of Health in the Western Hemisphere. En The Backbone of History. Health and Nutrition in the Western Hemisphere. editado por R. H. Steckel y J. C. Rose. pp. 563-582. Cambridge University Press. Cambridge.

Steckel, R. H. y J. C. Rose

2002 Introduction. En The Backbone of History. Health and Nutrition in the Western Hemisphere, editado por R. H. Steckel y J. C. Rose. pp. 3-10 Cambridge University Press. Cambridge.

Steinbock, R.T.

1976 Paleopathological Diagnosis and Interpretation. Bone Disease in Ancient Human Populations. Charles Thomas Publisher. Illinois.

Stini, W.

1985 Growth rates and sexual dimorphism. En Analysis of Prehistoric Diets, editado por R. Gibert y J. Mielke. pp.191-222 Academic Press, New York.

Storey, R.

1992 Life \& Death in the Ancient City of Teotihuacan. A modern paleodemographic synthesis. University of Alabama Press.

Stuart-Macadam, P.

1989 Nutritional Deficiency Diseases. En Reconstruction of Life from the Skeleton, editado por Ysacar Iscan y Kennedy. Alan Liss inc. New York.

Stuart-Macadam, P.

1992 Porotic Hiperostosis: A New Perspective. Am. J. Phys. Anthrop.;87:3948. 
Torres, L. M.

1911 Los primitivos habitantes del delta del Paraná. Universidad Nacional de La Plata

Turner, C. G. II

1979 Dental Anthropological indications of agricultura among the Jomon people of Central Japan: X. People of the Pacific. American Journal of Physical Anthropology. 51:619-36.

Ubelaker, D. H.

1974 Reconstruction of Demographic Profiles from Ossuary Skeletal Samples. Smithsonian Contributions to Anthropology. No. 18. Washington. USA.

Ubelaker, D. H.

1992 Enamel Hyploplasia in Ancient Ecuador. En Recent Contributions to the Study of Enamel Developmental Defects, editado por A H. Goodmen y L. L. Capasso. pp. 207-218. Edigrafital, Teramo.

Ubelaker, D. H.

1997 Skeletal Biology of Human Remains from La Tolita, Esmeraldas Province, Ecuador. Smithsonian Contributions to Anthropology 41. Washington. van der Hammen, T.

1974 The Pleistocene changes of vegetation and climate in tropical South America. Journal of Biogeography 1: 3-26.

Verano, J.

1992 Prehistoric Disease and Demography in the Andes. En Disease and Demography in the Americas. editado por $J$ Verano y D. H. Ubelaker, Smithsonian.

Viana V., R. Maurício, R. Matta-Machado e I. Pimenta

2002 Manejo de la regeneración natural de especies arbóreas nativas para la formación de sistemas silvopastoriles en las zonas de bosques secos del sureste de Brasil. Rev. Agroforesteria. Nro 33-34

Waldron T. 
1987 Death, Decay and Destruction. Manchester University Press.

Walter H. V.

1948 A Pre-historia da Regiao Lagoa Santa (Minas Gerais). Belo Horizonte.

Webb, S.

1995 Infectious disease. En Paleopathology of aboriginal Australians. Health and disease across a hunter-gatherer continent. pp.125-151. Cambridge University Press.

White, T. D.

1992 Prehistoric Cannibalism. Princenton University Press

White, T. D.

2000 Human Osteology. Academic Press.

Williams $\mathrm{J}$.

1994 Disease Profiles of Archaic and Woodland Populations in the Northern Plains. En Skeletal Biology in the Great Plains. Migration, Warfare, Health and Subsistence, editado por D. Owsley y R. Jantz. pp. 91-107. Smithsonian Institution Press, Washington.

Word J., G. Milner, H. Harpending y K. Weiss

1992 The Osteological Parax. Problems of Infering Prehistoric Health from Skeletal Simples. Current Anthropology Vol. 33. N 4.

Yacobaccio, H. D.

1987 El Universo desvocado. En Muestreo en Arqueología Argentina, editado por M. I. Figuerero Torres y M. Casiraghi. Programa de estudios prehistóricos CONICET - UBA. Buenos Aires. 
A NEXO INVENTARIO 


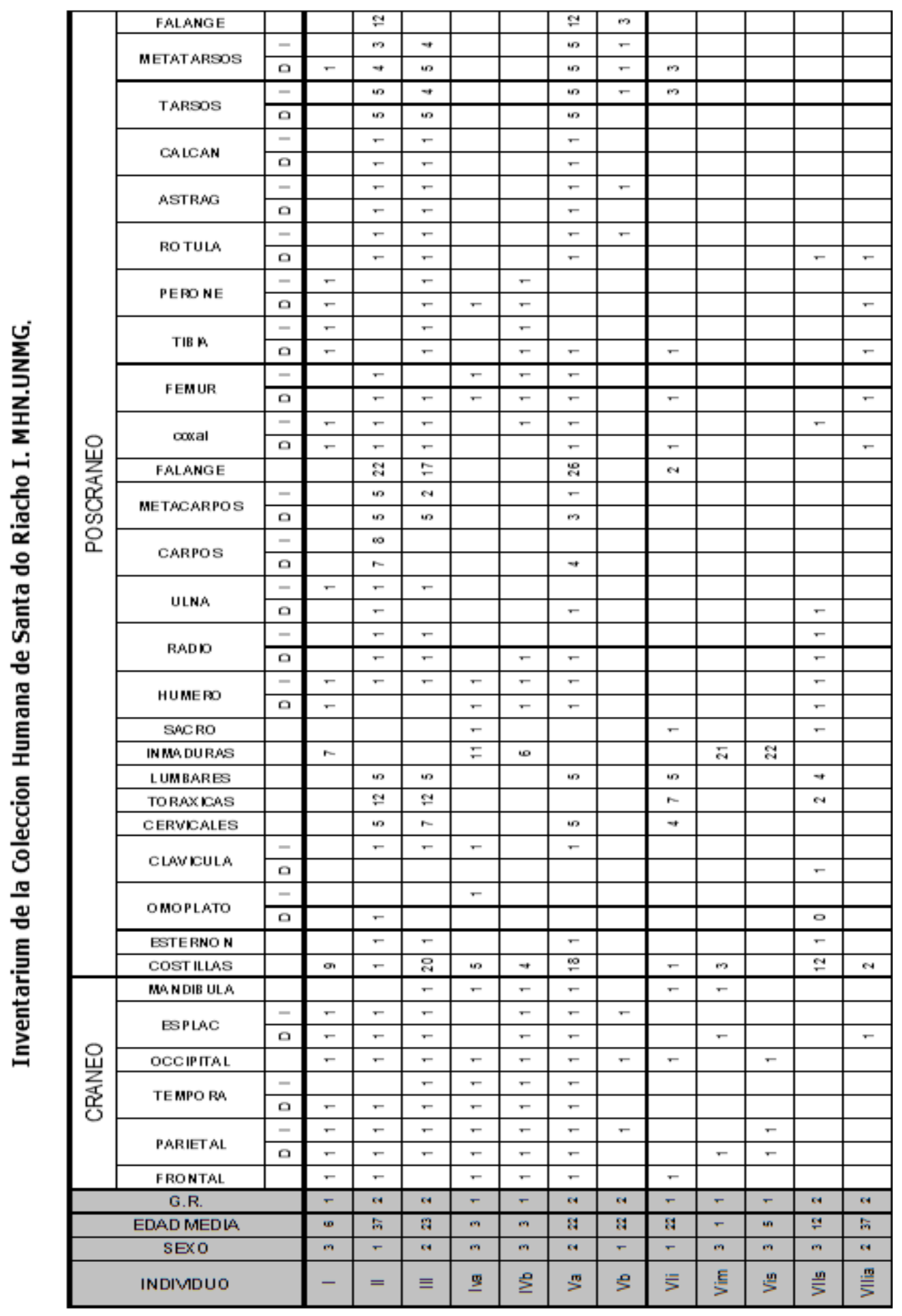




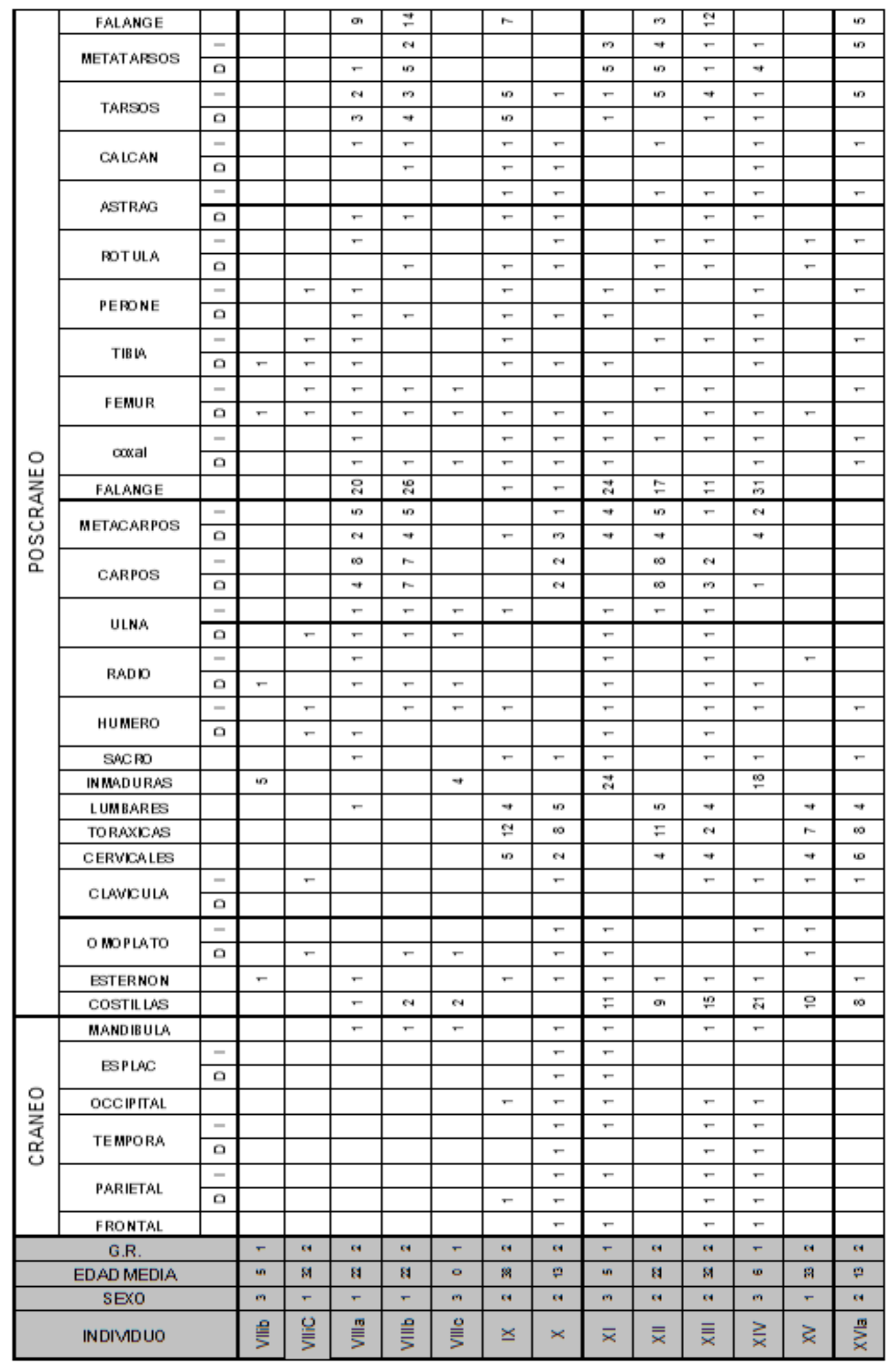




\begin{tabular}{|c|c|c|c|c|c|c|c|c|c|c|c|c|c|c|}
\hline & FALANGE & & & & $\rightarrow$ & & & & & $m$ & & & & $\omega$ \\
\hline & \multirow{2}{*}{ METATARSOS } & - & & & - & & & & $m$ & $\omega$ & & & & \\
\hline & & 0 & & $m$ & & & $N$ & & & $\omega$ & & & & \\
\hline & \multirow{2}{*}{ TARSOS } & - & & & & & & & $m$ & $\rightarrow$ & & & & \\
\hline & & 0 & & & & & & $\omega$ & & $\omega$ & & & & \\
\hline & \multirow{2}{*}{ CALCAN } & - & & & - & & & & & & & & & \\
\hline & & 0 & & & & & & - & & & & $r$ & & \\
\hline & \multirow{2}{*}{ AST RAGG } & - & & $r$ & - & & & - & & - & & & & - \\
\hline & & 0 & & $r$ & $r$ & & & & & - & & & & $r$ \\
\hline & \multirow{2}{*}{ ROTULA } & - & & & - & & & & & - & & & & \\
\hline & & 0 & & & & & & & & - & & & & \\
\hline & \multirow{2}{*}{ PERONE } & - & & - & & & & - & & & $r$ & & & \\
\hline & & 0 & & $r$ & & & & + & & & & & & \\
\hline & \multirow{2}{*}{ TIB LA } & - & & $r$ & & & & - & & & & & & \\
\hline & & 0 & & - & - & & & - & & & & & & \\
\hline & \multirow{2}{*}{ FE MUR } & - & - & - & 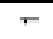 & - & & - & & & & & & \\
\hline & & 0 & - & $r$ & $r$ & & & & & & & & & \\
\hline & \multirow{2}{*}{ cowal } & - & - & $r$ & & & & - & & & $r$ & & & \\
\hline O & & 0 & - & & & & & - & & & & & & \\
\hline$\sum$ & FALANGE & & & $\stackrel{+}{\leftarrow}$ & $\omega$ & & $r$ & & & - & & $\rightarrow$ & $r$ & $\omega$ \\
\hline$\underline{\alpha}$ & \multirow{2}{*}{ MET ACA RP OS } & - & & & & & - & & & & & & & \\
\hline O & & 0 & & $\rightarrow$ & & & $\rightarrow$ & & & & & & & \\
\hline 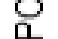 & \multirow{2}{*}{ CARPOS } & - & & & $m$ & & & & & & & & 0 & \\
\hline & & 0 & & & $N$ & & & & & & & $N$ & $m$ & \\
\hline & \multirow{2}{*}{ ULNA } & - & & - & & & - & & & & & - & & \\
\hline & & 0 & & & & & & & & & & & & \\
\hline & \multirow{2}{*}{ RADD } & - & & $r$ & - & & & & & - & & & & \\
\hline & & 0 & & & $r$ & & & & & & & & & \\
\hline & \multirow{2}{*}{ HUMERO } & - & & & & & $r$ & & & & & $r$ & & \\
\hline & & 0 & & & & & & - & & & & & & \\
\hline & SAC BO & & & - & & & - & - & & - & - & - & & \\
\hline & IN MADURAS & & $r$ & $\vec{A}$ & & & $\leftleftarrows$ & & & & & $\leftleftarrows$ & & \\
\hline & LUMBARES & & & & $\rightarrow$ & & $\rightarrow$ & $\rightarrow$ & & $\omega$ & $m$ & & & \\
\hline & TORAXICAS & & & & $r$ & & $\infty$ & $\rightarrow$ & & $\mathrm{N}$ & $\omega$ & & & \\
\hline & CERYCALES & & & & $\omega$ & & $\omega$ & & & $\omega$ & & & & \\
\hline & \multirow{2}{*}{ CLAYKCULA } & - & & - & & & - & & & - & & & & \\
\hline & & 0 & & & & & & - & & & - & & - & \\
\hline & & - & - & & & & & & & & & & & \\
\hline & OMOPLATO & 0 & & & & & & - & & - & & & & \\
\hline & ESTERNON & & & - & & & - & - & & - & - & - & & \\
\hline & COSTILLAS & & $\infty$ & $\mp$ & $\rightarrow$ & & $r$ & & & $r$ & $\infty$ & $N$ & & \\
\hline & MANDIBULA & & & - & & - & & - & & & 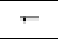 & & 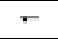 & \\
\hline & & - & & & & & & & & & & & & \\
\hline & ESPLE & 0 & & & & - & & - & & & & & & \\
\hline ய & OCCP TAL & & & & & - & & & & - & & $F$ & 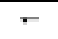 & \\
\hline$\frac{2}{4}$ & TELRORA & - & - & & & - & & & & & & & & \\
\hline$\sigma$ & ТЕМРОRЯ & 0 & & & & - & & & & $r$ & & & & \\
\hline & 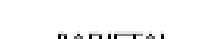 & - & & & & - & & & & & & & - & \\
\hline & PARIEIAL & 0 & & & & - & & & & + & & & 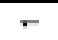 & \\
\hline & FRONTAL & & & & & - & & & & 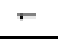 & & & & \\
\hline & G.R. & & $r$ & $r$ & ct & 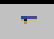 & $r$ & $c 4$ & & $c$ & ct & $r$ & $c t$ & ct \\
\hline & EDAD MEDIA & & $c 4$ & แ & S & $\omega$ & $\omega$ & & & 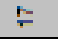 & E & แ & & \\
\hline & SEXO & & $m$ & $m$ & $r$ & $m$ & $m$ & - & $m$ & $c t$ & $m$ & $m$ & $m$ & $m$ \\
\hline & INDMDUO & & $\stackrel{0}{2}$ & $\gtreqless$ & $\equiv$ & $\underset{\times}{x}$ & $\underset{x}{x}$ & $\underset{\times}{x}$ & $\overline{\not ্}$ & $\underset{x}{\bar{x}}$ & $\stackrel{\underline{m}}{\bar{\equiv}}$ & 量 & $\frac{\gtrsim}{\not x}$ & $\underset{x}{\grave{X}}$ \\
\hline
\end{tabular}




\begin{tabular}{|c|c|c|c|c|c|}
\hline & FALANGE & & - & 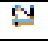 & \\
\hline & ADT ATADCOS & - & & $=$ & \\
\hline & | MIEI AI ARSOUS & 口 & & $=$ & \\
\hline & & - & & $\nabla$ & \\
\hline & IARsus & 口 & & $m$ & \\
\hline & & - & & $=$ & \\
\hline & WALCAIV & 口 & & & \\
\hline & & - & & - & \\
\hline & ADI KANO & 口 & & $=$ & \\
\hline & & - & & & \\
\hline & ROTULA & 口 & & 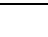 & \\
\hline & & - & & $=$ & \\
\hline & PERONE & o & & $=$ & \\
\hline & & - & & $=$ & $=$ \\
\hline & TIBLA & 口 & & $=$ & $=$ \\
\hline & & - & & $=$ & $=$ \\
\hline & FGMUR & 口 & & $=$ & $=$ \\
\hline & & - & & $=$ & \\
\hline 요 & coxal & 口 & & & \\
\hline 3 & FALANGE & & & \pm & \\
\hline 맛 & & - & & & \\
\hline 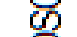 & MEI ALARPOS & 口 & & & \\
\hline 8 & & - & & $N$ & \\
\hline & CAKR US & 口 & & $=$ & \\
\hline & & - & & $=$ & \\
\hline & ULTA & 口 & & $=$ & \\
\hline & & - & & $=$ & \\
\hline & RADIO & 口 & & $=$ & \\
\hline & & - & & $=$ & \\
\hline & HUVIEKU & 口 & & $=$ & \\
\hline & SACRO & & & & \\
\hline & INMADURAS & & & & \\
\hline & LUMBARES & & & & \\
\hline & TORAXICAS & & & & \\
\hline & CBMCALES & & & & \\
\hline & & - & & & \\
\hline & CLAVCULA & 口 & & & \\
\hline & & - & & & \\
\hline & OMOPLATO & o & & & \\
\hline & ESTERNON & & & & \\
\hline & COSTILLAS & & & & $=$ \\
\hline & MANDIBULA & & & & \\
\hline & & - & & & \\
\hline & ESPLAC & 口 & & & \\
\hline Ш & OCCIPTAL & & & & \\
\hline$<$ & & - & - & & \\
\hline 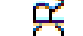 & TEMPORA & 口 & & & \\
\hline & & - & - & & \\
\hline & PARIEI AL & 口 & $=$ & & \\
\hline & FRONTAL & & & & \\
\hline & G.R. & & $\mathrm{A}$ & $\mathrm{N}$ & N \\
\hline & EDAD MEDIA & & & & \\
\hline & SEXO & & $m$ & - & - \\
\hline & INDIVID UO & & 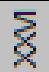 & $\bar{z}$ & $\overline{\bar{z}}$ \\
\hline
\end{tabular}




\section{INDICE DE CONTENIDOS}

$\begin{array}{ll}\text { INTRODUCCION } & 7\end{array}$

1 BASES TEÓRICAS

2 LOS INDICADORES OSEOS 21

2. INDICADORES DE SALUD

2.1. TALLA

2.2. DIMORFISMO SEXUAL

2.3. INDICADORES DE PATOLOGÍAS OSEAS

2.3.1. Hiploplasia dental

2.3.2. Hiperostosis Porótica - Cribra Orbitalia

2.3.3. Infecciosas Inespecíficas

2.3.4. Infecciosas Específicas

2.3.4.1. Caries

2.3.4.2. Periodontitis

2.3.5. Trauma

2.3.6. Nódulos de Schmorl

2.3.7. Artropatías

2.3.7.1. Osteoartritis

2.3.7.2. Osteofitosis vertebral

3. EL MEDIO AMBIENTE

45

3.1. LOCALIZACION GEOGRAFICA Y ECOLOGICA

3.1. LOCALIZACION GEOGRAFICA Y ECOLOGICA

3.2. ADAPTACIONES INDIGENAS EN EL BRASIL CENTRAL

4. LA HISTORIA DE LA INVESTIGACION EN LAGOA SANTA 53

4.1. HISTORIA DE LAS EXCAVACIONES

5. EL CONTEXTO ARQUEOLOGICO

58

5.1. EL SITIO 


\subsection{DATACIONES}

\subsection{EL CONTEXTO ARQUEOLOGICO}

5.3.1 Arqueofauna

5.3.2. Etnobotánica

5.3.3. Instrumental Lítico

5.3.4. Material Artefactual Óseo

5.3.5. Material Textil

5.3.6. Pigmentos

5.4. Los Enterratorios

6 MATERIALES Y METODOS 76

6.1. RELEVANCIA DE LA COLECCIÓN

6.2. ANTECEDENTES DE INVESTIGACIÓN DE LA COLECCION

6.3. PROGRAMA DE CURADORIA

6.4. LA MUESTRA

6.5. CARACTERIZACION, ESTRUCTURA Y

COMPOSICIÓN DE LA MUESTRA

6.6. ESTADO ACTUAL DE CONSERVACIÓN

6.7. EL RELEVAMIENTO DE DATOS

6.8. PROCEDIMIENTO CUANTITATIVO Y ESTADÍSTICO

6.9. METODOLOGIA

6.9.1. INDICADORES DE SALUD

6.9.1.1. Talla

6.9.1.2. Dimorfismo Sexual

6.9.1.3. Condición General De La Denticion

6.9.2.1 Hipoplasias Dentales

6.9.2.2. Cribra Orbitalia - Hiperostosis Porotica

6.9.2.3. Patologías de Origen Infeccioso: Infecciosas Inespecíficas 6.9.2.4. Patologias Infecciosas Específicas

6.9.2.4.1. Caries

6.9.2.4.2. Periodontitis

6.9.2.5. Traumas

6.9.2.6. Nódulos De Schmorl

6.9.2.7. Artropatías 
6.3.2.7.1. Osteofitos

7 RESULTADOS

97

7.1. RESULTADOS

7.1. RESULTADOS

7.1.1. INDICADORES DE SALUD

7.1.1.1. Talla

7.1.1.2. Dimorfismo Sexual-Ds-

7.1.1.3. Condición General De La Denticion

7.1.2. Indicadores Patológicos

7.1.2.1 Hipoplasias DENTALES

7.3.2.2. Cribra Orbitalia - Hiperostosis Porotica

7.3.2.3. Patologías De Origen Infeccioso: Infecciosas Inespecíficas

7.3.2.4. Patologias Infecciosas Específicas

7.3.2.4.1. Caries

7.3.2.4.2. Periodontitis

7.3.2.5. Traumas

7.3.2.6. Nódulos De Schmorl

7.3.2.7. Artropatías

7.3.2.7.1. Osteofitos

8 DISCUSION Y CONCLUSIONES 116

9 BIBLIOGRAFIA 126

ANEXO INVENTARIO 146 
CONTENIDO DE TABLAS

TABLA 2.1. TRAUMAS PROCEDENTES DE DIFERENTES SISTEMAS DE SUBSISTENCIA

TABLA 2.2. DISTRIBUCIÓN DE OSTEOARTRITIS EN POBLACIONES AGRÍCOLAS ANTERIORES AL 1150 AD

TABLA 2.3. DISTRIBUCION DE OSTEOARTRITIS EN PREHORTICULTORES EN NE DE MISSOURI (WILLIAMS, 1994).

TABLA 5.1. FECHADOS RADIOCARBÓNICOS DEL SITIO SR1

TABLA 5.2. DISTRIBUCIÓN DE LOS RESTOS FAUNÍSTICOS HALLADOS EN SR1 SEGÚN SU NIVEL ESTRATIGRÁFICO.

TABLA 5.3. ESPECIES VEGETALES HALLADAS EN EL REGISTRO REPRESENTADAS POR NIVEL TABLA 5.4. ORIENTACIÓN Y POSICIÓN IN SITU DE LOS ESQUELETOS.

TABLA 6.1. DISTRIBUCIÓN DE LA MUESTRA POR SEXO Y EDAD

TABLA 6.2. DISTRIBUCIÓN PORCENTUAL POR SEXO Y EDAD

TABLA 6.3. DISTRIBUCIÓN POR CATEGORÍAS DE LOS ELEMENTOS DENTALES ADULTOS DE LA COLECCIÓN SANTANA DO RIACHO 1

TABLA 7.1. LONGITUD FEMORAL (EN MM) POR SEXO Y EDAD.

TABLA 7.2. MEDIDAS DE LA CABEZA FEMORAL (EN MM)

TABLA 7.3. ESTADÍSTICA DESCRIPTIVA DMF

TABLA 7.4. FRECUENCIAS DE HIPOPLASIA DE ESMALTE DENTAL

TABLA 7.5. DISTRIBUCIÓN DE AFECCIONES POR INDIVIDUO, SEXO, EDAD Y LOCALIZACIÓN ANATÓMICA.

TABLA 7.6 DISTRIBUCIÓN DE CARIES POR ELEMENTO DENTAL

TABLA 7.7. DISTRIBUCIÓN PORCENTUAL DE LESIONES TRAUMÁTICAS

TABLA 7.8. DISTRIBUCIÓN DE FRACTURAS POR SEXO

TABLA 7.9. DISTRIBUCIÓN DE AFECCIONES ARTRÓSICAS POR SEXO 
TABLA 7.10. DISTRIBUCIÓN DE OSTEOFITOS

POR SEGMENTOS VERTEBRALES

INDICE DE FIGURAS

FIGURA 3.1. LOCALIZACIÓN DEL SITIO, SEGÚN EL ATLAS MUNDIAL ENCARTA (2000).

FIGURA 3.2. ABRIGO GRANDE

FIGURA 4.1. PETER W. LUND

FIGURA 4.2. LAPPA DO MOSQUITO, LAGOA SANTA, 1837.

FIGURA 4.3. EXCAVACIÓN EN EL ABRIGO GRANDE DE SANTANA DO RIACHO. (FOTO 58 PROUS Y MALTA, 1991: 411)

FIGURA 5.1. EXCAVACIÓN EN SANTANA DO RIACHO

FIGURA 5.2. ENTERRATORIO XII. (JUNQUEIRA, 1991: 90).

FIGURA 5.3. ENTERRATORIO XVI. (JUNQUEIRA, 1991: 89).

FIGURA 5.4. Y 5.5. DISTRIBUCIÓN DE LOS ENTERRATORIOS EN EL SITIO. ADAPTADO DE PROUS Y MALTA (1991: 24-25).

FIGURA 6.1. ESPECIMENES DE LA COLECCIÓN SANTANA DO RIACHO CON COBERTURA DE COLA DE ISOPOR EN EL CAMPO ANTES DEL TRATAMIENTO DE CURADORÍA. FOTOGRAFÍAS DE VERÓNICA WESOLOWSKI.

FIGURA 6.2. CRÁNEO INFANTIL DE SR1 RECUPERADO DESPUÉS DEL PROCESO DE CURADORÍA

FIGURA 6.3. CALVARIA DE UN ADULTO MASCULINO DE SR1 RECUPERADO DESPUÉS DEL PROCESO DE CURADORÍA

FIGURA 6.4. ESQUELETO INFANTIL PROVENIENTE DE SR1

FIGURA 6.5. ESTRUCTURA ETARIA DE LA MUESTRA DE SR1 POR VALORES ABSOLUTOS

FIGURA 6.6. ESTRUCTURA ETARIA DE LA MUESTRA POR VALORES PORCENTUALES 
FIGURA 6.7. MATERIALES EN EL MUSEO DE HISTORIA NATURAL E JARDIM BOTÁNICO DE LA UNIVERSIDAD FEDERAL DE MINAS GERAIS, BELO HORIZONTE

FIGURA 7.1. DIÁMETRO MÁXIMO DE LA CABEZA FEMORAL

FIGURA 7.2. INDIVIDUO VA. HIPEROSTOSIS PORÓTICA SOBRE EL PARIETAL IZQUIERDO

FIGURA 7.3. AFECCIONES INFECCIOSAS EN EL INDIVIDUO II

FIGURA 7.4. AFECCIONES INFECCIOSAS EN EL INDIVIDUO VB.

FIGURA 7.5. AFECCIONES INFECCIOSAS EN EL INDIVIDUO VIIIA

FIGURA 7.6. AFECCIONES INFECCIOSAS EN EL INDIVIDUO VIIIC

FIGURA 7.7 INDIVIDUO VIIIA. TIBIA Y PERONÉ.

FIGURA 7.8 INDIVIDUO VIIIA. DETALLE DEL PERONÉ.

FIGURA 7.9. AFECCIONES INFECCIOSAS EN EL INDIVIDUO IX Y FIGURA 7.10. AFECCIONES INFECCIOSAS EN EL INDIVIDUO XV

FIGURA 7.11. CARIES OCLUSAL DEL INCISIVO CENTRAL IZQUIERDO EN EL

INDIVIDUO VA.

FIGURA 7.12. ESTERNÓN AFECTADO EN EL INDIVIDUO VA 154

FIGURA 7.13. INDIVIDUO VIIIC

FIGURA 7.14. VÉRTEBRA TORÁXICA CON FRACTURA DE COMPRESIÓN DEL INDIVIDUO XV

FIGURA 7.15 NÓDULOS DE SCHMORL EN EL INDIVIDUO VA 158

FIGURA 7.16 DISTRIBUCIÓN DE LAS LESIONES ARTROPÁTICAS POR ARTICULACIÓN

FIGURA 8.3. POBLAMIENTO DE LA REGIÓN SEGÚN LOS DIFERENTES MOMENTOS CLIMÁTICOS. ADAPTADO DEL MODELO ARAUJO, NEVES Y PILÓ (2002) 
